\title{
VNS in children : more than just seizure reduction
}

Citation for published version (APA):

Klinkenberg, S. (2015). VNS in children : more than just seizure reduction. [Doctoral Thesis, Maastricht University]. Datawyse / Universitaire Pers Maastricht. https://doi.org/10.26481/dis.20150206sk

Document status and date:

Published: 01/01/2015

DOI:

10.26481/dis.20150206sk

Document Version:

Publisher's PDF, also known as Version of record

\section{Please check the document version of this publication:}

- A submitted manuscript is the version of the article upon submission and before peer-review. There can be important differences between the submitted version and the official published version of record.

People interested in the research are advised to contact the author for the final version of the publication, or visit the DOI to the publisher's website.

- The final author version and the galley proof are versions of the publication after peer review.

- The final published version features the final layout of the paper including the volume, issue and page numbers.

Link to publication

\footnotetext{
General rights rights.

- You may freely distribute the URL identifying the publication in the public portal. please follow below link for the End User Agreement:

www.umlib.nl/taverne-license

Take down policy

If you believe that this document breaches copyright please contact us at:

repository@maastrichtuniversity.nl

providing details and we will investigate your claim.
}

Copyright and moral rights for the publications made accessible in the public portal are retained by the authors and/or other copyright owners and it is a condition of accessing publications that users recognise and abide by the legal requirements associated with these

- Users may download and print one copy of any publication from the public portal for the purpose of private study or research.

- You may not further distribute the material or use it for any profit-making activity or commercial gain

If the publication is distributed under the terms of Article $25 \mathrm{fa}$ of the Dutch Copyright Act, indicated by the "Taverne" license above, 


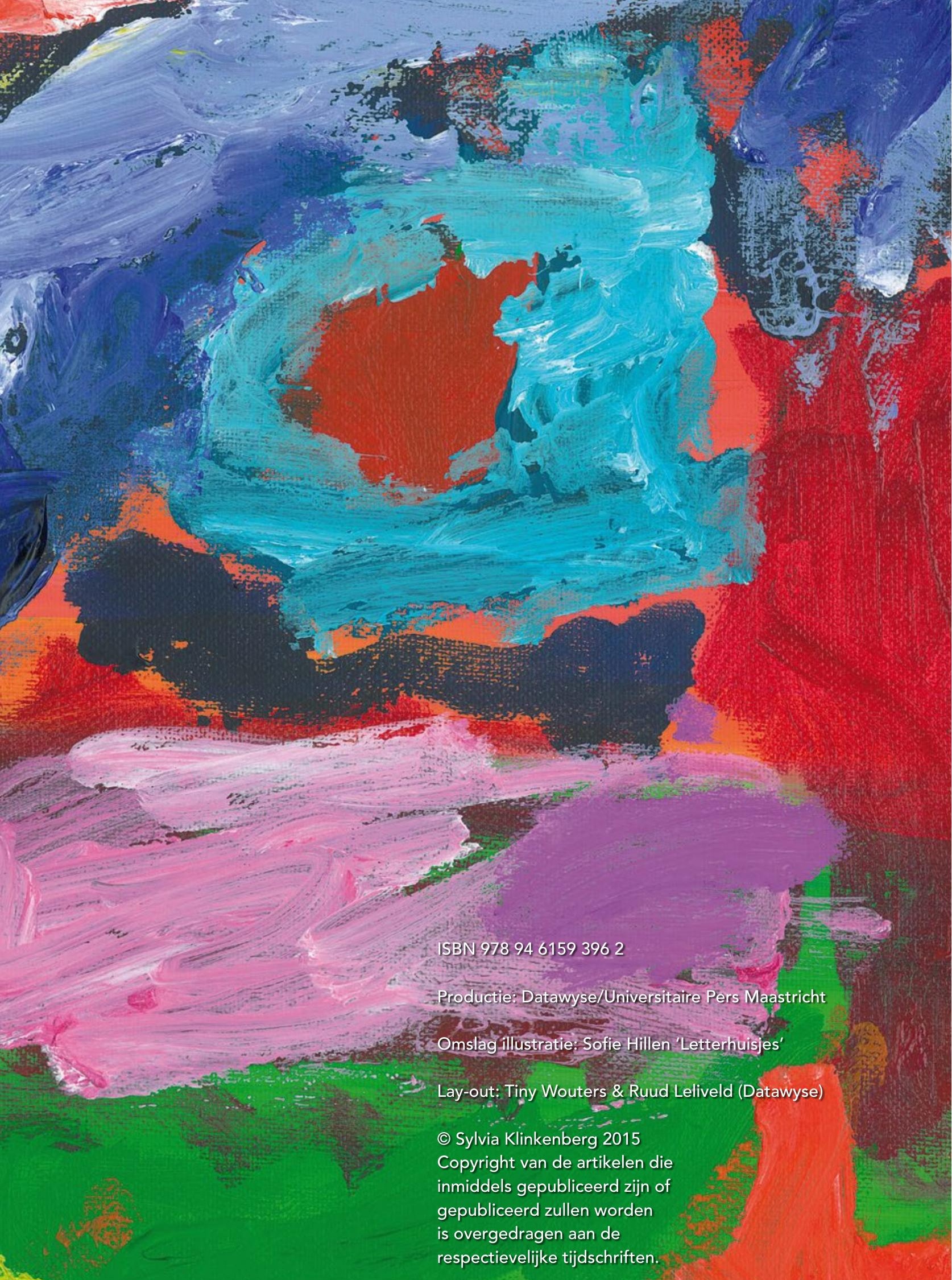




\section{VNS in children}

\section{more than just seizure reduction}

\section{PROEFSCHRIFT}

ter verkrijging van de graad van doctor aan de Universiteit Maastricht, op gezag van de Rector Magnificus, Prof. dr. L.L.G. Soete volgens het besluit van het College van Decanen, in het openbaar te verdedigen op vrijdag 6 februari 2015 om 12.00 uur

$$
\text { door }
$$

Sylvia Klinkenberg

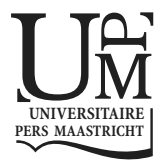




\section{Promotores}

Prof. dr. J.S.H. Vles

Prof. dr. A.P. Aldenkamp

\section{Copromotor}

Dr. H.J.M. Majoie

\section{Beoordelingscommissie}

Prof. dr. R.J. van Oostenbrugge (voorzitter)

Prof. dr. R.P.C. Kessels (UMCN)

Prof. dr. L. Lagae (UZ Leuven)

Dr. J. Nicolai

Prof. dr. Y. Temel 


\section{CONTENTS}

Abbreviations

6

Chapter 1 General introduction

Chapter 2 Vagus nerve stimulation in children with epilepsy a review of literature on efficacy, secondary effects, and side-effects

Chapter 3 Vagus nerve stimulation in children with intractable epilepsy: a randomized controlled trial Developmental Medicine \& Child neurology 2012;54:855-861

Chapter 4 The effects of vagus nerve stimulation on pro- and anti inflammatory cytokines in children with refractory epilepsy: an exploratory study Neuroimmunomodulation 2012;19:352-358

Chapter 5 The effect of vagus nerve stimulation on tryptophan metabolites in children with intractable epilepsy Epilepsy \& Behavior 2014; 37:133-138

Chapter 6 Vagus nerve stimulation has a positive effect on mood in patients with refractory epilepsy Clin Neurol Neurosurg 2012;114:336-340

Chapter 7 Behavioral and cognitve effects during vagus nerve stimulation 97 in children with intractable epilepsy: a randomized controlled trial Eur J Paedriatr Neurol 2013;17:82-e90

Chapter 8 General discussion and summary

Discussie en samenvatting

Addendum valorisatie

Dankwoord

Curriculum vitae

List of publications 


\section{ABBREVIATIONS}

\begin{tabular}{ll} 
AA & Anthranillic acid \\
AED & Anti-epileptic drug \\
BMI & Body mass index \\
CSF & Cerebrospinal fluid \\
CPAP & Continuous positive airway pressure \\
EDTA & Ethylenediaminetetraacetic acid \\
EEG & Electroencephalogram \\
FDA & Food and Drug administration \\
HARCES & The Hague Restrictions in Childhood epilepsy scale \\
3HAA & 3-hydroxyantranillic acid \\
3HK & 3-hydroxykynurenine \\
5-HT & Serotonin \\
IDO & Indoleamine 2,3-dioxygenase \\
IED & Interictal epileptic discharges \\
IL-6 & Interleukin-6 \\
IL-1 13 & Interleukin-1beta \\
IL-10 & Interleukin-10 \\
ILAE & International League Against Epilepsy \\
IQ & Intelligence Quotient \\
K-QOLCE & Korean version of QoL in Childhood Epilepsy Questionnaire \\
KYNA & Kynurenic acid \\
LC-MS/MS & Liquid chromatography-tandem mass spectrometry \\
MCD & Malformation of cortical development \\
NHS & The adapted Chalfont Seizure Severity Scales \\
KYN & Kynurenine \\
PARS-III & Personal adjustment and Role Skill Scale III \\
POMS & Profile of Mood States questionnaires \\
PPVT-III-NL & Peabody Picture Vocabulary test \\
PSG & Polysomnography \\
QoL & Quality of life \\
QOLIE-89 & Quality of Life in Epilepsy Inventory \\
REM sleep & Rapid Eye Movement Sleep \\
TMD & Total Mood disturbance score \\
TNF- $\alpha$ & Tumor necrosis factor alpha \\
TRP & Tryptophan \\
VNS & Vagus nerve stimulation \\
VABS & Vineland Adaptive Behaviour Scale \\
VAS & Visual Analogue Scale \\
XA & Xanthurenic acid \\
\hline
\end{tabular}




\section{CHAPTER 1}

General introduction and outline of thesis 



\section{Epilepsy in children}

Epilepsy is a common neurological disease, with a lifetime cumulative risk of 1-2\%. Approximately one-half of the epilepsies, have their onset during childhood. ${ }^{1-3}$ The developing brain has a higher epileptic susceptibility and is, therefore, in the case of brain injury or temporary changes affecting the brain, more likely to respond with epileptic seizures.

Epilepsy is characterized by recurrent, unpredictable and unprovoked epileptic seizures which interfere with normal brain function. An epileptic seizure is a transient occurrence of signs and/or symptoms due to excessive and synchronous neuronal activity in the brain. ${ }^{4}$

Epilepsy is not a disease entity, but a collection of diseases with various causes and a variety of clinical manifestations. A diagnosis can be established after the occurrence of at least two unprovoked epileptic seizures. Seizure semiology depends on location and spread of abnormal neuronal activity. But age, or more specifically cerebral maturation, also plays an important role.

Seizures can be classified by location of onset of epileptic discharges: generalized, i.e. both cerebral hemispheres are (rapidly) involved; or focal, i.e. within a circumscribed region of one of the cerebral hemispheres; or the location of onset remains unknown. A further categorization of this classification of focal seizures can be made according to the degree of impairment of consciousness or awareness. Independent of etiology, an effort is made to strive for a syndrome classification. This classification of epileptic syndromes consists of a group of clinical entities reliably identified by a cluster of electro-clinical characteristics. Especially description or video registration of seizure and EEG characteristics, socalled seizure semiology, play an important role. In children, age is also an important factor, since EEG findings and clinical signs are largely dependent on maturational factors rather than being due to an evolutionary disease process.

Another classification might be by etiology, allowing three categories to be distinguished: e.g. age-related benign childhood epilepsies with a good prognosis, although some genetic epilepsies cause a disastrous epileptic encephalopathy; structural or metabolic epilepsies, e.g. perinatal or infantile causes or other acquired brain injuries like trauma, tumor, infection or cerebrovascular disorders and epilepsies of unknown cause.

This classification was recommended in 2010 by the International League Against Epilepsy (ILAE), but it is probably not possible to reach a syndrome diagnosis in half of children. $^{5}$

While assessing the data of the trials comprising this thesis, the debate started on this new classification. We, therefore, used the classification established by the ILAE, ${ }^{6}$ which divides the epilepsies into generalized and partial seizures rather than focal seizures, as applied during inclusion in the trial. Etiologies of epilepsy are divided into symptomatic (proposed new classification "structural or metabolic epilepsy"), cryptogenic (no underlying etiology identified, proposed new classification "epilepsy of unknown cause") 
and idiopathic (no underlying cause, proposed new classification "genetic"). This facilitates comparison with previously reported studies.

\section{Intractable childhood epilepsy}

Although several synonyms are used in the literature for 'intractability of epilepsy', e.g. refractory, drug-resistant, or pharmaco-resistant, these terms all describe the same condition. A Task Force appointed by the ILAE formulated the following consensus definition: "Failure of adequate trials of two tolerated, appropriately chosen and used antiepileptic drug schedules (whether as monotherapy or in combination) to achieve sustained seizure freedom". ${ }^{7}$ The importance of this definition is that the same language is used to describe this clinical condition despite the heterogeneous origin of the seizures and variation in chosen $\operatorname{drug}(s)$. It also helps to improve understanding of various dimensions in treatment outcome and is of importance in research allowing comparisons between different studies.

In most children with newly diagnosed epilepsy, the long-term prognosis of epilepsy is favorable, and they will eventually reach remission. Approximately one out of 10 children has intractable seizures in the early course of the disorder. ${ }^{3}$ The risk of developing intractability is largely dependent on the type of epilepsy. Children with an epileptic encephalopathy will more rapidly become intractable than children with a focal cause of epilepsy, or with an unknown cause. Sometimes intractability develops over time. Especially in focal epilepsies, both symptomatic (structural) and cryptogenic (without known underlying etiology), this delayed intractability occurs several years after the diagnosis. During follow-up, 3 out of 10 children became intractable at some stage. ${ }^{8}$ These numbers differ slightly from those in adults.

\section{Impact and co-morbidity}

Seizures, especially in case of intractability, might interfere with age-dependent neurodevelopment and behavior. Increased incidence of cognitive and other behavioral problems have been found in children with epilepsy, even when compared to other chronic pediatric illnesses such as asthma or diabetes. ${ }^{5}$ Childhood epilepsy, especially intractable epilepsy, is a chronic illness with an unpredictable nature which may affect not only the child but the entire family.

In the majority of the epilepsies, children have normal cognitive abilities. Although cognitive impairment might develop as a consequence of the disorder, this occurs more often in the case of refractory epilepsy. Seizures and cognitive dysfunction may both be a symptom of the same underlying etiology, e.g. brain damage or dysfunction. Educational underachievement is a frequently occurring phenomenon in children with epilepsy. ${ }^{10}$ Contributing factors are focal or symptomatic epilepsies, polypharmacy and frequent epileptiform EEG discharges. Children with intractable epilepsy are prone to educational delay. ${ }^{10}$ 
Psychiatric disorders - in particular, attention deficit hyperactivity disorder, depression, conduct or anxiety disorders - are the most prevalent co-morbidities in children with epilepsy after developmental delay. These psychiatric co-morbidities are, in turn, associated with low QoL scores during follow-up, regardless of seizure control. ${ }^{2}$

\section{Treatment}

Treatment for epilepsy is approached in stepwise fashion, usually initiated with an antiepileptic drug (AED). AEDs are effective, straightforward as far as dosage and use are concerned, even in young children. Of importance are the correct choice of drug, depending on the seizure syndrome, compliance of child and parents and maintaining a reasonable dosage for a sufficiently long period of time to allow effectiveness to be evaluated. During the past 20 years, the number of AEDs has doubled, with several novel mechanisms of action and a broad range of indications. Moreover, there is a large selection of options and possible combinations. Usually the choice will be made on the basis of the epilepsy syndrome, but speed of titration or potential additive benefits for existing co-morbidity can also be taken into account. Monotherapy enjoys preference, but after failure of one or more AEDs, a combination therapy is usually considered. In recent years, studies have shown that most AEDs may also have side-effects, cognitive side-effects being the most prevalent.

Surgical management is the first consideration in case of intractability to two or more AEDs. ${ }^{11}$ Ideally there is one epileptic focus in the non-eloquent cortex and surgical risks are considered to be low. The purpose would then be to carry out curative surgery, aiming at seizure freedom without neurological sequelae. If surgery is not a possibility, or if parents decline to take the risk of an operation, several high fat-low carbohydrate dietary options can be considered; of these the ketogenic diet is probably the one most frequently applied. ${ }^{12}$ In addition to conventional drug therapy, vagus nerve stimulation is a treatment-alternative.

High dose corticosteroids, intravenous immunoglobulins, palliative epilepsy surgery (e.g. hemispherectomy or corpus callosotomy), deep brain stimulation and herbal treatments are last resort options. ${ }^{13-17}$ Finally, in case of intractability, minimization of overtreatment and obtaining the best possible quality of life are also important goals.

In this thesis, we will discuss several aspects of application of Vagus Nerve Stimulation (VNS) in intractable epilepsy. Some background information on the vagus nerve and VNS is, therefore, provided.

\section{The vagus nerve}

The vagus nerve (cranial nerve $\mathrm{X}$ ) is the longest of the twelve cranial nerves; it is also called the wanderer. It is a mixed nerve consisting of both myelinated A- and B-fibers and unmyelinated thin $\mathrm{C}$ fibers. 
The vagus nerve arises from the medulla oblongata. It courses between the inferior olive and the inferior cerebellar peduncle and exits the medulla below the glossopharyngeal nerve (cranial nerve IX). The vagus nerve is located in the carotid sheath between the carotid artery and the internal jugular vein. Mid-cervical, rostral to the carotid bifurcation, the $n$. laryngeus superior branches off.

The cell bodies are located in the superior (nodose) and inferior (jugular) vagal ganglia which project to the dorsal motor nucleus, area postrema, the nucleus cunneatus and the nucleus of the tractus solitarius (NTS). The NTS connects by synapses to the hypothalamus, dorsal raphe nuclei, nucleus ambiguous, dorsal motor nucleus of the vagus nerve, the amygdala and the thalamus. In turn these structures project to the insular cortex. These central projections represent important neuronal pathways influencing the autonomic nerve system.

The majority of efferent neurons are unmyelinated and originate from receptors in the lungs, aorta, gastrointestinal tract and a very small part of the concha of the ear. They provide parasympathetic innervation of the lungs, heart and gastrointestinal tract and are responsible for innervation of voluntary muscles in the larynx and pharynx. Cardiovascular efferents of the vagus nerve regulate heart rate and blood pressure. The heart is innervated asymmetrically. The right vagus nerve has more cardial efferent fibers than the left vagal nerve and innervates the sinoatrial nodus, which is involved in the pacemaker function of the heart. The left vagus nerve innervates the left atrio-ventricular nodus, which regulates the force of contraction of the heart muscle as a function of the volume of blood returned to the heart, and has less influence over heart rate. To minimize cardiac rhythm-related - effects by VNS, the left vagus nerve is stimulated.

\section{Vagus nerve stimulation}

During a surgical procedure, a bipolar electrode is wrapped around the left vagus nerve (Figure 1.1A) and connected to a subcutaneously placed pulse generator just below the clavicle (Figure 1.1B). Usually patients go home the same day or the morning after this procedure. A programming wand, kept above the generator, magnetically transmits information from a handheld computer to the generator to program device settings (Figure 1.1C). The device then delivers intermittent cyclic stimulation of the vagus nerve using preprogrammed settings. Stimulation is tailored to the individual. Parameters are adjusted stepwise with an interval of at least several weeks, depending on toleration and effect. Stimulus current is set to $0.25 \mathrm{~mA}$ and gradually increased; this usually varies between 0.75 and $2.5 \mathrm{~mA}$. The most frequently applied settings: signal on-time is 30 seconds, signal off-time 5 minutes, signal frequency $30 \mathrm{~Hz}$, pulse width 250 or $500 \mu$ s. In addition, a preset stimulus can be delivered by placing a VNS-magnet close to the generator for a period of several seconds. This is a way to activate the device manually in order to deliver an extra stimulation in case a patient experiences the onset of a seizure or a caregiver witnesses a seizure starting, since use of VNS on demand, using the magnet, 
might abort seizures. Battery life depends on chosen stimulation parameters and device model; it varies between 3 and 10 years.
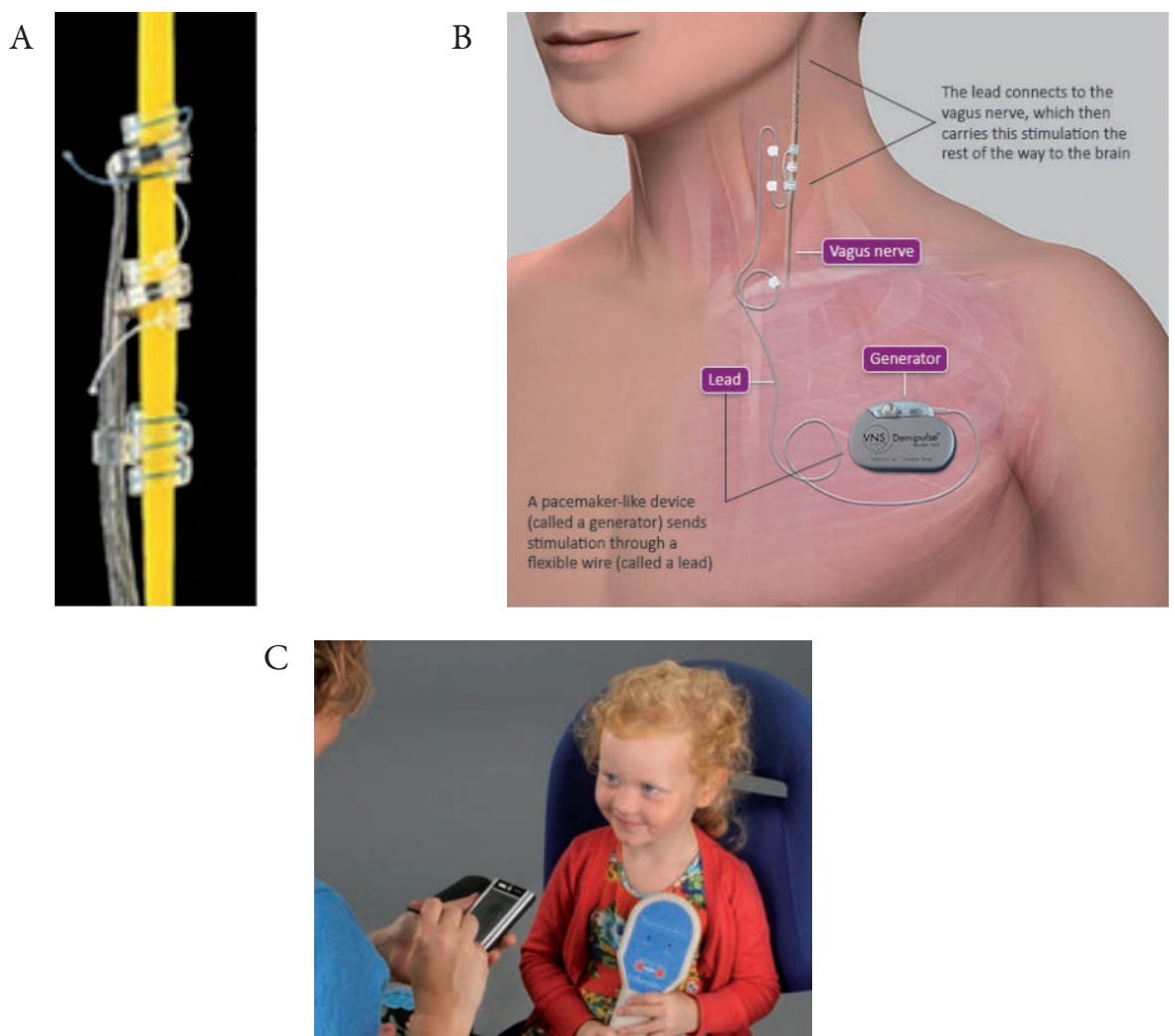

Figure 1.1 A. Bipolar electrode: negative and positive electrode and an anchor tether (Courtesy of Cyberonics, Inc.). B. The bipolar electrode is wrapped around the left vagus nerve, the lead is connected to the subcutaneous placed pulse generator (Courtesy of Cyberonics, Inc.). C. Programming of the device with the programmable wand and handheld computer

Mechanism of action is still not fully understood and clinical response cannot be predicted beforehand. It is known to reduce inter-spike discharges and to cluster them. ${ }^{18}$ But most likely there are several components which contribute to the effectiveness of VNS. Stimulation of vagus nerve affects multiple circuits in the brain through its widespread projections. The locus coeruleus is most probably an important link: in animal studies, lesioning of the locus coeruleus eliminates the effect of VNS. ${ }^{19}$ Both locus coeruleus and raphe nuclei are involved in changes in serotonin and norepinephrine levels in cerebrospinal fluid. ${ }^{20}$ Bilateral increased blood flow in thalamus, hypothalamus and insular cortex and reduced blood flow in a large part of the limbic sytem (amygdala, hippocampus, posterior cingular gyri bilaterally) are also effects of VNS. Furthermore, it is known to have mood-regulating effects; FDA approved this treatment for therapy- 
resistant depressions. Besides the effect on seizure frequency reduction, VNS is assumed to have additional effects on mood and behavior and since these are frequently encountered co-morbidities in case of intractable epilepsy, this is of added value.

Stimulus-related side-effects are due to stimulation of efferent branches, e.g. sore throat or unilateral vocal cord paralysis. Because the n. laryngeus recurrens runs alongside the $\mathrm{n}$. vagus, it is also influenced by stimulation which can cause vibration of the left vocal cord and hoarseness. ${ }^{21}$

Historical overview ${ }^{22-25}$

1884 Dr Corning, a New York neurologist, experimented with vagal nerve compression and electrical stimulation of the vagus nerve to abort seizures and stated "...that this form of treatment may prove of value in epilepsy"

1938 Bailey and Bremmer noted the effect of VNS on sensory cortex

1951 Dell and Olson demonstrated thalamic, cortical and cerebellar projections of the vagus nerve

1952 Zanchetti demonstrated elimination of interictal events in a cat seizure model

1985 Zabara proved effectiveness of VNS on seizure control in animals

1988 Penry performed the first human implant of VNS

1990 Penry and Dean reported the first results of VNS in 11 adults with refractory epilepsy

1992 First randomized controlled study on VNS

1994 Approval by European community for patients with intractable partial epilepsy aged 12 years and over

1996 Five completed randomized controlled studies (EO1-EO5) by the VNS working group

1997 Approval by Food and Drug administration in USA

2010 Estimation $>60,000$ patients treated worldwide $\approx 25 \%$ children

2011 First randomized controlled study in children (Klinkenberg et al.)

\section{Aim and outline of this thesis}

The aim of the present study was to gain more insight into the effect of VNS in children with intractable epilepsy. In chapter 2, we describe our systematic search and review of the literature. A study of efficacy of VNS in treatment-resistant epilepsy is presented in chapter 3. In chapter 4, we report the evaluation of possible changes in cytokine profile as a result of VNS. Chapter 5 sets out the aim to evaluate VNS effects on tryptophan metabolites as well as our investigation into whether the antiepileptic effectiveness correlated with changes in tryptophan metabolism. Chapter 6 presents our assessment of the effects of VNS on cognition, mood, and QoL in adults, and chapter 7, the assessment of these effects in children. For both adults and children (chapters 6 and 7), we determined whether these effects were related to seizure control. In children, we also investigated the effects of VNS on epilepsy-related restrictions and psychosocial adjustment (chapter 7). The findings of this thesis are summarised in chapter 8 together with a discussion of clinical implications and future directions. 


\section{REFERENCES}

1 Linehan C, Kerr MP, Walsh PN, Brady G, Kelleher C, Delanty N, Dawson F, Glynn M. Examining the prevalence of epilepsy and delivery of epilepsy care in Ireland. Epilepsia. 2010;51:845-52.

2 Baca CB, Vickrey BG, Caplan R, Vassar SD, Berg AT. Psychiatric and medical comorbidity and quality of life outcomes in childhood-onset epilepsy. Pediatrics. 2011; 128:e1532-e43.

3 Berg A, Shinnar S, Levy S, Testa F, Smith-Rapaport S, Beckerman B. Early development of intractable epilepsy in children A prospective study. Neurology. 2001;56:1445-52.

4 Fisher RS, Boas WvE, Blume W, Elger C, Genton P, Lee P, Engel J. Epileptic seizures and epilepsy: definitions proposed by the International League Against Epilepsy (ILAE) and the International Bureau for Epilepsy (IBE). Epilepsia. 2005;46:470-2.

$5 \quad$ Engel J, Jr. Seizures and epilepsy. New York: Oxford University press. 2013.

6 Commission on Classification and Terminology of the International League Against Epilepsy. Proposal for revised classification of epilepsies and epileptic syndromes. Epilepsia. 1989;30:389-99.

7 Kwan P, Arzimanoglou A, Berg AT, Brodie MJ, Allen Hauser W, Mathern G, Moshé SL, Perucca E, Wiebe S, French J. Definition of drug resistant epilepsy: consensus proposal by the ad hoc Task Force of the ILAE Commission on Therapeutic Strategies. Epilepsia. 2010;51:1069-77.

8 Berg AT, Vickrey BG, Testa FM, Levy SR, Shinnar S, DiMario F, Smith S. How long does it take for epilepsy to become intractable? A prospective investigation. Ann Neurol. 2006;60:73-9.

9 Kwan P, Brodie MJ. Early identification of refractory epilepsy. N Engl J Med. 2000;342: 314-9.

10 Aldenkamp AP, Weber B, Overweg-Plandsoen WC, Reijs R, van Mil S. Educational underachievement in children with epilepsy: a model to predict the effects of epilepsy on educational achievement. J Child Neurol. 2005;20:175-80.

11 Cross JH, Jayakar P, Nordli D, Delalande O, Duchowny M, Wieser HG, Guerrini R, Mathern GW. Proposed criteria for referral and evaluation of children for epilepsy surgery: recommendations of the Subcommission for Pediatric Epilepsy Surgery. Epilepsia. 2006;47:952-9.

12 Neal EG, Chaffe H, Schwartz RH, Lawson MS, Edwards N, Fitzsimmons G, Whitney A, Cross JH. The ketogenic diet for the treatment of childhood epilepsy: a randomised controlled trial. Lancet Neurol. 2008;7:500-6.

13 Gayatri N, Ferrie C, Cross H. Corticosteroids including ACTH for childhood epilepsy other than epileptic spasms. Cochrane Database Syst Rev 1. 2007.

14 Schachter SC. Botanicals and herbs: a traditional approach to treating epilepsy. Neurotherapeutics. 2009;6:415-20.

15 Billiau AD, Witters P, Ceulemans B, Kasran A, Wouters C, Lagae L. Intravenous immunoglobulins in refractory childhood-onset epilepsy: effects on seizure frequency, EEG activity, and cerebrospinal fluid cytokine profile. Epilepsia. 2007;48:1739-49.

16 Benabid AL, Minotti L, Koudsié A, de Saint Martin A, Hirsch E. Antiepileptic effect of high-frequency stimulation of the subthalamic nucleus (corpus luysi) in a case of medically intractable epilepsy caused by focal dysplasia: a 30-month follow-up: technical case report. Neurosurgery. 2002;50: 1385-92.

17 Perry MS, Duchowny M. Surgical management of intractable childhood epilepsy: curative and palliative procedures. Semin Pediatr Neurol. 2011:195-202.

18 Koo B. EEG changes with vagus nerve stimulation. J Clin Neurophysiol. 2001;18:434-41.

19 Takaya M, Terry WJ, Naritoku DK. Vagus nerve stimulation induces a sustained anticonvulsant effect. Epilepsia. 1996;37:1111-6.

20 Ben-Menachem E, Hamberger A, Hedner T, Hammond EJ, Uthman BM, Slater J, Treig T, Stefan H, Ramsay RE, Wernicke JF, et al. Effects of vagus nerve stimulation on amino acids and other metabolites in the CSF of patients with partial seizures. Epilepsy Res. 1995;20:221-7.

21 Ben-Menachem E. Vagus-nerve stimulation for the treatment of epilepsy. Lancet Neurol. 2002;1: 477-82.

22 Lanska DJ. J.L. Corning and vagal nerve stimulation for seizures in the 1880s. Neurology. 2002;58: 452-9.

23 Murphy JV, Patil A. Stimulation of the nervous system for the management of seizures: current and future developments. CNS Drugs. 2003;17:101-15.

24 Lulic D, Ahmadian A, Baaj AA, Benbadis SR, Vale FL. Vagus nerve stimulation. Neurosurg Focus. 2009;27:E5. 
CHAPTER 1

25 Klinkenberg S, Aalbers MW, Vles JS, Cornips EM, Rijkers K, Leenen L, Kessels FG, Aldenkamp AP, Majoie M. Vagus nerve stimulation in children with intractable epilepsy: a randomized controlled trial. Dev Med Child Neurol. 2012;54:855-61. 


\section{CHAPTER 2}

Vagus nerve stimulation in children with epilepsy a review of literature on efficacy, secondary effects, and side-effects

S. Klinkenberg, H.J.M. Majoie, M.W. Aalbers, R.J.A. de Kinderen, A.G. Kessels,

A.P. Aldenkamp, J.S.H.Vles 


\begin{abstract}
Vagus nerve stimulation (VNS) is a neuromodulatory treatment alternative for intractable epilepsy in children if curative epilepsy surgery is not a treatment option. We performed a systematic search and reviewed the literature on VNS in children. We provided an overview on efficacy and performed a meta-analysis in 326 children. This revealed a responder rate for VNS ( $\geq 50 \%$ seizure frequency reduction) of $38 \%$. VNS in children is well tolerated and procedure related problems are limited. Device related problems are discussed. An overview is given on secondary effects of VNS concerning sleep, immunology, behavior and quality of life. Finally, we conclude that VNS is followed by cost-saving in intractable epilepsy in children.
\end{abstract}




\section{INTRODUCTION}

Although vagus nerve stimulation (VNS) is frequently applied in children with refractory epilepsy, data on effectiveness give variable results and as far as we are aware only one randomized controlled trial has been carried out. The controlled registration studies (EO1-EO5), which led to approval for VNS by both the European Community and the Food and Drug Administration in the United States for patients with intractable partial epilepsy, aged twelve years and over, included a total of 454 patients. ${ }^{1-5}$ Only 19 of the 454 patients were children aged 12 years or over. In the present study, we performed a systematic search and review of the literature on VNS in children with refractory epilepsy. ${ }^{6}$ Reviewing available data on the above-mentioned items may help future selection of children who could benefit from this treatment alternative for intractable epilepsy. We aim to answer the following questions:

1. What is the effect of VNS on seizure frequency in children with intractable epilepsy?

2. What is the effect of VNS on seizure severity in children with intractable epilepsy?

3. What are the device settings applied to achieve seizure control or reduction of seizure severity in children with intractable epilepsy?

4. Is VNS on demand, using a magnet, successful in aborting seizures?

5. Is there a specific patient category in children with intractable epilepsy which responds to VNS?

6. Is VNS well tolerated in children with intractable epilepsy?

7. What are the effects of VNS on sleep and sleep-related breathing in children with intractable epilepsy?

8. What are the immunological effects of VNS in children with intractable epilepsy?

9. What are the effects of VNS on cognition and behavioral aspects in children with intractable epilepsy?

10. What is cost-effectiveness of VNS in children with intractable epilepsy?

11. What are the effects of VNS on quality of life in children with intractable epilepsy?

\section{METHODS}

Search strategy

In November 2013, a search was performed in PubMed, MEDLINE, Cochrane, and EMBASE for all peer-reviewed articles on VNS in children using the following terms: "VNS", or "vagal nerve stimulation", or "vagus nerve stimulation" combined with 
“seizure", or "epilepsy” with limits set to "human" and "all children" (aged 0-18). This resulted in a total of 338 hits. References from all selected articles were further examined in order to find additional suitable studies and to identify possible patient duplication.

\section{Selection criteria}

Titles, abstracts and full text were reviewed and selected by two reviewers independently (MM, SK). Figure 2.1 provides details of search and selection strategy. A minimum of one month post-operative follow-up was required for inclusion. Randomized controlled trial (RCT) and prospective studies were identified and were considered eligible for inclusion in the attempt to answer questions 1 to 5 , if seizure frequency reduction or classification of seizure frequency reduction was described.

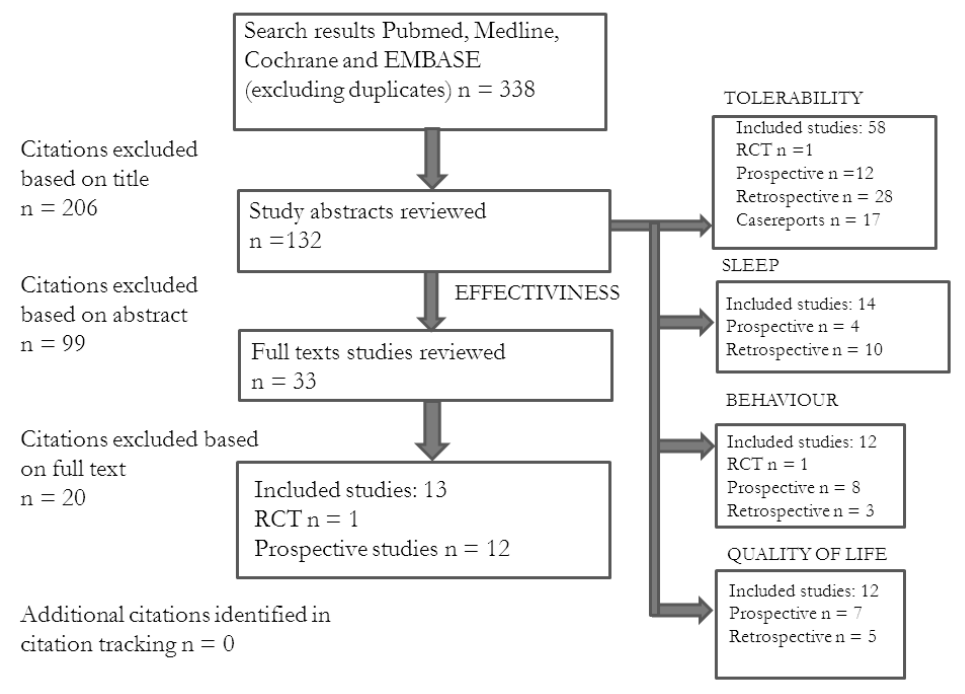

Figure 2.1 Citation flowchart concerning effectiveness, tolerability, sleep, behavioural aspects and quality of life.

In order to answer question 6, retrospective studies and case reports on side-effects and complications of VNS in children were also included, as certain adverse events are extremely rare. Prospective and retrospective clinical studies describing secondary effects of VNS in children with intractable epilepsy were identified to answer questions 7 till 9 and 11. Studies concerning cost-effectiveness of VNS in children were selected to answer question 10.

Exclusion criterion was the inclusion of two or more patients older than 18 years. Except for question 6, case reports were also excluded. Studies which described 5 patients or fewer were considered as case reports. Overlap and reviews of literature were discarded. 
Search and data collection was performed systematically for all eligible studies by the same reviewers, independently .

\section{Data analysis}

To answer the first question, a meta-analysis was conducted on both prospective obtained data and randomized controlled data in children with metan in STATA using a random effect model to reveal the effect size of VNS (responder $\geq 50 \%$ seizure frequency reduction) on seizure frequency. Statistical heterogeneity was assessed by calculating $\mathrm{I}^{2}$ and p-value. ${ }^{7}$

All described adverse effects were divided into subgroups (procedure-related complications, stimulus-related complications, delayed complications, and remarkable complications) and counted. If possible, a percentage was given for the total number of children in whom adverse effects or positive effects were described.

\section{RESULTS}

1. What is the effect of VNS on seizure frequency in children with intractable epilepsy?

Seizure frequency reduction as result of VNS in children with intractable epilepsy was described in one RCT and 12 prospective studies. ${ }^{8-20}$ These studies were conducted in various centers worldwide, and comprised a total of 332 children. Follow-up data are available for 326 children. An overview and details of the included studies is presented in Table 2.1.

The single RCT showed no significant effect at the end of the double-blind phase after 20 weeks when the high output stimulation group was compared to the low output control group. Nonetheless, at the end of the open label phase, $26 \%$ of children had a reduction in seizure frequency of $50 \%$ or more. 


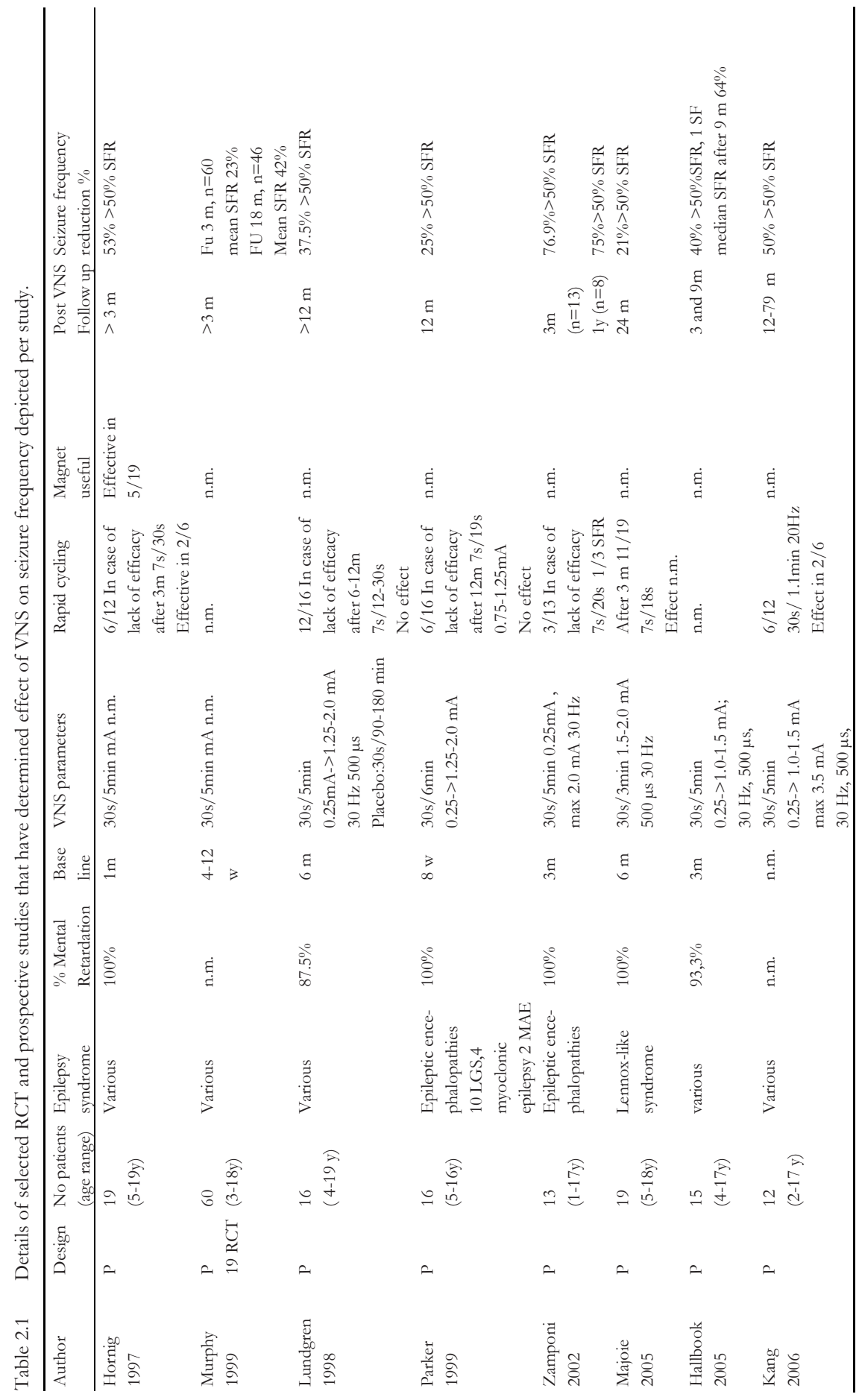




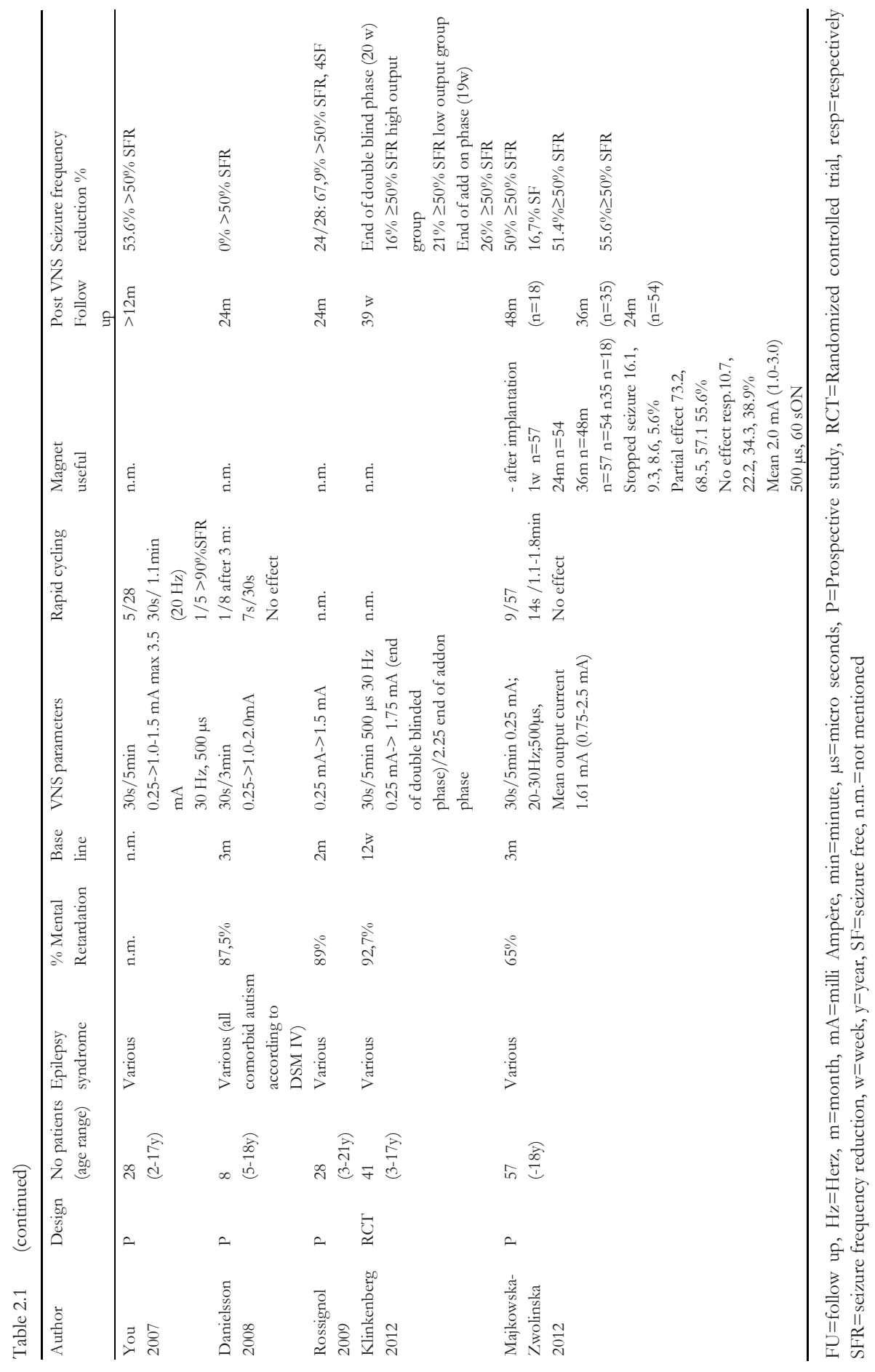




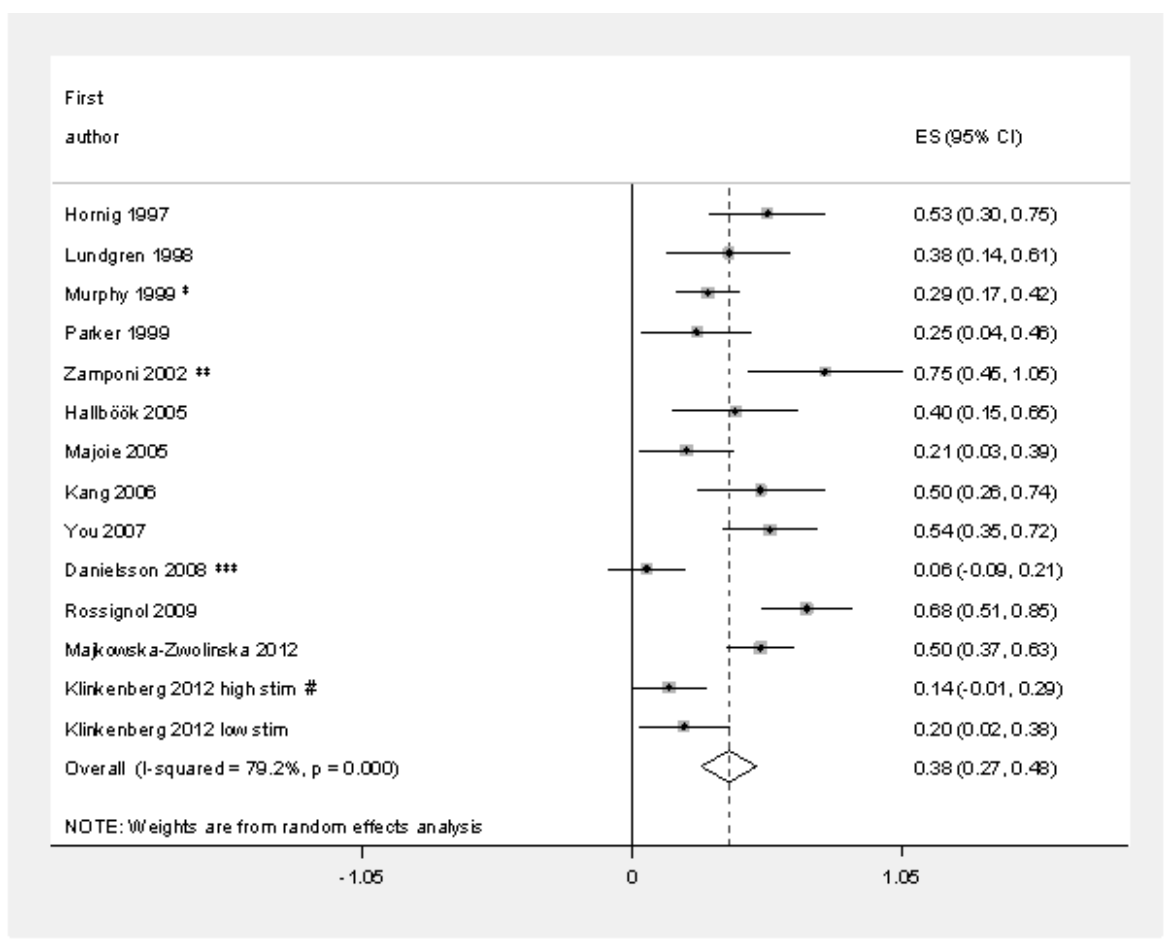

Figure 2.2 Forrest plot of VNS effect size on seizure frequency reduction.

$\mathrm{ES}=$ effect size, $\mathrm{CI}=95 \%$ Confidence Interval, $\mathrm{I}^{2}=$ statistical heterogeneity. Pooled analysis of responder rate of individual studies and overall effect size of VNS ( $\geq 50 \%$ seizure frequency reduction) $38 \%$ (CI 27\%-49\%). $\mathrm{I}^{2}=80 \%$, p $<0,001 .{ }^{*}$ Murphy et al. describe effect of VNS in 51 patients after 1 year follow-up instead of the included 60 patients. ${ }^{* *}$ Zamponi et al. describe effect of VNS in 8 patients after 1 year follow-up instead of initial included 13 patients. We added 0.05 to the cell of Danielsson et al. ${ }^{* * *}$, according to Egger $^{1}$ since they had no responders (lack of events). The RCT of Klinkenberg et al. " was subdivided in two groups: 'high stim' is defined as the treatment group and 'low stim' is the active control group.

1. Egger M, Smith GD, Altman D. Systematic reviews in health care: meta-analysis in context: John Wiley \& Sons; 2008.

Responder rates were defined as the percentage of patients with seizure frequency reduction of $\geq 50 \%$ and ranged from 0 to $90 \%$ of reported studies. A meta-analysis in 326 children revealed a responder rate ( $\geq 50 \%$ seizure frequency reduction) of $38 \%$ ( $95 \%$ confidence interval 27-49\%). Figure 2.2 shows the overall effect size and effect size for the individual studies. The variability across studies was large, with a high heterogeneity $\left(\mathrm{I}^{2}\right)$ of $80 \%$ (P value of $\left.\left.<0,001\right)\right)^{7}$ Possible explanations might be the lack of blinding in the prospective studies included and variations in study design, e.g. length of follow-up, stimulation parameters applied, patient population and inclusion criteria. Moreover, the quality of the studies was variable. In particular, only a few studies used seizure diaries 
maintained by the parent or caregiver to record seizure frequency. Selection bias might also contribute. The range of effect size in reported studies is large.

\section{Conclusion}

VNS results in $\geq 50 \%$ seizure frequency reduction in $38 \%$ of the children. The variability between studies is, however, high and the evidence is limited, as only one RCT has been performed examining the effectiveness of VNS in children.

2. What is the effect of VNS on seizure severity in children with intractable epilepsy?

Seizure severity was assessed in $4^{13,9,14,20}$ of 13 selected studies. The adapted Chalfont Seizure Severity Scales (NHS ${ }^{3}$ ), as presented by O'Donoghue, was used in all four studies to assess seizure severity. ${ }^{22}$ This questionnaire about seizure-related factors was administered by the caregiver who witnessed the seizures. NHS $^{3}$ improved during treatment period in all 4 studies and this improvement reached statistical significance in both the study by Majoie et al. and that of Klinkenberg et al.. ${ }^{14,20}$ The optimal effect on seizure severity was reached at 6 months of follow-up.

\section{Conclusion}

VNS stimulation appears to improve seizure severity in children with intractable epilepsy.

3. What are the device settings applied to achieve seizure control or reduction of seizure severity in children with intractable epilepsy?

Initial device settings are mentioned in all but one study. ${ }^{18}$ The most frequently applied duty cycle was 30 seconds ON, 5 minutes OFF, stimulation frequency $30 \mathrm{~Hz}$, pulse width $500 \mu \mathrm{s}$. The maximal output current used was $2.5 \mathrm{~mA}$. Data on vagus nerve electrophysiology in children are scarce. ${ }^{23}$ Due to age-dependent, incomplete maturation of the vagus nerve, threshold currents might be higher and conduction velocities might be lower in younger children. Nonetheless, device settings used in children are comparable to those in adults. ${ }^{3-5}$ In case of lack of efficacy of regular duty cycle, the device was set to rapid cycling after at least 3 months in 9 out of 13 studies. The most frequently applied duty cycle for rapid cycling was 7 seconds ON, 12-30 seconds OFF. Of the 332 children reported, 55 received rapid cycling at some stage; the effect was mentioned in 35 children. Four of 35 children (12\%) responded to rapid cycling with $\geq 50 \%$ reduction in seizure frequency. 


\section{Conclusion}

Device settings are consistent among different studies in the literature, although information is lacking about optimal device settings in children. The additional value of rapid cycling remains to be established.

\section{Is VNS on demand, using a magnet, successful in aborting seizures?}

No randomized studies on the efficacy of magnet use for the abortion of seizures have been performed. Usually the reported output parameters for the magnet are $0.25 \mathrm{~mA}$ higher than regular stimulation settings. The stimulation duration in case of magnet activation is commonly 60 seconds.

Hornig et al. reported the effect of the magnet in aborting seizures in 5/19 children. ${ }^{8}$ According to Majkowska-Zwolinska, the usefulness of the magnet decreases over time. ${ }^{19}$ In the first week after activation of the stimulator, magnet use completely aborted seizures in 16\% (9/57 children). After four years, this effect was achieved in only $6 \%$ (1/18 children). Partial effect of the magnet declined to a lesser extent, from $74 \%(42 / 57$ children) in the first week after activation, to $56 \%$ (10/18 children) after 4 years.

\section{Conclusion}

Stimulation on demand using a magnet can abort seizures in a subpopulation of children but the evidence for this is limited.

5. Is there a specific patient category in children with intractable epilepsy which responds to VNS?

Available data are insufficient and heterogeneity is too high to allow sub-analysis based on specific etiology or epilepsy syndrome, except for the epileptic encephalopathies. After 12-24 months of follow-up, $42 \%$ (18/45 children) experienced a seizure frequency reduction of $\geq 50 \%{ }^{11,12,14}$ No differences in responder rates have been found between various age groups. ${ }^{10,16,19,20}$

Aldenkamp et al. found the largest treatment effect of VNS in their subgroup with the highest mental age. ${ }^{24}$ We could not confirm this by looking at responder profiles in the studies involved. A high rate of learning disability (ranging from 65-100\%) is described in children in the included studies; information about cognitive function is lacking in 3 of them..$^{10,15,16}$

\section{Conclusion}

A subpopulation of patients which responds favorably to VNS cannot currently be identified, except for the group of children with epileptic encephalopathies. This subpopulation tends to respond just as well as the whole group of children with therapyresistant epilepsy. 


\section{Is VNS well tolerated in children with intractable epilepsy?}

Included studies concerning adverse effects consist of one RCT, 12 prospective studies, 28 retrospective studies and 16 case reports comprising a total of 1249 children. $8,11,13-17,19,20,25-63$ If possible, side-effects were counted in the different studies and divided by the total number of children in those studies to produce a percentage.

\section{Procedure-related complications}

ECG-monitoring during surgery is still recommended, as bradycardia is the most frequently reported intra-operative complication in adults, seen in $0.1 \% .{ }^{64}$ In children, procedure-related arrhythmias were not mentioned. Trauma of the left vagal nerve itself causes unilateral vocal cord dysfunction resulting in hoarseness in $1 \%(3 / 230)^{27,28,39}$ and dyspnoea in $<1 \%(1 / 230){ }^{40}$ In $1 \%(3 / 210)$, fluid collection occurred around the stimulator; this dissolved spontaneously. ${ }^{38,45}$ Hematoma at the insertion site was reported once. ${ }^{40}$ In a 6-year-old girl, left-sided Horner syndrome was reported 18 hours postoperatively, which resolved spontaneously after several weeks. ${ }^{62}$ Infection was reported in 3\% (23/662) of all implanted children. The infection rate varied from 0$11.1 \%$ in individual studies. Deep infections may result in removal of the device. ${ }^{65}$ In case of an infection, removal of device occurred in 57\% (13/23). . $1,18,25,30,31,38,40,45$ Air et al. mentioned conservative management options to salvage infected VNS systems in children. They reported an infection rate of 5.2\% in 191 implantations ${ }^{66}$ Skin necrosis at the device location is one of the most serious side-effects; however, this is reported only once. $^{10}$

\section{Device-related complications}

In the Elliot cohort $(\mathrm{n}=141)$, revision was necessary on 61 occasions in 49 children over a period of 11.5 years. In case of a revision, this involved generator replacement only in 51 procedures; in 10 procedures there was a complete revision of device and lead..$^{45}$ One of the most important reasons for device revision was hardware failure. Lead fracture occurred in 3\% (11/337 children $)^{89,26,27,44}$, and Saneto et al. reported 1 disconnection of the lead. ${ }^{33}$

In case of transmission failure, the device was reimplanted in $4 \%$ (8/216 children). $9,26,30,37,38,42$ The most common cause of a revision was generator power depletion. ${ }^{9} 18,29,30,44$ Due to discomfort, a device had to be replaced twice. ${ }^{18}$ Increased seizure frequency is the most reported symptom of device dysfunction due to an empty battery, disconnection, lead fracture or high impedance due to scar tissue. ${ }^{9,45}$ Other presenting symptoms in patients with hardware failure may be increased seizure severity, feeling of irregular, less intense, or a painful stimulation, deterioration of behavior, dyspepsia, sore throat, and impaired breathing during exercise. ${ }^{41,66}$ Revision of the device usually relieved symptoms and restored seizure control.

Lack of efficacy was the indication for device removal in $8 \%$ ( $35 / 436$ children), 9,10,13,15,26,29,30,37,44 and performance of an MR-imaging in $8 \%$ (11/141 children).45 
Stimulus-related complications

Most frequently mentioned side-effects of VNS are stimulus-related with reported frequencies up to $80 \%{ }^{48}$ Usually these side-effects are mild and therefore tolerable and in most children they are transient. Most frequently reported complaints are voice alterations, paresthesia in the neck and sore throat, coughing, sialorrhea, dyspnea or a sensation of breathlessness while awake or asleep. ${ }^{9-11,13-16,18-20,24,26,28,30,33,37,38,42,44-46,67}$ These complications usually resolve after lowering the stimulation settings and if possible reducing the stimulus duration $(250 \mu \mathrm{s})$. Otherwise, output current or frequency can be reduced. These adaptations may, however, be accompanied by reduced seizure control. An alternative approach was described by Kumar and colleagues, who successfully used botulin injection in a 16-year-old boy with inconvenient laryngospasms..$^{52}$ Aspiration or swallowing problems due to vocal cord dysfunction during stimulation is reported in 5\% (17/342 children). $14,24,26,27,30,33,37,68$ Adjustment of device settings or use of a handheld magnet, taped to the stimulator to switch it off during meals, can provide a solution for this serious side-effect. ${ }^{67}$ Of the two children who died due to aspiration pneumonia, the authors stated that this was unrelated to stimulation. ${ }^{10,18}$

\section{Delayed complications}

Structural changes to a stimulated nerve can occur. Tubbs and collegues reported severe demyelination in a histological post-mortem study of the vagal nerve of a five-year-old boy who died of sudden unexplained death in epilepsy patients (SUDEP). ${ }^{61}$ The output parameters were well within the range of the clinically used parameters (i.e. rapid cycling, $1.5 \mathrm{~mA}, 20 \mathrm{~Hz}, 250 \mu \mathrm{s})$. Although no intra-operative cardiac arrhythmias have been reported in children, several cardiac side-effects can occur during VNS therapy. Four cases of delayed arrhythmias in children were reported in the literature. ${ }^{47,48,53,55}$ Stimulation-dependent brady-arrhythmias caused syncope-like episodes in a 17 -year-old boy 28 months after implantation of VNS. ${ }^{56}$ An increase in seizure frequency, in combination with a second degree heart block occurred in a 13-year-old boy, which caused a prolonged asystole 6.5 years after implantation of VNS. ${ }^{54}$ In both children, arrhythmias disappeared after cessation of stimulation. Eleven years after implantation, a 13-year-old boy experienced episodic bradycardias which did not respond to switching off the stimulator. ${ }^{49}$ Inspection of the lead revealed tethering of vagus nerve by the lead. After replacement of the lead, the bradycardia dissipated, and seizure control was restored.

\section{Remarkable complications}

Extrapyramidal side-effects of VNS were seen in a 13-year-old girl with mental retardation and intractable epilepsy caused by a double cortex syndrome. ${ }^{53}$ These side-effects disappeared after the stimulator had been switched off for 1.5 weeks. In addition, the handheld magnet of the VNS can change the pressure setting of a strata valve of a ventriculoperitoneal drain, causing drain dysfunction. ${ }^{57}$ Other exceptional complications were piercing of the stimulation lead while trying to obtain intravenous access for the treatment of status epilepticus, and neck paresthesias on turning the neck to the right 
due to insufficient strain relief. ${ }^{55}$ Intermittent loss of sight is mentioned once. ${ }^{51}$ The author assumed a possible explanation of vasospasm of the communal carotid artery provoked by stimulation.

Death during follow-up

There were 5 SUDEPs $^{30,39,61}$ and 4 unrelated deaths $s^{10,18,30,38}$ during the observation period of the studies.

Conclusion

VNS is well tolerated in children with refractory epilepsy. Adverse events or side-effects occur often ( $70-80 \%)$, in the beginning of treatment, but in the majority of the patients $(\sim 95 \%)$ they either resolve spontaneously during the course of treatment or can be treated easily.

7. What is the effect of VNS on sleep and sleep-related breathing in children with intractable epilepsy?

Four prospective ${ }^{16,18,68,69}$ and $10^{29,33,35,39,70-75}$ retrospective studies in children found that VNS may influence sleep and sleep-related breathing by several mechanisms. First of all, the vagus nerve has connections to the brainstem respiratory control center influencing respiratory effort during sleep. ${ }^{76}$ The thalamus has a GABA-mediated effect on sleep and is also influenced by VNS. ${ }^{68}$ Furthermore, the vagus nerve helps to relay information from chemo-, baro- and, stretch-receptors and other sensors in the lungs. Besides its central influence on the brain, VNS also has peripheral influences on the upper airway musculature (soft palatum, pharynx, larynx and striated muscle fibers of the upper part of the esophagus). ${ }^{76}$ VNS may also indirectly influence sleep through improvement of seizure control and reduction of epileptiform discharges. Treatment with VNS most probably results in a combination of the above-mentioned factors.

\section{Positive effects of VNS on sleep}

Hallbook et al. studied the effect of VNS on sleep in 15 children, aged 4-17 years, with refractory epilepsy and mental retardation. ${ }^{68}$ They compared results of polysomnography (PSG) 3 months prior to VNS implantation to those 9 months after implantation. VNS improved sleep quality by significantly reducing sleep latency and sleep stage I, and by increasing slow-wave-sleep (sleep stage III-IV). The vast majority of these children $93 \%$ $(14 / 15)$ showed a decrease in seizure severity and a decrease in epileptiform activity and clinical seizures $67 \%(10 / 15)$. It is, therefore, difficult to disentangle whether the improved sleep was a direct effect of VNS or whether it resulted from the improved seizure control. In another study, caregivers reported that night sleep improved in 93\% (26/28 children).$^{18}$ Reduced level of snoring was reported once. ${ }^{77}$ 
Negative effects of VNS on sleep

The medical records of 174 children aged 6-20 years were reviewed for VNS-induced, sleep-related breathing problems in children reported by parents. ${ }^{76}$ Parents or caregivers reported snoring or loud breathing in 8 children and excessive daytime sleepiness in 1 child. In $8 / 9$ children, the sleep-related problems could be confirmed: 6 had a high overall apnea hypopnea index, 1 child had a high apnea hypopnea index related to REMsleep; in one this was in supine position only. All children were on regular stimulation parameters. Remarkably, the average Body mass index (BMI) of these children was 30.0 which may have contributed to the sleep-related problems. The problems proved to be stimulus-induced in only one child and could be treated with continuous positive airway pressure (CPAP). Another retrospective chart review revealed anamnestic sleep-related breathing problems in 5 of 26 children with intractable epilepsy. ${ }^{35}$ In $4 / 5$ obstructive sleep, apnea was confirmed on the PSG. All 4 children were on rapid cycling. Three out of four underwent a tonsillectomy and adenotomy; the fourth underwent a readenotomy and embarked on CPAP treatment. Several other studies report stimulusinduced, sleep-related breathing problems in 6\% (9/143 children), without specific PSG data. ${ }^{16,27,33,39,70}$

VNS induced changes of heart rate, respiratory frequency, or a combination of both.

During PSG recordings in refractory epileptic children, a stimulus-related increase in respiration frequency and reduction of oxygen saturation was noted in small cohorts of children with anamnestic sleep-related breathing problems. ${ }^{74,77}$ VNS also influences heart rate variability during sleep $\mathrm{p}^{71,75}$ and modifies the synchronization between cardiac and respiratory activity, resulting in decrease in respiration amplitude and oxygen saturation $(1-5 \%) .^{72-74,77}$

\section{Conclusion}

There are some indications that VNS improves sleep quality by direct stimulation effect on the brain or by reducing effect of seizure frequency. Before implanting a VNS device, attention should be paid to sleep-related breathing disorder, especially in children with learning disabilities, obesitas, and/or large tonsils who are at risk for obstructive sleep apnea syndrome. During the course of treatment, attention should be paid to altered breathing patterns during sleep (snoring, breathing stops) and excessive daytime sleepiness. A PSG is indicated in case of sleep-related altered breathing patterns.

\section{What are the immunological effects of VNS in children with intractable epilepsy?}

The vagus nerve plays a role in anti-inflammatory and immunological processes. ${ }^{78,79}$ Since inflammatory processes are thought to play a role in certain forms of epilepsy, the neuroimmulogical function of the vagus nerve may contribute to beneficial effects of 
VNS on seizure. In children, Aalbers et al. found no significant changes in interictal plasma cytokine levels during active controlled VNS treatment. ${ }^{80}$

\section{Conclusion}

So far, there is no evidence that VNS causes neuroimmunological activity in children.

\section{What are effects of VNS on cognition and behavioural aspects in children with intractable epilepsy?}

Studies have used different tests and questionnaires to assess the effects of VNS on behavior. In addition, some subscales on quality of life also provide information about behavioral changes. This makes it difficult to combine data for comparison.

The anatomical connections of the vagus nerve may explain the effects of VNS on behavior, mood in particular. The vagus nerve projects to the nucleus of the tractus solitarius which in turn projects directly to the dorsal raphe nucleus and the locus coeruleus, the most important sources of serotonin and norepinephrine, respectively.

VNS may influence these pathways, which are involved in mood regulation, due to direct stimulation effects. Neurochemical studies support the theory that VNS may also induce changes in neurotransmitters. ${ }^{81-83}$

\section{Positive consequences on mood and behavior}

In contrast to some anti-epileptic drugs, especially when given in combination, ${ }^{84} \mathrm{VNS}$ has no negative effects on cognition, as reported by various studies. ${ }^{13,14,17,18,28,85}$

Improvement of behavior in general is mentioned by several authors; in the majority of reports, this is unrelated to seizure frequency reduction. ${ }^{13-16,25,26}$ Both Parker et al. and Zamponi et al used The Vineland Adaptive Behaviour Scale (VABS) to evaluate behavioral aspects of VNS in children with an epileptic encephalopathy after a treatment period of a year. The VABS is a multifactorial instrument which measures 4 domains (e.g. communication, daily living skills, socialization, and motor skills). Parker et al. found no changes in their cohort of 16 children; in contrast to Zamponi et al., who reported an improvement in $4 / 8$ children. ${ }^{11,12}$ Others reported an improvement in playfulness, global interaction, or increased alertness despite only a modest or even poor effect on seizure frequency. ${ }^{15,16,18,31,38,39}$

Murphy et al. reported behavioral improvement based on independent observations of both parents and school, which stopped after switching OFF the stimulator and which was renewed after switching $\mathrm{ON}$ again. ${ }^{26}$ Within this small group of children with hamartomas, the magnet was effective in aborting rages in one child. Positive effects of VNS on mood have been reported by several authors; sometimes this was a subscale in the quality of life questionnaire, ${ }^{15}, 16$ sometimes a specific mood-related questionnaire was used. ${ }^{85}$ 
Negative consequences on behavior

Behavioral problems are mentioned occasionally as an adverse effect of VNS treatment. ${ }^{31,39}$ Hyperactivity was only reported in a few children by Helmers et al.; this seems to be an age-specific side-effect, since it is not reported in adults. ${ }^{28}$ In studies with specific interest in behavioral consequences of VNS, no negative effects on behavior are mentioned.

\section{Conclusion}

VNS has no negative effects on behavior. Moreover, VNS may contribute to improvement in behavior and mood. This is independent of effectiveness on seizure frequency.

\section{What is the cost-effectiveness of VNS in children with intractable epilepsy?}

We are aware of only two studies dealing with the costs of vagus nerve stimulation for epilepsy, solely measured in children. The first study, conducted in 2000 in The Netherlands, covered the cost-effectiveness of 16 children with Lennox Gastaut syndrome. ${ }^{86}$ Direct medical costs (e.g. costs of healthcare utilization), direct non-medical costs (e.g. out-of-pocket expenses), and indirect costs (e.g. productivity losses) were measured 6 months before and after VNS implantation. Resource utilization was obtained by using data and invoices from the University Hospital and a tertiary epilepsy center. Furthermore, cost diaries were used in which parents recorded all medical consumption related to the epilepsy of their child, out-of-pocket expenses, travel expenses, productivity losses and other related costs. The researchers found a total cost reduction in the postoperative period compared to the baseline period of 2,876 Euros, with a significant reduction in direct non-medical costs and a 2.3 year pay-back period. The second study was a retrospective, longitudinal, open-cohort design, in which data was used from Medicaid, a US government health-insurance program designed to serve, among others, those with chronic disabling conditions. ${ }^{87}$ Data was gathered from 445 patients, 6 months prior to and (at least) 6 months after VNS implantation. Children (111 years old, $\mathrm{n}=238$ ) and adolescents (12-17 year old, $\mathrm{n}=207)$ were analysed separately. Only direct medical costs were measured (e.g. costs of healthcare utilization and drugs). Resource utilization and epilepsy-related events were reduced during the postoperative period compared to the pre-VNS period for both groups. Epilepsy-related hospitalizations, visits and status epilepticus events were reduced post-VNS in children. The adjusted overall cost difference was 2,181 USD in children with a pay-back period of 1.5 years. Comparing the healthcare utilization of adolescents showed a reduction in all hospitalizations, emergency room visits, outpatient visits and epilepsy-related clinical events, except for the number of fractures. The adjusted overall cost difference between pre-VNS and the postoperative period was 3,229 USD with a pay-back period of 1 year. 


\section{Conclusion}

Taking different contexts into account, these studies demonstrate that VNS is followed by cost-saving in childhood epilepsy. The intrinsic value of these studies is, however, limited by the sample size and the duration of follow-up. In order to inform the decisionmaking process, more detailed (prospective) research with a long follow-up and a control group is necessary.

\section{What are the effects of VNS on quality of life in children with intractable epilepsy?}

There was a large variation in approaches to measuring quality of life (QoL). As all these types of measurement are conceptually distinct, it is impossible to compare the outcomes. Lundgren et al. measured QoL with a modified Visual Analogue Scale (VAS).9 After 1 year, 4 children showed no improvement while 12 children experienced an improvement varying between 10 and 100 points. Two other studies also used a VAS in order to measure QoL in children with epilepsy, ${ }^{13,25}$ and one study applied VAS in combination with the VABS. ${ }^{37}$

Different versions of the VAS were used, ranging from $0-100,{ }^{37}$ from -10 to $+10^{13}$ and -1 to $+1 .{ }^{25}$ They all reported improvements in QoL, except for Hallböök et al. who found a decrease in QoL in 14\% of the children. ${ }^{13}$ Zamponi et al. detected great improvements in QoL following VNS when using the VAS, results which could not be confirmed with the VABS measurement in this specific group of young children with catastrophic epilepsy. ${ }^{37}$ In an earlier study by Zamponi et al., they showed a significant improvement in the ageequivalent VABS compared to their baseline score before surgery in 4 of 8 children with a drug-resistant partial epilepsy. ${ }^{12}$

Other researchers assessed QoL by looking at areas of functioning that are recognised in daily life based on three different scales, measuring independence, behavior, and mood characteristics and found no significant changes. ${ }^{14}$ Several studies made use of multidimensional instruments. ${ }^{11,15,16,88}$ Parker et al. measured QoL in 16 patients with the Wellcome QoL assessment which contains 9 domains and was specially developed for children with Lennox Gastaut Syndrome ${ }^{11}$. A significant improvement was only found on the subscale side-effects and general behavior. Both You et al. and Kang et al. used the Korean version of the QoL in Childhood Epilepsy questionnaire (K-QOLCE). ${ }^{15,16}$ Of 28 children, 12 showed improved mood and alertness, 11 improved behavior, 9 improved memory, 8 improved verbal skills and 6 showed an improvement in achievement. In another study, the Impact of Childhood Neurological Disability Scale was used to measure QoL. ${ }^{36}$ They analysed the epilepsy subscale only, and did not use the other 3 dimensions. They also used a global rating of QoL consisting of a 6-point Likert-type rating scale (range from 1 meaning poor QoL to 6 meaning excellent $\mathrm{QoL}$ ). Based on the epilepsy subscale, 5/34 children showed a decrease in QoL, 11/34 an increase in QoL; the others remained unchanged. Analyzing the global QoL rating scale, 3/34 of the children showed a decrease in QoL, 5/34 had an increase of QoL, the others remained 
unchanged. A 5-point Likert-type was used by Helmers et al. to measure QoL in 95 patients. ${ }^{28}$ In total, $8 \mathrm{QoL}$ domains were measured with this rating scale. After three months, 46/95 children showed improvement (better or much better) in alertness, $34 / 95$ improvement in clustering, 26/95 improvement in verbal communication and postictal periods, 21/95 improvement in school achievements and mood, while in 13/95, memory, and in 5/95 ambulation improved. Furthermore, Benifla et al. reported an improvement in the QoL of patients following VNS in 17 of the 41 patients and a worsening of QoL in 2 patients without mentioning any details about the instruments or scales used while measuring QoL. ${ }^{31}$

One study found a correlation between improvement in quality of life and a reduction of seizure severity, ${ }^{13}$ although mostly the effect of VNS was unrelated to seizure frequency reduction.

\section{Conclusion}

VNS in children does not seem to impact negatively on QoL. Most studies report stable outcomes or improvements in (subscales of) QoL. There is no consensus in the literature concerning the relation between seizure frequency reduction and positive effect on QoL. These conclusions should, however, be treated with some caution, due to the use of different measurement approaches.

For future research, we recommend using a combination of a validated disease-specific and a generic instrument to measure QoL.

\section{OVERALL CONCLUSION}

VNS has been widely used since the late 1990s to treat therapy-resistant epilepsy in both adults and children not suitable for epilepsy surgery. VNS might reduce seizure frequency, although evidence is limited in children. Long-term adverse events in children appear to be moderate and usually resolve over time. There are some implantation risks of VNS, although numbers are very small. No convincing negative effects have been found on behavior, quality of life or on sleep, although careful attention should be paid to sleep-related breathing problems, especially in specific cases.

VNS reduces health resource utilization and non-medical costs, although more extensive studies might be necessary in order to confirm this. 


\section{REFERENCES}

1 Penry JK, Dean JC. Prevention of intractable partial seizures by intermittent vagal stimulation in humans: preliminary results. Epilepsia. 1990;31 Suppl 2:S40-3.

2 Uthman BM, Wilder BJ, Penry JK, Dean C, Ramsay RE, Reid SA, Hammond EJ, Tarver WB, Wernicke JF. Treatment of epilepsy by stimulation of the vagus nerve. Neurology. 1993;43:1338-45.

3 The VNS Study Group. A randomized controlled trial of chronic vagus nerve stimulation for treatment of medically intractable seizures. Neurology. 1995;45:224-30.

4 Labar D, Murphy J, Tecoma E. Vagus nerve stimulation for medication-resistant generalized epilepsy. E04 VNS Study Group. Neurology. 1999;52:1510-2.

5 Handforth A, DeGiorgio CM, Schachter SC, Uthman BM, Naritoku DK, Tecoma ES, Henry TR, Collins SD, Vaughn BV, Gilmartin RC, Labar DR, Morris GL, 3rd, Salinsky MC, Osorio I, Ristanovic RK, Labiner DM, Jones JC, Murphy JV, Ney GC, Wheless JW. Vagus nerve stimulation therapy for partial-onset seizures: a randomized active-control trial. Neurology. 1998;51:48-55.

6 Grant MJ, Booth A. A typology of reviews: an analysis of 14 review types and associated methodologies. Health Information \& Libraries Journal 2009;26:91-108.

7 Higgins JP, Thompson SG, Deeks JJ, Altman DG. Measuring inconsistency in meta-analyses. BMJ: British Medical Journal. 2003;327:557.

8 Hornig GW, Murphy JV, Schallert G, Tilton C. Left vagus nerve stimulation in children with refractory epilepsy: an update. South Med J. 1997;90:484-8.

9 Lundgren J, Amark P, Blennow G, Stromblad LG, Wallstedt L. Vagus nerve stimulation in 16 children with refractory epilepsy. Epilepsia 1998;39:809-13.

10 Murphy JV. Left vagal nerve stimulation in children with medically refractory epilepsy. The Pediatric VNS Study Group. J Pediatr. 1999;134:563-6.

11 Parker AP, Polkey CE, Binnie CD, Madigan C, Ferrie CD, Robinson RO. Vagal nerve stimulation in epileptic encephalopathies. Pediatrics. 1999;103:778-82.

12 Zamponi N, Rychlicki F, Cardinali C, Luchetti A, Trignani R, Ducati A. Intermittent vagal nerve stimulation in paediatric patients: 1-year follow-up. Childs Nerv Syst. 2002;18:61-6.

13 Hallbook T, Lundgren J, Stjernqvist K, Blennow G, Stromblad LG, Rosen I. Vagus nerve stimulation in 15 children with therapy resistant epilepsy; its impact on cognition, quality of life, behaviour and mood. Seizure. 2005;14:504-13.

14 Majoie HJ, Berfelo MW, Aldenkamp AP, Renier WO, Kessels AG. Vagus nerve stimulation in patients with catastrophic childhood epilepsy, a 2-year follow-up study. Seizure. 2005;14:10-8.

15 Kang HC, Hwang YS, Kim DS, Kim HD. Vagus nerve stimulation in pediatric intractable epilepsy: a Korean bicentric study. Acta Neurochir Suppl. 2006;99:93-6.

16 You SJ, Kang HC, Kim HD, Ko TS, Kim DS, Hwang YS, Kim DS, Lee JK, Park SK. Vagus nerve stimulation in intractable childhood epilepsy: a Korean multicenter experience. J Korean Med Sci. 2007;22:442-5.

17 Danielsson S, Viggedal G, Gillberg C, Olsson I. Lack of effects of vagus nerve stimulation on drug-resistant epilepsy in eight pediatric patients with autism spectrum disorders: a prospective 2-year follow-up study. Epilepsy Behav. 2008;12:298-304.

18 Rossignol E, Lortie A, Thomas T, Bouthiller A, Scavarda D, Mercier C, Carmant L. Vagus nerve stimulation in pediatric epileptic syndromes. Seizure. 2009;18:34-7.

19 Majkowska-Zwolinska B, Zwolinski P, Roszkowski M, Drabik K. Long-term results of vagus nerve stimulation in children and adolescents with drug-resistant epilepsy. Childs Nerv Syst. 2012;28:621-8.

20 Klinkenberg S, Aalbers MW, Vles JS, Cornips EM, Rijkers K, Leenen L, Kessels FG, Aldenkamp AP, Majoie M. Vagus nerve stimulation in children with intractable epilepsy: a randomized controlled trial. Dev Med Child Neurol. 2012;54:855-61.

21. Egger M, Smith GD, Altman D. (2008) Systematic reviews in health care: meta-analysis in context. John Wiley \& Sons.

22 O'Donoghue MF, Duncan JS, Sander JW. The National Hospital Seizure Severity Scale: a further development of the Chalfont Seizure Severity Scale. Epilepsia. 1996;37:563-71.

23 Koo B, Ham SD, Sood S, Tarver B. Human vagus nerve electrophysiology: a guide to vagus nerve stimulation parameters. J Clin Neurophysiol. 2001;18:429-33. 
24 Aldenkamp AP, Majoie HJ, Berfelo MW, Evers SM, Kessels AG, Renier WO, Wilmink J. Long-term effects of 24-month treatment with vagus nerve stimulation on behaviour in children with Lennox-Gastaut syndrome. Epilepsy Behav. 2002;3:475-9.

25 Patwardhan RV, Stong B, Bebin EM, Mathisen J, Grabb PA. Efficacy of vagal nerve stimulation in children with medically refractory epilepsy. Neurosurgery. 2000;47:1353-7; discussion 7-8.

26 Murphy JV, Wheless JW, Schmoll CM. Left vagal nerve stimulation in six patients with hypothalamic hamartomas. Pediatr Neurol. 2000;23:167-8.

27 Rychlicki F, Zamponi N, Cesaroni E, Corpaci L, Trignani R, Ducati A, Scerrati M. Complications of vagal nerve stimulation for epilepsy in children. Neurosurg Rev. 2006;29:103-7.

28 Helmers SL, Wheless JW, Frost M, Gates J, Levisohn P, Tardo C, Conry JA, Yalnizoglu D, Madsen JR. Vagus nerve stimulation therapy in pediatric patients with refractory epilepsy: retrospective study. J Child Neurol. 2001;16:843-8.

29 Nagarajan L, Walsh P, Gregory P, Lee M. VNS therapy in clinical practice in children with refractory epilepsy. Acta Neurol Scand. 2002;105:13-7.

30 Alexopoulos AV, Kotagal P, Loddenkemper T, Hammel J, Bingaman WE. Long-term results with vagus nerve stimulation in children with pharmacoresistant epilepsy. Seizure. 2006;15:491-503.

31 Benifla M, Rutka JT, Logan W, Donner EJ. Vagal nerve stimulation for refractory epilepsy in children: indications and experience at The Hospital for Sick Children. Childs Nerv Syst. 2006;22:1018-26.

32 Blount JP, Tubbs RS, Kankirawatana P, Kiel S, Knowlton R, Grabb PA, Bebin M. Vagus nerve stimulation in children less than 5 years old. Childs Nerv Syst. 2006;22:1167-9.

33 Saneto RP, Sotero de Menezes MA, Ojemann JG, Bournival BD, Murphy PJ, Cook WB, Avellino AM, Ellenbogen RG. Vagus nerve stimulation for intractable seizures in children. Pediatr Neurol. 2006;35: 323-6.

34 Wilfong AA, Schultz RJ. Vagus nerve stimulation for treatment of epilepsy in Rett syndrome. Dev Med Child Neurol. 2006;48:683-6.

35 Khurana DS, Reumann M, Hobdell EF, Neff S, Valencia I, Legido A, Kothare SV. Vagus nerve stimulation in children with refractory epilepsy: unusual complications and relationship to sleep-disordered breathing. Childs Nerv Syst. 2007;23:1309-12.

36 Sherman EM, Connolly MB, Slick DJ, Eyrl KL, Steinbok P, Farrell K. Quality of life and seizure outcome after vagus nerve stimulation in children with intractable epilepsy. J Child Neurol. 2008;23:991-8.

37 Zamponi N, Rychlicki F, Corpaci L, Cesaroni E, Trignani R. Vagus nerve stimulation (VNS) is effective in treating catastrophic 1 epilepsy in very young children. Neurosurg Rev. 2008;31:291-7.

38 Kabir SM, Rajaraman C, Rittey C, Zaki HS, Kemeny AA, McMullan J. Vagus nerve stimulation in children with intractable epilepsy: indications, complications and outcome. Childs Nerv Syst. 2009;25: 1097-100.

39 Shahwan A, Bailey C, Maxiner W, Harvey AS. Vagus nerve stimulation for refractory epilepsy in children: More to VNS than seizure frequency reduction. Epilepsia 2009;50:1220-8.

40 Abd-El-Barr MM, Joseph JR, Schultz R, Edmonds JL, Wilfong AA, Yoshor D. Vagus nerve stimulation for drop attacks in a pediatric population. Epilepsy Behav. 2010;19:394-9.

41 Arhan E, Serdaroglu A, Kurt G, Bilir E, Durdag E, Erdem A, Aksakal FN, Ozcelik A, Baykaner K. The efficacy of vagal nerve stimulation in children with pharmacoresistant epilepsy: practical experience at a Turkish tertiary referral center. Eur J Paediatr Neurol. 2011;14:334-9.

42 Zamponi N, Petrelli C, Passamonti C, Moavero R, Curatolo P. Vagus nerve stimulation for refractory epilepsy in tuberous sclerosis. Pediatr Neurol. 2010;43:29-34.

43 Coykendall DS, Gauderer MW, Blouin RR, Morales A. Vagus nerve stimulation for the management of seizures in children: an 8-year experience. J Pediatr Surg. 2010;45:1479-83.

44 Thompson EM, Wozniak SE, Roberts CM, Kao A, Anderson VC, Selden NR. Vagus nerve stimulation for partial and generalized epilepsy from infancy to adolescence: Clinical article. Journal of Neurosurgery: Pediatrics 2012;10:200-5.

45 Elliott RE, Rodgers SD, Bassani L, Morsi A, Geller EB, Carlson C, Devinsky O, Doyle WK. Vagus nerve stimulation for children with treatment-resistant epilepsy: a consecutive series of 141 cases. J Neurosurg Pediatr. 2011;7:491-500.

46 Cersosimo RO, Bartuluchi M, De Los Santos C, Bonvehi I, Pomata H, Caraballo RH. Vagus nerve stimulation: effectiveness and tolerability in patients with epileptic encephalopathies. Childs Nerv Syst. 2011;27:787-92.

47 Chen C-Y, Lee H-T, Chen C-C, Kwan S-Y, Chen S-J, Hsieh L-P, Tsai J-D. Short-term results of vagus nerve stimulation in pediatric patients with refractory epilepsy. Pediatrics \& Neonatology. 2012;53:184-7. 
48 Ryzi M, Brazdil M, Novak Z, Chrastina J, Oslejskova H, Rektor I, Kuba R. Long-term vagus nerve stimulation in children with focal epilepsy. Acta Neurol Scand. 2013;127:316-22.

49 Clark AJ, Kuperman RA, Auguste KI, Sun PP. Intractable episodic bradycardia resulting from progressive lead traction in an epileptic child with a vagus nerve stimulator: a delayed complication. J Neurosurg Pediatr. 2012;9:389-93.

50 Aron M, Vlachos-Mayer H, Dorion D. Vocal cord adduction causing obstructive sleep apnea from vagal nerve stimulation: Case report. J Pediatr. 2012;160:868-70.

51 Sheck L, Meyer HD. Episodic monocular vision loss after implantation of a vagal nerve stimulator. Ann Intern Med. 2011;155:648-9.

52 Kumar S, Sharafkhaneh A, Edmonds J, Schultz R, Hopkins B. Treatment of vns-induced laryngospasm with botulinum toxin. Neurology. 2009; 73:1808-10.

53 Cukiert A, Mariani PP, Burattini JA, Cukiert CM, Forster C, Baise C, Argentoni-Baldochi M, Mello V. Parkinsonism induced by VNS in a child with double-cortex syndrome. Epilepsia. 2009;50:2667-9.

54 Borusiak P, Zilbauer M, Cagnoli S, Heldmann M, Jenke A. Late-onset cardiac arrhythmia associated with vagus nerve stimulation. J Neurol. 2009;256:1578-80.

55 Pearl PL, Conry JA, Yaun A, Taylor JL, Heffron AM, Sigman M, Tsuchida TN, Elling NJ, Bruce DA, Gaillard WD. Misidentification of vagus nerve stimulator for intravenous access and other major adverse events. Pediatr Neurol. 2008;38:248-51.

56 Amark P, Stodberg T, Wallstedt L. Late onset bradyarrhythmia during vagus nerve stimulation. Epilepsia. 2007;48:1023-4.

57 Guilfoyle MR, Fernandes H, Price S. In vivo alteration of Strata valve setting by vagus nerve stimulatoractivating magnet. Br J Neurosurg. 2007;21:41-2.

58 Shih JJ, Devier D, Behr A. Late onset laryngeal and facial pain in previously asymptomatic vagus nerve stimulation patients. Neurology. 2003;60:1214

59 Vassilyadi M, Strawsburg RH. Delayed onset of vocal cord paralysis after explantation of a vagus nerve stimulator in a child. Childs Nerv Syst. 2003;19:261-3.

60 Heberle C, Berquin P, Larnicol N, Wallois F. Vagus nerve stimulation in a case of epilepsy with CSWSS: respiratory side effects during sleep. Epilepsia. 2002;43:1268-70.

61 Tubbs RS, Patwardhan R, Palmer CA, Kelly DR, Elton S, Blount JP, Bebin M, Grabb PA. Histological appearance of a chronically stimulated vagus nerve in a pediatric patient. Pediatr Neurosurg. 2001;35:99-102.

62 Kim W, Clancy RR, Liu GT. Horner syndrome associated with implantation of a vagus nerve stimulator. Am J Ophthalmol. 2001;131:383-4.

63 Duhaime AC, Melamed S, Clancy RR. Tonsillar pain mimicking glossopharyngeal neuralgia as a complication of vagus nerve stimulation: case report. Epilepsia. 2000;41:903-5.

64 Fahy BG. Intraoperative and perioperative complications with a vagus nerve stimulation device. J Clin Anesth. 2010;22:213-22.

65 Patel NC, Edwards MS. Vagal nerve stimulator pocket infections. Pediatr Infect Dis J. 2004;23:681-3.

66 Air EL, Ghomri YM, Tyagi R, Grande AW, Crone K, Mangano FT. Management of vagal nerve stimulator infections: do they need to be removed. Clinical article? J Neurosurg Pediatr. 2009;3:73-8.

67 Lundgren J, Ekberg O, Olsson R. Aspiration: a potential complication to vagus nerve stimulation. Epilepsia. 1998;39:998-1000.

68 Hallbook T, Lundgren J, Kohler S, Blennow G, Stromblad LG, Rosen I. Beneficial effects on sleep of vagus nerve stimulation in children with therapy resistant epilepsy. Eur J Paediatr Neurol. 2005;9: 399-407.

69 Rychlicki F, Zamponi N, Trignani R, Ricciuti RA, Iacoangeli M, Scerrati M. Vagus nerve stimulation: clinical experience in drug-resistant pediatric epileptic patients. Seizure. 2006;15:483-90.

70 You SJ, Kang HC, Ko TS, Kim HD, Yum MS, Hwang YS, Lee JK, Kim DS, Park SK. Comparison of corpus callosotomy and vagus nerve stimulation in children with Lennox-Gastaut syndrome. Brain Dev. 2008;30:195-9.

71 Pruvost M, Zaaimi B, Grebe R, Wallois F, Berquin P, Perlitz V. Cardiorespiratory effects induced by vagus nerve stimulation in epileptic children. Med Biol Eng Comput. 2006;44:338-47.

72 Zaaimi B, Grebe R, Berquin P, Wallois F. Vagus nerve stimulation induces changes in respiratory sinus arrhythmia of epileptic children during sleep. Epilepsia. 2009;50:2473-80.

73 Zaaimi B, Grebe R, Berquin P, Wallois F. Vagus nerve stimulation therapy induces changes in heart rate of children during sleep. Epilepsia. 2007;48:923-30. 
74 Zaaimi B, Heberle C, Berquin P, Pruvost M, Grebe R, Wallois F. Vagus nerve stimulation induces concomitant respiratory alterations and a decrease in $\mathrm{SaO} 2$ in children. Epilepsia. 2005; 46:1802-9.

75 Jansen K, Vandeput S, Milosevic M, Ceulemans B, Van Huffel S, Brown L, Penders J, Lagae L. Autonomic effects of refractory epilepsy on heart rate variability in children: influence of intermittent vagus nerve stimulation. Developmental Medicine \& Child Neurology. 2011;53:1143-9.

76 Hsieh T, Chen M, McAfee A, Kifle Y. Sleep-related breathing disorder in children with vagal nerve stimulators. Pediatr Neurol. 2008;38:99-103.

77 Nagarajan L, Walsh P, Gregory P, Stick S, Maul J, Ghosh S. Respiratory pattern changes in sleep in children on vagal nerve stimulation for refractory epilepsy. Can J Neurol Sci. 2003;30:224-7.

78 De Herdt V, Puimege L, De Waele J, Raedt R, Wyckhuys T, El Tahry R, Libert C, Wadman W, Boon P, Vonck K. Increased rat serum corticosterone suggests immunomodulation by stimulation of the vagal nerve. J Neuroimmunol. 2009;212:102-5.

79 Majoie HJ, Rijkers K, Berfelo MW, Hulsman JA, Myint A, Schwarz M, Vles JS. Vagus nerve stimulation in refractory epilepsy: effects on pro- and anti-inflammatory cytokines in peripheral blood. Neuroimmunomodulation. 2011;18:52-6.

80 Aalbers MW, Klinkenberg S, Rijkers K, Verschuure P, Kessels A, Aldenkamp A, Vles J, Majoie M. The Effects of Vagus Nerve Stimulation on Pro-and Anti-Inflammatory Cytokines in Children with Refractory Epilepsy: An Exploratory Study. Neuroimmunomodulation. 2012;19:352-8.

81 Hammond EJ, Uthman BM, Wilder BJ, Ben-Menachem E, Hamberger A, Hedner T, Ekman R. Neurochemical effects of vagus nerve stimulation in humans. Brain Res. 1992;583:300-3.

82 Ben-Menachem E, Hamberger A, Hedner T, Hammond EJ, Uthman BM, Slater J, Treig T, Stefan H, Ramsay RE, Wernicke JF, et al. Effects of vagus nerve stimulation on amino acids and other metabolites in the CSF of patients with partial seizures. Epilepsy Res. 1995;20:221-7.

83 Klinkenberg S, van den Bosch CN, Majoie HJ, Aalbers MW, Leenen L, Hendriksen J, Cornips EM, Rijkers K, Vles JS, Aldenkamp AP. Behavioural and cognitive effects during vagus nerve stimulation in children with intractable epilepsy - A randomized controlled trial. Eur J Paediatr Neurol. 2013;17:82-90.

84 Aldenkamp AP, Krom MD, Reijs R. Newer antiepileptic drugs and cognitive issues. Epilepsia. 2003;44: 21-9.

85 Klinkenberg S, van den Bosch CN, Majoie HJ, Aalbers MW, Leenen L, Hendriksen J, Cornips EM, Rijkers K, Vles JS, Aldenkamp AP. (2012) Behavioural and cognitive effects during vagus nerve stimulation in children with intractable epilepsy - A randomized controlled trial. Eur J Paediatr Neurol.

86 Majoie HJ, Berfelo MW, Aldenkamp AP, Evers SM, Kessels AG, Renier WO. Vagus nerve stimulation in children with therapy-resistant epilepsy diagnosed as Lennox-Gastaut syndrome: clinical results, neuropsychological effects, and cost-effectiveness. J Clin Neurophysiol. 2001;18:419-28.

87 Helmers SL, Duh MS, Guérin A, Sarda SP, Samuelson TM, Bunker MT, Olin BD, Jackson SD, Faught E. Clinical outcomes, quality of life, and costs associated with implantation of vagus nerve stimulation therapy in pediatric patients with drug-resistant epilepsy. European Journal of Paediatric Neurology. 2012;16:449-58.

88 Alapirtti T, Rinta S, Hulkkonen J, Makinen R, Keranen T, Peltola J. Interleukin-6, interleukin-1 receptor antagonist and interleukin-1beta production in patients with focal epilepsy: A video-EEG study. J Neurol Sci. 2009;280:94-7. 


\section{CHAPTER 3}

Vagus nerve stimulation in children with intractable epilepsy: a randomized controlled trial

S. Klinkenberg*, M. Aalbers*, J. Vles, E. Cornips, K. Rijkers, L. Leenen, A. Kessels, A. Aldenkamp, M. Majoie

${ }^{*}$ These authors contributed equally 


\begin{abstract}

\section{Objectives}

We aimed to evaluate the effects of vagus nerve stimulation (VNS) in children with intractable epilepsy on seizure frequency and severity and in terms of tolerability and safety.
\end{abstract}

\title{
Methods
}

In this study, the first randomized active controlled trial of its kind in children, 41 children ( 23 boys; mean age at implantation 11 years 2 months, standard deviation 4 years 2 months) were included. Thirty-five patients suffered from localization-related epilepsy ( 25 symptomatic, 10 cryptogenic), while 6 patients had generalized epilepsy ( 4 symptomatic, 2 idiopathic).

During a baseline period of 12 weeks, seizure frequency and severity were recorded using seizure diaries and the adapted Chalfont Seizure Severity Scale (NHS3), after which the patients entered a blinded active controlled phase of 20 weeks. During this phase, half of the patients received high output VNS (maximally $1.75 \mathrm{~mA}$ ) and the other half received low output stimulation $(0.25 \mathrm{~mA})$. Finally, all patients received high output stimulation for 19 weeks. For both phases, seizure frequency and severity were assessed as during the baseline phase. Overall satisfaction, and adverse events were assessed by semistructured interviews.

\section{Results}

At the end of the randomized controlled blinded phase, seizure frequency reduction of $50 \%$ or more occurred in $16 \%$ in the high output stimulation group and in $21 \%$ in the low output stimulation group $(\mathrm{p}=1.00)$. There was no significant difference in decrease of seizure severity between patients in both stimulation groups. Overall, VNS reduced seizure frequency by $50 \%$ or more in $26 \%$ of patients at the end of the add-on phase. The overall seizure severity also improved $(\mathrm{p} \leq 0.001)$.

\section{Conclusion}

VNS is a safe and well-tolerated adjunctive treatment of epilepsy in children. Our results suggest that the effect of VNS on seizure frequency in children is limited. However, the possible reduction in seizure severity and improvement in well-being makes this treatment worth considering in the individual child with intractable epilepsy. 


\section{INTRODUCTION}

Vagus nerve stimulation (VNS) is a neuromodulatory treatment that is used as an adjunctive therapy for patients with medically refractory epilepsy who are not eligible for epilepsy surgery or for whom surgery has failed and in whom non-epileptic events are excluded. VNS consists of chronic intermittent electrical stimulation of the vagus nerve, delivered by a programmable pulse generator.

Randomized active-controlled trials, which predominantly included adults, have demonstrated the safety and efficacy of $\mathrm{VNS}^{1,2}$ : seizure frequency decreased $>50 \%$ in $28-31 \%$ of patients in the treatment group compared to $13-15 \%$ in the placebo group. These trials led to Food and Drug Administration approval in 1997 for VNS as adjunctive therapy in patients $>12$ years with partial epilepsy refractory to treatment with available anti-epileptic drugs (AED).

The effectiveness of VNS might be more variable in children compared to adults: several prospective and retrospective studies describing more than 650 children, aged 0-19 years at various centres worldwide report $>50 \%$ seizure frequency reduction in $0-90 \%{ }^{3-28}$ However, these studies were uncontrolled, and there is a large variation in study groups for example regarding age, epilepsy syndromes, and follow up duration that varied from 3 months to 10 years. In addition, Murphy et al have reported the effects of VNS in 19 adolescents aged 12 or above that were part of the above mentioned randomized controlled trials. ${ }^{5}$

Yet, a randomized active-controlled paediatric trial that unequivocally demonstrates the efficacy of VNS in children has not been conducted so far. Therefore, we aim to evaluate the tolerability and effectiveness of VNS in children with intractable epilepsy in a randomized active-controlled study. Moreover, we aim to identify responder characteristics that may improve future patient selection.

\section{METHODS}

\section{Study design}

This study is a randomized active-controlled double blinded add on design. The study was divided into a baseline (12 weeks) and a blinded treatment phase ( 20 weeks). During the treatment phase patients received either high (therapeutic) or low (active control) stimulation. This active control group was incorporated to protect the blinding, because patients can notice stimulation. Additionally, at the end of the blinded phase all patients participated in a non-controlled follow up receiving high stimulation (19 weeks; add-on phase).

All parents and guardians and patients aged twelve and older gave informed consent and all procedures were approved by the Ethical Committee of Maastricht University Medical Center. 


\section{Patients}

41 Children with medically refractory epilepsy were included. Inclusion criteria were:

- Medically refractory epilepsy with adequate and stable AED concentrations

- Age between 4 and 18 years at implantation

- Not eligible for epilepsy surgery

- Written and signed informed consent from parents or guardians

Exclusion criteria included the following:

- Non-epileptic seizures

- Documented history of generalized status epilepticus in the previous three months

- Evidence of a progressive cerebral lesion, degenerative disorder, malignancy in the previous 5 years

- Unstable medical disease (i.e. cardiovascular, hepatic, renal, musculoskeletal, gastrointestinal, metabolic, endocrine) in the previous 2 years

- Schizophrenia or any psychotic symptomatology

- High risks of complications (obstructive respiratory disease, gastric disorders, cardiac rhythm disorders)

- History of alcohol or drug abuse, psychiatric disorder requiring electro-convulsive therapy, or chronic use of major tranquillizers (neuroleptics, antidepressants, or MAO inhibitors) in the previous 6 months

- Regular treatment with antihistamines, metoclopramide, or central nervous systemactive compounds

- Treatment with an experimental drug during the previous 30 days

\section{Device and implantation}

All surgical procedures were performed at the Maastricht University Medical Centre. Bipolar electrodes were placed around the left vagus nerve and connected to the programmable pulse generator (Neurocybernetic prothesis NCP, Cyberonics Inc., Webster, TX, USA), which was implanted subcutaneously or underneath the pectoral muscle below the clavicle.

\section{Randomization, blinding, and device settings}

The treating neurologist (MM), patients, parents, and guardians were blinded to treatment conditions. Patients were allocated to a treatment condition by one trial nurse (LL) using a computer program. The trial nurse also adjusted device settings according to a fixed protocol: 2 weeks after surgery the device was set to the parameters depicted in Table 3.1. Thereafter, in the treatment group the current was increased stepwise at 2week intervals to the maximally tolerated output current (maximum $1.75 \mathrm{~mA}$ ) on the basis of the clinical evaluation of the treating neurologist. The stepwise increase was stopped when a patient experienced a seizure reduction of $50 \%$ or more or was delayed or set back to the highest tolerable level in case of side effects. 
In the active control group, the output current was increased temporarily during each visit and switched back to the initial output current at the end of the visit. At the end of the blinded phase, the output parameters of the active control group were adjusted according to the schedule and parameters of the treatment group. The maximally applied current at the end of this phase was set at $2.25 \mathrm{~mA}$ for both groups.

Table $3.1 \quad$ Initial device settings.

\begin{tabular}{lcc}
\hline & Treatment group & Active control group \\
\hline Output current $(\mathrm{mA})$ & 0.25 & 0.25 \\
Pulse width $(\mathrm{ms})$ & 0.5 & 0.1 \\
Frequency $(\mathrm{Hz})$ & 30 & 1 \\
Duty cycle: on $(\mathrm{sec}) /$ off $(\mathrm{min})$ & $30 / 5$ & $14 / 60$ \\
\hline
\end{tabular}

\section{Outcome parameters}

Seizure frequency was recorded by patients' parents or guardians using a diary. Several seizure types were scored separately. Seizures were classified according to the ILAE classification..$^{29}$ Seizure frequency was recorded in the 12 weeks prior to implantation to serve as a baseline.

Seizure severity was estimated by administering the adapted Chalfont Severity Scales (NHS3) at baseline and at the end of the blinded and add-on phase to the caregiver who witnessed the seizures. ${ }^{30}$ This scale contains seven seizure-related factors and generates a score from 1 to 27 , the higher the score, the more severe the seizures.

Overall satisfaction was evaluated at the end of the unblinded add-on phase by standardized questioning the parents or guardians.

Adverse events were recorded at each visit (12 in total) by questioning parents or guardians using a semi-structured interview.

IQ was assessed using the Peabody Picture Vocabulary test (PPVT-III-NL) ${ }^{31}$ and the Beery VMI 5th edition, ${ }^{32}$ a developmental test of visual motor integration. To calculate IQ, raw scores were converted to age-equivalents in months, which were divided by age in months at the date of testing and multiplied by 100 . Finally, the average of both tests was calculated.

\section{Statistical analysis}

Power analysis was performed based on the assumption that $40 \%$ and $5 \%$ of patients in treatment and control groups respectively, had a clinically relevant response, which was defined as $50 \%$ or more seizure frequency reduction. Assuming a level of significance of 0.05 (two-tailed) and a power of $80 \%$ the size of our study population was calculated at two times 18.

Statistical analysis was performed using SPSSv19 for MacOX. 


\section{Seizure frequency}

Seizure frequency during the blinded phase was expressed as a percentage change compared to seizure frequency during baseline for each patient. Seizure frequency changes were classified into different categories $(\geq 50 \%$ increase, no response $(<50 \%$ increase or decrease), $\geq 50 \%$ decrease). The number of patients experiencing a $50 \%$ or more reduction in seizure frequency was compared between the high and low output group using Fisher's exact test. Furthermore, we compared the percentage change in seizure frequency between the low and high output group. First the percentage change was transformed by calculating the natural logarithm of each value, as these data were not normally distributed. The resulting values were normally distributed in both groups and therefore, were compared using the Student's t-test. The same analysis was repeated for the final 30 days of the blinded phase in order to assess any lag in efficacy or increased effectiveness over time. Overall improvement of seizure frequency was calculated by comparing the seizure frequency at the end of the add-on phase with baseline by a related-samples Wilcoxon signed rank test. Finally, seizure frequency changes were classified into different categories ( $\geq 50 \%$ increase, no response, $\geq 50 \%$ decrease).

\section{Seizure severity}

To asses seizure severity, first a mean NHS3 score was calculated for each patient by summing up the scores from each time point and dividing them by the number of seizure types. The median differences between groups were compared using a Mann-Whitney U test. Overall improvement of seizure severity was calculated by comparing the NHS3 score at the end of the add-on phase with baseline using a paired t-test.

\section{Responder characteristics}

We analyzed the relationship between the final outcome at the end of the add-on phase and the following parameters by correlation analysis (Kendall's tau): age at implantation, age at onset, and number of AEDs that had been used before implantation. The MannWhitney $U$ test was used for the variables sex and presence of bilateral interictal discharges, and the Kruskal-Wallis test was used for aetiology.

A p-value $<0.05$ was considered statistically significant.

\section{RESULTS}

\section{Demographics}

Forty-one children were implanted with VNS after appropriate regulatory approval. Inclusion took place over a two-year period. The mean age at implantation was 11 years 2 months (range 3 years 10 months to 17 years 8 months, median 12 years 4 months) and twenty-three were boys. Seizure onset occurred at a mean age of 2 years 4 months (range $0-12$ years, median 1 year 2 months) 
Two patients had undergone unsuccessful epilepsy surgery several years before VNS. Patients had been exposed to a mean of 7.2 AEDs and were receiving a mean of 2.4 AEDs at implantation. Fifteen of the 41 children had been on the ketogenic diet.

The majority of patients had localization related epilepsy, which in 10 patients was cryptogenic and in 25 was symptomatic. Four patients had symptomatic generalized epilepsy and only two patients had idiopathic generalized epilepsy. All but three children had learning disabilities. Twenty-five patients had multiple seizure types and 16 patients had a single seizure type.

An overview of baseline characteristics of both groups is provided in Table 3.2. There were no significant differences at baseline between the high and low stimulation groups with regard to sex, age at implantation, age at onset, seizure frequency, ILAE classification (localization related: symptomatic, cryptogenic; generalized: idiopathic or symptomatic), or number of AEDs used before surgery.

Three out of 41 patients who entered the study were excluded from seizure frequency calculations because of unreliable/ incomplete seizure diaries. Two of the excluded patients were in the high and one was in the low stimulation group. Additionally, information for four patients regarding the last 30 days of the add-on phase was missing.

\section{Effects of low versus high stimulation - end of randomized controlled blinded phase}

\section{Seizure frequency}

Three patients in the high group (16\%) and four in the low group (21\%) had a greater than $50 \%$ seizure frequency reduction $(\mathrm{p}=1.00$; Figure 3.1A). Among patients receiving high stimulation, the median seizure frequency increased by $23.4 \%$ compared with baseline, whereas among patients receiving low stimulation, seizure frequency fell by a median of $8.8 \%$ (comparison $\log$ transformed values, $\mathrm{p}=0.63$ ). Focussing on the last thirty days of the blinded phase, the median seizure frequency decrease was $3.1 \%$ and $5.1 \%$ in the high and low group respectively (comparison log transformed values, $\mathrm{p}=0.47)$. 
Table 3.2 Baseline characteristics of study groups.

\begin{tabular}{lcc}
\hline & High & Low \\
\hline Number of patients (male/ female) & $21(11 / 10)$ & $20(12 / 8)$ \\
Mean age at implantation (range) & $10 \mathrm{y} 11 \mathrm{~m}$ & $11 \mathrm{y} 6 \mathrm{~m}$ \\
& $(3 \mathrm{y} 10 \mathrm{~m}-17 \mathrm{y} 8 \mathrm{~m})$ & $(4 \mathrm{y} 2 \mathrm{~m}-17 \mathrm{y} 2 \mathrm{~m})$ \\
Mean age at onset (range) & $2 \mathrm{y} 10 \mathrm{~m}(0-12)$ & $1 \mathrm{y} 8 \mathrm{~m}(0-5)$ \\
Median age at onset (range) & $1 \mathrm{y} 2 \mathrm{~m}(0-12)$ & $1 \mathrm{y} 2 \mathrm{~m}(0-5)$ \\
Mean interval onset-implantation (range) & $7 \mathrm{y} 8 \mathrm{~m}(2-16)$ & $9 \mathrm{y} 5 \mathrm{~m}(3-15)$ \\
Median seizure frequency at baseline (range), seizures/day & $2.1(0.1-53.7)$ & $0.9(0.1-31.7)$ \\
ILAE classification & & \\
Localization related & $19(90 \%)$ & $16(80 \%)$ \\
$\quad$ Symptomatic & $15(71 \%)$ & $10(50 \%)$ \\
$\quad$ Cryptogenic & $4(19 \%)$ & $6(30 \%)$ \\
Generalized & $2(10 \%)$ & $4(20 \%)$ \\
$\quad$ Idiopathic & 0 & $2(10 \%)$ \\
$\quad$ Symptomatic & $2(10 \%)$ & $2(10 \%)$ \\
Mean number of AEDs & $7.0(5-10)$ & $7.3(4-14)$ \\
\hline
\end{tabular}

$\mathrm{AED}=$ antiepileptic drug; ILAE=International League Against Epilepsy; $\mathrm{m}=\mathrm{month} ; \mathrm{y}=$ years.

\section{Seizure severity}

Patients in the high stimulation group had a mean decrease in NHS3 score of 0.3 , while patients in the low stimulation group had a mean decrease of $0.6(p=0.71)$.

\section{Overall effects of stimulation - end of add-on phase}

\section{Seizure frequency}

Nine out of 34 patients (26\%) experienced a $50 \%$ or more seizure frequency reduction, five $(15 \%)$ experienced a $50 \%$ or more increase, and 20 (59\%) did not respond at all (Figure 3.1B). Seizure frequency decreased from a median of 1.61 seizures per day during the baseline phase to a median of 1.12 at the end of the add-on phase $(p=0.02)$.

\section{Seizure severity}

Seizure severity improved from a mean score of 9.5 at baseline to a mean score of 8.3 at the end of the add-on phase $(\mathrm{p}=0.00)$ (Figure 3.1C).

\section{Overall satisfaction}

Seventy-eight percent of the patients $(n=32)$ perceived some kind of positive effect at the end of the add-on phase.

\section{Responder characteristics}

There was weak evidence of a correlation between seizure frequency reduction at the end of the add-on phase and age at onset $(\tau=.21, \mathrm{p}=0.08)$ : children with a lower age at onset tended to respond better. Age at implantation and the number of AEDs that had been used before implantation were not correlated with seizure frequency reduction. No 
statistically significant differences in seizure frequency reduction were observed between boys and girls, between different aetiologies, and between the children with or without bilateral interictal activity.
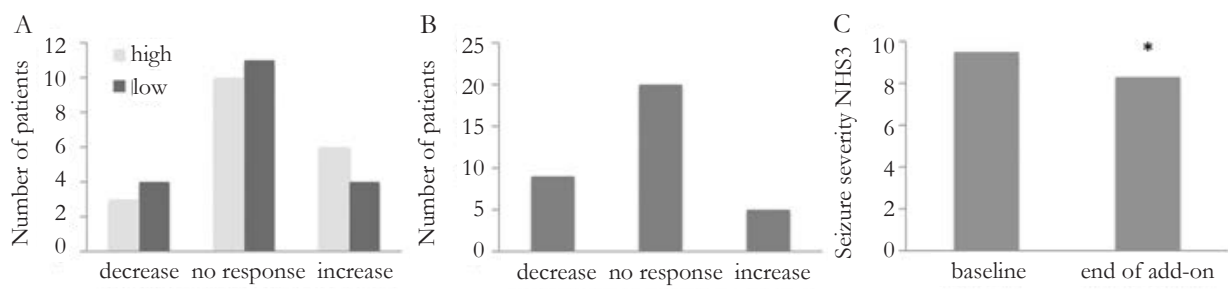

Figure 3.1 Effect of VNS on seizure frequency and severity. A Response distribution for high and low stimulation group during double blind phase $\geq 50 \%$ increase, no response, $\geq 50 \%$ decrease; B Distribution overall response at the end of the add-on phase $\geq 50 \%$ decrease, no response, $\geq 50 \%$ increase; C Mean seizure severity score according to the Chalfont Seizure Severity Scale, baseline compared to end of add-on phase, ${ }^{*} \mathrm{p}<0.05$.

\section{Adverse events}

The most frequently reported adverse events were voice alterations, coughing, and throat pain (Table 3.3). The majority of side effects were transient and most of them were stimulus related - some did not appear to be directly related to VNS. Reported behavioural changes consisted of agitation, crying, or frequent startles. Wound infection occurred in two patients. There was no need for device removal - both infections were successfully treated with short-term antibiotics. There were no other surgery-related side effects. Discontinuation during the study because of side effects did not occur.

Table $3.3 \quad$ Adverse effects.

\begin{tabular}{lc}
\hline Adverse event & Number of patients \\
\hline Voice alterations & $8(20 \%)$ \\
Coughing & $3(7 \%)$ \\
Throat pain & $3(7 \%)$ \\
Tingling sensations in throat & $2(5 \%)$ \\
Behavioural changes & $3(7 \%)$ \\
Infection & $2(5 \%)$ \\
Headache & $1(2 \%)$ \\
Spontaneous swelling around stimulator & $1(2 \%)$ \\
Pain around stimulator during exercise & $1(2 \%)$ \\
Itch & $1(2 \%)$ \\
\hline
\end{tabular}




\section{DISCUSSION}

This study is the first randomized active-controlled study on the effectiveness of VNS in children. We observed no statistically significant difference in seizure frequency reduction and seizure severity when comparing high and low stimulation groups. However, both seizure frequency and seizure severity at the end of the add-on phase were significantly decreased compared to baseline. A $\geq 50 \%$ seizure frequency reduction was reached in $26,4 \%(9 / 34)$ of patients at the end of the add-on phase. There was a trend towards a significant correlation between onset age and a favourable response to VNS. Strikingly, completion rate and overall satisfaction were very high, as in only one out of 41 patients, stimulation was discontinued, and more than three-quarters of the parents and guardians reported some kind of improvement.

Our results confirm previous reports demonstrating VNS in children is safe, when performed by experienced neurosurgeons: no major adverse events occurred and side effects of VNS were mild and mostly transient and related to stimulation. Infection occurred in two patients only and completely resolved with short-term antibiotics.

We were not able to demonstrate a favourable effect of high stimulation versus low stimulation as observed in adult randomized trials. ${ }^{1,2}$ Several factors may account for this. First of all, the size of our population might have been too small. Due to the lack of other randomized studies in children the power analysis was based on open label studies which suggested a larger effect than in adults. According to the current results future studies should include larger study population. Secondly differences exist in vagus nerve electrophysiology between adult and paediatric populations: threshold currents are higher and conduction velocities are lower in younger children compared older children and adults, indicating that maturation of the vagus nerve is not yet completed in young children. ${ }^{33}$ Moreover, the developing brain may respond differently to VNS. De Herdt et al. observed lower efficacy of VNS in children as compared to adults as well. ${ }^{34}$

Our results particularly contrast with the findings of Murphy et al, who reported a median seizure frequency reduction of $23 \%$ after three months of stimulation. This difference may be explained by differences in experimental design: Murphy et al. included 41 patients form the compassionate protocol as well. As this protocol is an uncontrolled protocol, VNS effectiveness may have been overestimated. Indeed, several other studies observed no seizure frequency reduction in part of their study popula$\operatorname{tion}^{7,8,11,12,22,24}$ or in the entire study population. ${ }^{26,27}$

In our study seizure frequency reduction in the lower output group was higher than expected. A decrease in seizure frequency may have resulted from the natural fluctuation of the disease which is probably higher in children than in adults. ${ }^{\text {7ddendum }}$ Indeed, children were twice as likely as adults to respond with a $>50 \%$ seizure frequency reduction during placebo treatment. ${ }^{35}$ Although active controlled treatment is not equivalent to placebo treatment, is it unlikely that low stimulation may yield a true 
effect, as previous studies have demonstrated that the chosen combination of current intensity and pulse width does not evoke an action potential. ${ }^{33,36}$

Overall, VNS reduced seizure frequency $\geq 50 \%$ in $26.4 \%$ patients. Effectiveness of VNS has possibly been influenced by several factors. First of all, it has been suggested that learning disabilities may be a negative predictor. ${ }^{20,26,37,38}$ As all but three of our patients had learning disabilities, this may have contributed to the modest effect of VNS. Chosen stimulation parameters may have affected VNS efficacy as well. In our study, output current was no higher than $1.75 \mathrm{~mA}$ during the blinded phase and $2.25 \mathrm{~mA}$ during the add-on phase, to prevent demyelinisation of the nerve that can already occur at normal output currents $(1.5 \mathrm{~mA}, 250 \mu \mathrm{s}, 20 \mathrm{~Hz}) .{ }^{39}$ It is unlikely that a further increase of output current would have resulted in a larger effect of VNS, as our results demonstrated that a higher output current was not correlated with a more favourable response. Furthermore, even low output current $(<1 \mathrm{~mA})$ can reduce seizure frequency in a substantial portion of patients. ${ }^{40}$ Moreover, we did not adjust the duty cycle to rapid cycling, i.e. a mode of stimulation with a faster intermittent pulse stimulation. Presumably, this did not influence seizure reduction significantly because several studies have shown that rapid cycling does not provide any additional persistent seizure control over normal cycling. ${ }^{10,41,42}$ We can not exclude that a longer follow-up would have yielded different results. Some studies have suggested that a larger percentage of patients responds at longer follow up ${ }^{23,43,44}$ while others demonstrate no effect of longer stimulation. ${ }^{12,26}$ However in our study, the number of responders at the end of the add-on phase was not significantly different from the blinded period.

An increase in seizure severity in response to VNS was observed as well, just as described in the adult trials $s^{2,45}$ and in two prospective and one retrospectivepaediatric trial. ${ }^{4,7,10}$ This might be explained by the natural course of the disease that is variable over time: the 2 patients described by Parker who had an initial increase in seizure frequency, both returned to baseline seizure frequencies when follow up duration was prolonged. ${ }^{7 a d d e n d u m}$ In 1 out of 6 patients described by Helmers et al. with a $>50 \%$ seizure frequency increase after 3 months, the increased seizure frequency persisted after 6 months. ${ }^{10}$

Several other studies have tried to identify a profile of responders. In line with the results of Patwardhan et al. we found a trend towards a correlation between onset age and response to VNS. According to Jansky et al. absence of bilateral interictal epileptic discharges (IED) or presence of malformation of cortical development (MCD) were factors predicting a favourable outcome. ${ }^{46}$ In our responding group seven out of nine patients with $\geq 50 \%$ seizure frequency reduction had bilateral IED versus 18 out of 25 non-responders. Only one of the patients with $\operatorname{MCD}(n=8)$ had a $\geq 50 \%$ seizure frequency reduction. Callosotomy prior to VNS treatment was reported to be associated with a positive response, ${ }^{10,46}$ but our patient who had undergone a callosotomy did not respond favourable. 
Finally it is important to realize that a moderate effect on seizure frequency does not signify low utility of VNS. After all, this population of patients is highly refractory. For comparison: only $3 \%$ of children with refractory epilepsy becomes seizure free after addition of merely a third AED. ${ }^{47}$ Furthermore, contrary to AEDs, when children respond positively to VNS, this response is long-lasting., ${ }^{5,10,25,48}$ The benefits therefore might be of great value for the individual child with therapy resistant epilepsy. This is especially true when the safety of the implantation procedure and favourable side effect profile of VNS are taken into account. Moreover, irrespective of the (lack of) effect on seizure frequency, the possible improvement of seizure severity and well-being makes this treatment worthwhile considering. ${ }^{49,50}$ 


\section{REFERENCES}

1. Handforth A, DeGiorgio CM, Schachter SC, Uthman BM, Naritoku DK, Tecoma ES, et al. Vagus nerve stimulation therapy for partial-onset seizures: a randomized active-control trial. Neurology. 1998;51:48-55.

2. The VNS Study Group. A randomized controlled trial of chronic vagus nerve stimulation for treatment of medically intractable seizures. Neurology. 1995;45:224-30.

3. Murphy JV, Hornig G, Schallert G. Left vagal nerve stimulation in children with refractory epilepsy. Preliminary observations. Arch Neurol. 1995;52:886-9.

4. Hornig GW, Murphy JV, Schallert G, Tilton C. Left vagus nerve stimulation in children with refractory epilepsy: an update. South Med J. 1997;90:484-8.

5. Murphy JV. Left vagal nerve stimulation in children with medically refractory epilepsy. The Pediatric VNS Study Group. J Pediatr. 1999;134:563-6.

6. Lundgren J, Amark P, Blennow G, Stromblad LG, Wallstedt L. Vagus nerve stimulation in 16 children with refractory epilepsy. Epilepsia. 1998;39:809-13.

7. Parker AP, Polkey CE, Binnie CD, Madigan C, Ferrie CD, Robinson RO. Vagal nerve stimulation in epileptic encephalopathies. Pediatrics. 1999;103:778-82.

8. Patwardhan RV, Stong B, Bebin EM, Mathisen J, Grabb PA. Efficacy of vagal nerve stimulation in children with medically refractory epilepsy. Neurosurgery. 2000;47:1353-7.

9. Murphy JV, Wheless JW, Schmoll CM. Left vagal nerve stimulation in six patients with hypothalamic hamartomas. Pediatr Neurol. 2000;23:167-8.

10. Helmers SL, Wheless JW, Frost M, Gates J, Levisohn P, Tardo C, et al. Vagus nerve stimulation therapy in pediatric patients with refractory epilepsy: retrospective study. J Child Neurol. 2001;16:843-8.

11. Majoie HJ, Berfelo MW, Aldenkamp AP, Evers SM, Kessels AG, Renier WO. Vagus nerve stimulation in children with therapy-resistant epilepsy diagnosed as Lennox-Gastaut syndrome: clinical results, neuropsychological effects, and cost-effectiveness. J Clin Neurophysiol. 2001;18:419-28.

12. Majoie HJ, Berfelo MW, Aldenkamp AP, Renier WO, Kessels AG. Vagus nerve stimulation in patients with catastrophic childhood epilepsy, a 2-year follow-up study. Seizure. 2005;14:10-8.

13. Parain D, Penniello MJ, Berquen P, Delangre T, Billard C, Murphy JV. Vagal nerve stimulation in tuberous sclerosis complex patients. Pediatr Neurol. 2001;25:213-6.

14. Nagarajan L, Walsh P, Gregory P, Lee M. VNS therapy in clinical practice in children with refractory epilepsy. Acta Neurol Scand. 2002;105:13-7.

15. Kossoff EH, Pyzik PL. Improvement in alertness and behavior in children treated with combination topiramate and vagus nerve stimulation. Epilepsy Behav. 2004;5:256-9.

16. Kang HC, Hwang YS, Kim DS, Kim HD. Vagus nerve stimulation in pediatric intractable epilepsy: a Korean bicentric study. Acta Neurochir Suppl. 2006;99:93-6.

17. Alexopoulos AV, Kotagal P, Loddenkemper T, Hammel J, Bingaman WE. Long-term results with vagus nerve stimulation in children with pharmacoresistant epilepsy. Seizure. 2006;15:491-503.

18. Benifla M, Rutka JT, Logan W, Donner EJ. Vagal nerve stimulation for refractory epilepsy in children: indications and experience at The Hospital for Sick Children. Childs Nerv Syst. 2006;22:1018-26.

19. Blount JP, Tubbs RS, Kankirawatana P, Kiel S, Knowlton R, Grabb PA, et al. Vagus nerve stimulation in children less than 5 years old. Childs Nerv Syst. 2006;22:1167-9.

20. Rychlicki F, Zamponi N, Cesaroni E, Corpaci L, Trignani R, Ducati A, et al. Complications of vagal nerve stimulation for epilepsy in children. Neurosurg Rev. 2006;29:103-7.

21. Saneto RP, Sotero de Menezes MA, Ojemann JG, Bournival BD, Murphy PJ, Cook WB, et al. Vagus nerve stimulation for intractable seizures in children. Pediatr Neurol. 2006;35:323-6.

22. Khurana DS, Reumann M, Hobdell EF, Neff S, Valencia I, Legido A, et al. Vagus nerve stimulation in children with refractory epilepsy: unusual complications and relationship to sleep-disordered breathing. Childs Nerv Syst. 2007;23:1309-12.

23. Zamponi N, Passamonti C, Cappanera S, Petrelli C. Clinical course of young patients with Dravet syndrome after vagal nerve stimulation. Eur J Paediatr Neurol. 2011;15:8-14.

24. Kabir SM, Rajaraman C, Rittey C, Zaki HS, Kemeny AA, McMullan J. Vagus nerve stimulation in children with intractable epilepsy: indications, complications and outcome. Childs Nerv Syst. 2009;25: 1097-100.

25. Shahwan A, Bailey C, Maxiner W, Harvey AS. Vagus nerve stimulation for refractory epilepsy in children: More to VNS than seizure frequency reduction. Epilepsia. 2009;50:1220-8. 
26. Danielsson S, Viggedal G, Gillberg C, Olsson I. Lack of effects of vagus nerve stimulation on drug-resistant epilepsy in eight pediatric patients with autism spectrum disorders: a prospective 2-year follow-up study. Epilepsy Behav. 2008;12:298-304.

27. Arthur TM, Saneto RP, de Menezes MS, Devinsky O, Lajoie J, Murphy PJ, et al. Vagus nerve stimulation in children with mitochondrial electron transport chain deficiencies. Mitochondrion. 2007;7:279-83.

28. Rossignol E, Lortie A, Thomas T, Bouthiller A, Scavarda D, Mercier C, et al. Vagus nerve stimulation in pediatric epileptic syndromes. Seizure. 2009;18:34-7.

29. Commission on Classification and Terminology of the International League Against Epilepsy. Proposal for revised classification of epilepsies and epileptic syndromes. . Epilepsia. 1989;30:389-99.

30. O'Donoghue MF, Duncan JS, Sander JW. The National Hospital Seizure Severity Scale: a further development of the Chalfont Seizure Severity Scale. Epilepsia. 1996;37:563-71.

31. Dunn L, Dunn L. Peabody Picture Vocabulary Test--III--NL, Nederlandse versie door Liesbeth Schlichting. Amsterdam: Harcourt Assessment B.V. 2005.

32. Beery K, Beery N. The Beery---Buktenica Developmental Test of Visual-Motor Integration. BeeryTM VMI. Administration, Scoring and Teaching Manual. 5th ed. Minneapolis: NCS Pearson 2006.

33. Koo B, Ham SD, Sood S, Tarver B. Human vagus nerve electrophysiology: a guide to vagus nerve stimulation parameters. J Clin Neurophysiol. 2001;18:429-33.

34. De Herdt V, Boon P, Ceulemans B, Hauman H, Lagae L, Legros B, et al. Vagus nerve stimulation for refractory epilepsy: a Belgian multicenter study. Eur J Paediatr Neurol. 2007;11:261-9.

35. Rheims S, Cucherat M, Arzimanoglou A, Ryvlin P. Greater response to placebo in children than in adults: a systematic review and meta-analysis in drug-resistant partial epilepsy. PLoS Med. 2008;5: e166.

36. Heck C, Helmers SL, DeGiorgio CM. Vagus nerve stimulation therapy, epilepsy, and device parameters: scientific basis and recommendations for use. Neurology. 2002;59(6 Suppl 4):S31-7.

37. Aldenkamp AP, Majoie HJ, Berfelo MW, Evers SM, Kessels AG, Renier WO, et al. Long-term effects of 24month treatment with vagus nerve stimulation on behaviour in children with Lennox-Gastaut syndrome. Epilepsy Behav. 2002;3:475-9.

38. Hallbook T, Lundgren J, Blennow G, Stromblad LG, Rosen I. Long term effects on epileptiform activity with vagus nerve stimulation in children. Seizure. 2005; 14:527-33.

39. Tubbs RS, Patwardhan R, Palmer CA, Kelly DR, Elton S, Blount JP, et al. Histological appearance of a chronically stimulated vagus nerve in a pediatric patient. Pediatr Neurosurg. 2001;35:99-102.

40. Bunch S, DeGiorgio CM, Krahl S, Britton J, Green P, Lancman M, et al. Vagus nerve stimulation for epilepsy: is output current correlated with acute response? Acta Neurol Scand. 2007;116:217-20.

41. Labar D. Vagus nerve stimulation for 1 year in 269 patients on unchanged antiepileptic drugs. Seizure. 2004; 13:392-8.

42. Scherrmann J, Hoppe C, Kral T, Schramm J, Elger CE. Vagus nerve stimulation: clinical experience in a large patient series. J Clin Neurophysiol. 2001;18:408-14.

43. Ben-Menachem E. Vagus-nerve stimulation for the treatment of epilepsy. Lancet Neurol. 2002;1: 477-82.

44. George R, Salinsky M, Kuzniecky R, Rosenfeld W, Bergen D, Tarver WB, et al. Vagus nerve stimulation for treatment of partial seizures: 3. Long-term follow-up on first 67 patients exiting a controlled study. First International Vagus Nerve Stimulation Study Group. Epilepsia. 1994;35:637-43.

45. Ben-Menachem E, Manon-Espaillat R, Ristanovic R, Wilder BJ, Stefan H, Mirza W, et al. Vagus nerve stimulation for treatment of partial seizures: 1. A controlled study of effect on seizures. First International Vagus Nerve Stimulation Study Group. Epilepsia. 1994;35:616-26.

46. Janszky J, Hoppe M, Behne F, Tuxhorn I, Pannek HW, Ebner A. Vagus nerve stimulation: predictors of seizure freedom. J Neurol Neurosurg Psychiatry. 2005;76:384-9.

47. Sheth RD, Stafstrom CE. Intractable pediatric epilepsy: vagal nerve stimulation and the ketogenic diet. Neurol Clin. 2002;20:1183-94.

48. Arhan E, Serdaroglu A, Kurt G, Bilir E, Durdag E, Erdem A, et al. The efficacy of vagal nerve stimulation in children with pharmacoresistant epilepsy: practical experience at a Turkish tertiary referral center. Eur J Paediatr Neurol. 2011;14:334-9.

49. Aldenkamp AP, Van de Veerdonk SH, Majoie HJ, Berfelo MW, Evers SM, Kessels AG, et al. Effects of 6 Months of Treatment with Vagus Nerve Stimulation on Behavior in Children with Lennox-Gastaut Syndrome in an Open Clinical and Nonrandomized Study. Epilepsy Behav. 2001;2:343-50. 
50. Murphy JV, Torkelson R, Dowler I, Simon S, Hudson S. Vagal nerve stimulation in refractory epilepsy: the first 100 patients receiving vagal nerve stimulation at a pediatric epilepsy center. Arch Pediatr Adolesc Med. 2003;157:560-4. 



\section{CHAPTER 4}

The effects of vagus nerve stimulation on pro- and anti-inflammatory cytokines in children with refractory epilepsy: an exploratory study

M. Aalbers, S. Klinkenberg, K. Rijkers, P. Verschuure, A. Aldenkamp, J. Vles, M. Majoie 


\begin{abstract}

\section{Background}

The vagus nerve has important immunological and anti-inflammatory actions that might be relevant to the beneficial effects of vagus nerve stimulation (VNS).

\section{Objectives}

Therefore, we conducted an exploratory study on VNS effects on cytokine levels in plasma and cerebrospinal fluid of children suffering from refractory epilepsy. Moreover, as predictors of the response are lacking, we also aimed to determine if cytokine changes predicted the clinical response.
\end{abstract}

\title{
Methods
}

VNS was performed according to a randomized double-blind design: plasma levels were compared between patients who received 20 weeks of high output (therapeutic) $(n=21)$ or low output (active control) stimulation $(n=20)$. Thereupon, all patients received high output stimulation for another 19 weeks; levels during this period were compared to baseline. Interictal interleukin-1 $\beta$, interleukin-6, and interleukin- 10 were determined by ELISA.

\section{Results}

No significant changes were found between high and low output groups and between the last nineteen weeks of stimulation and baseline. Changes in interleukin-1 $\beta$ correlated with improved IQ $(\tau=.42$, $\mathrm{p}<0.01)$. Lower baseline plasma levels of interleukin-6 were associated with more seizure frequency reduction $\left[\mathrm{R}^{2}=0.105(1,35), \mathrm{p}=0.050\right]$.

\section{Conclusion}

Interictal cytokine levels were not altered by VNS but baseline interleukin- 6 predicted clinical response. In the future patient selection may be aided by determination of the cytokine profile of the patient. 


\section{INTRODUCTION}

Vagus nerve stimulation (VNS) is an adjunctive treatment for medically refractory epilepsy. In addition to anticonvulsive effects, VNS has positive effects on behavior, mood, and cognition. ${ }^{1}$ Not all patients respond to VNS: in epilepsy, 23-39\% of VNS treated patients experience more than 50\% seizure frequency reduction versus $13-19 \%$ of placebo treated patients who received non-therapeutic low output stimulation. ${ }^{2-4}$ It is unclear why the effects of VNS are limited and predictors to identify patients that are most likely to respond are lacking. Moreover, the mechanism of action of VNS is not fully understood.

In this context, the immuno-modulatory function of the vagus nerve is of particular interest. Afferent signals can activate the so-called cholinergic anti-inflammatory pathway upon inflammation. ${ }^{5}$ Through this pathway, efferent vagus nerve fibres inhibit release of pro-inflammatory cytokines and in this way reduce inflammation. In recent years, inflammation has been strongly implicated in development of seizures and epilepsy ${ }^{6}$ and therefore the activation of the anti-inflammatory pathway by VNS could decrease the inflammatory response and thereby explain its clinical effects.

While several animal studies have demonstrated that electrical and chemical stimulation of the vagus nerve affects the immune response, ${ }^{7-16}$ only a few studies on the immunomodulatory effects of VNS have been performed in humans. VNS has been reported to increase circulating pro-and anti-inflammatory cytokines in depressed patients, ${ }^{17}$ but in epilepsy patients the results are inconclusive: VNS has been shown to alter the immune response $^{18}$ but fails to affect systemic inflammation. ${ }^{19,20}$ So far there are no studies available that evaluated neuro-immunomodulation by VNS in children. Therefore the purpose of this study was to determine whether VNS treatment caused changes cytokine levels in children and if these changes were related to such clinical effects as seizure frequency reduction and IQ. Furthermore, we aimed to determine if the changes in cytokine levels could predict clinical response. Therefore, we determined levels of interleukin-1beta (IL-1 $\beta$ ) and interleukin-6 (IL-6), while these cytokines were increased in epilepsy patients. ${ }^{21-26}$ Additionally, we also evaluated levels of interleukin-10, as this is one of the most important anti-inflammatory cytokines. ${ }^{27}$

\section{METHODS}

\section{Patients}

We included 41 children ( 23 boys) with medically refractory epilepsy, which was defined as failure of adequate trials of at least two tolerated, appropriately chosen and used antiepileptic drug schedules to achieve sustained seizure freedom. ${ }^{28}$ The mean age at implantation was 11.2 years. Thirty-five patients had localization related epilepsy, 6 patients had generalized epilepsy (for details see Table 4.1). Twenty patients had focal 
seizures, 11 patients had generalized seizures, and 10 patients had both focal and generalized seizures. All patients had undergone an extensive clinical evaluation, which included EEG, CT/MRI, and genetic and or metabolic screening as needed. Patients with a progressive cerebral lesion, malignancy, or any degenerative or immunological disorder such as Rasmussen encephalitis or acute disseminated encephalomyelitis were excluded. Medication regimens remained unchanged throughout the study and none of the patients were treated with antihistamines, metoclopramide, or anti-inflammatory drugs. Visits were postponed if patients displayed any clinical signs of infection during the study. The most frequent administered anti-epileptic drugs (AEDs) included valproic acid $(n=18)$, lamotrigine $(n=16)$, clobazam $(n=11)$, topiramate $(n=10)$, and levetiracetam $(n=9)$.

Table 4.1 Patient characteristics.

\begin{tabular}{lcc}
\hline & High output VNS & Low output VNS \\
\hline Number of patients (male/ female) & $21(11 / 10)$ & $20(12 / 8)$ \\
Mean age at implantation (range) & $10 \mathrm{y} 11 \mathrm{~m}$ & $11 \mathrm{y} 6 \mathrm{~m}$ \\
& $(3 \mathrm{y} 10 \mathrm{~m}-17 \mathrm{y} 8 \mathrm{~m})$ & $(4 \mathrm{y} 2 \mathrm{~m}-17 \mathrm{y} 2 \mathrm{~m})$ \\
Mean age at onset (range) & $2 \mathrm{y} 10 \mathrm{~m}(0-12)$ & $1 \mathrm{y} 8 \mathrm{~m}(0-5)$ \\
Mean interval onset-implantation (range) & $7 \mathrm{y} 8 \mathrm{~m}(2-16)$ & $9 \mathrm{y} 5 \mathrm{~m}(3-15)$ \\
Median seizure frequency at baseline (range), seizures/day & $2.1(0.1-53.7)$ & $0.9(0.1-31.7)$ \\
ILAE classification (Epilepsy, 1989) & & \\
Localization related & $19(90 \%)$ & $16(80 \%)$ \\
$\quad$ Symptomatic & $15(71 \%)$ & $10(50 \%)$ \\
$\quad$ Cryptogenic & $4(19 \%)$ & $6(30 \%)$ \\
Generalized & $2(10 \%)$ & $4(20 \%)$ \\
$\quad$ Idiopathic & 0 & $2(10 \%)$ \\
$\quad$ Symptomatic & $2(10 \%)$ & $2(10 \%)$ \\
Total number of AEDs ever administered (range) & $7.0(5-10)$ & $7.3(4-14)$ \\
Mean number of AEDs used during the study (range) & $2.5(1-5)$ & $2.5(1-4)$ \\
Mean maximal output during blinded phase, mA & 0.99 & n.a. \\
Mean maximal output during add-on phase, mA & 1.98 & 1.29 \\
\hline
\end{tabular}

$\mathrm{M}=$ months; $\mathrm{n} . \mathrm{a} .=$ not applicable; $\mathrm{y}=$ years.

After a baseline period of twelve weeks, patients were implanted with a programmable pulse generator (Neurocybernetic prothesis NCP, Cyberonics Inc., Webster, TX, USA). Patients were randomly assigned to two groups: patients received either high (therapeutic) or low (active control) stimulation. This active control group was incorporated to protect the blinding, because patients can notice stimulation, and to control for the presence of the electrode. Initial stimulation parameters are depicted in Table 4.2. In the treatment group, current was stepwise increased with two-week intervals to the maximally tolerated output current (maximum $1.75 \mathrm{~mA}$ ). After 20 weeks, all patients entered an unblinded follow up of 19 weeks. During this add-on phase both groups received high output stimulation (maximum $2.25 \mathrm{~mA}$ ) (See Figure 4.1 for study design). 
All procedures were approved by the Central Medical Ethical Committee of Maastricht University Medical Centre and written informed consent was obtained from all caregivers and patients if aged over twelve.

Table 4.2 Initial device settings.

\begin{tabular}{lcc}
\hline & Active control group & Treatment group \\
\hline Output current $(\mathrm{mA})$ & 0.25 & 0.25 \\
Pulse width $(\mathrm{ms})$ & 0.1 & 0.5 \\
Frequency $(\mathrm{Hz})$ & 1 & 30 \\
Duty cycle: on $(\mathrm{sec}) /$ off $(\mathrm{min})$ & $14 / 60$ & $30 / 5$ \\
\hline
\end{tabular}

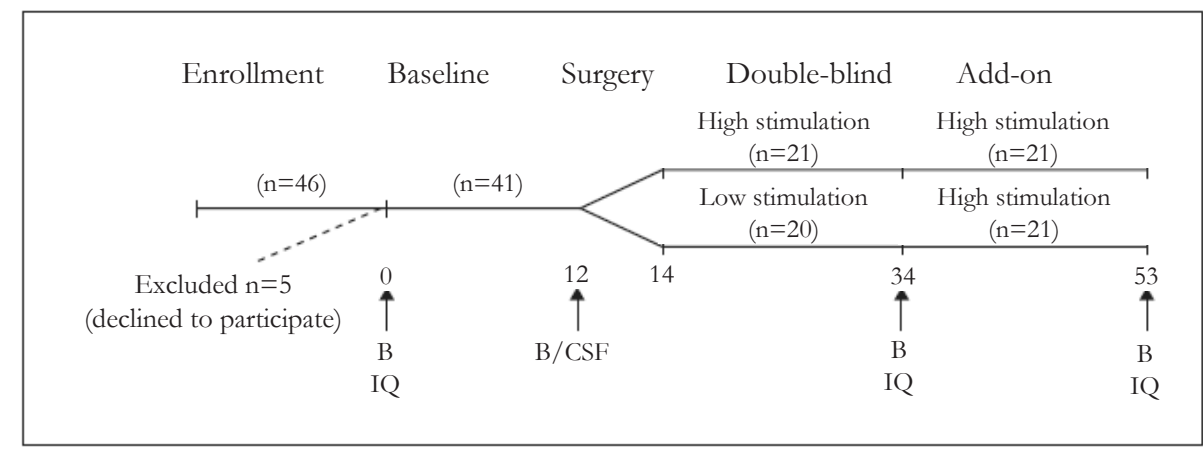

Figure 4.1 Study design.

After a 12-week baseline, patients were implanted with the vagus nerve stimulator. During the double blind phase (20 weeks) half of the patients received high output stimulation and the other half received low output stimulation. During the add-on phase (19 weeks), all patients received high output stimulation. Arrows indicate data and sample collection: $\mathrm{B}=$ blood, $\mathrm{CSF}=$ cerebro spinal fluid; time depicted in weeks.

\section{VNS effects}

We evaluated VNS effects on seizure frequency and cognitive function. Seizure frequency was recorded in a seizure diary by caregivers. The effect of VNS was calculated by expressing the mean seizure frequency during the last 19 weeks of VNS as a percentage of seizure frequency at baseline.

Cognitive function was assessed using the Peabody Picture Vocabulary test $(\text { PPVT-III-NL })^{29}$ and the Beery VMI $5^{\text {th }}$ edition. ${ }^{30}$ To calculate IQ, raw scores were converted to age-equivalents in months, which were divided by age in months at the date of testing and multiplied by 100 . Finally, the average of both tests was calculated.

\section{Cytokine measurements}

EDTA plasma was obtained at baseline, at the end of the blinded phase after 20 weeks of stimulation, and at the end of the add-on phase after 39 weeks of stimulation (Figure 
4.1). Plasma and cerebrospinal fluid (CSF) were also collected immediately before surgery when patients were under general anesthesia. Patients did not experience seizures in $>12$ hours preceding sample collection in order to determine interictal, overall cytokine levels.

Levels of interleukin-1 $\beta$ (IL-1 $\beta$ ), interleukin-6 (IL-6), and interleukin-10 (IL-10) were determined in duplicate using commercially available enzyme-linked immunosorbent assays (R\&D Systems, Abingdon, United Kingdom; detection limits 0.125, 0.156, $0.78 \mathrm{pg} / \mathrm{ml}$ respectively) following the manufacturer's instructions. Values below the detection limit were converted to a value of 0.5 times the detection limit for statistical analysis, as these cannot be considered missing. ${ }^{20,31}$

\section{Statistics}

Statistical analysis was performed using SPSSv19 for MacOSX. Cytokine levels at the end of the blinded phase were compared between the high and low output groups using the Mann-Whitney U Test. Cytokine levels at the end of the add-on phase were compared with baseline by a Related-Samples Wilcoxon Signed Rank Test.

To analyze the relationship between cytokines changes and VNS effects we performed a correlation analysis (Kendall's tau) between the percentage change of cytokines and IQ and seizure frequency.

To evaluate whether baseline and pre-operative cytokine plasma and CSF levels could predict seizure frequency reduction, univariate linear regression analysis was performed using seizure reduction during the add-on phase as the dependent variable.

A p-value $<0.05$ was considered statistically significant.

\section{RESULTS}

There were no statistically significant differences in cytokine levels between the high and low stimulation group at the end of the blinded phase or between cytokines levels at baseline and at the end of the add-on phase (Table 4.3).

Table 4.3 Plasma cytokine levels.

\begin{tabular}{llcllll}
\hline & \multicolumn{1}{c}{ Baseline } & $\begin{array}{c}\text { Blind phase: } \\
\text { active control group }\end{array}$ & $\begin{array}{c}\text { Blind phase: } \\
\text { treatment group }\end{array}$ & End of add-on & $p^{I}$ & $p^{2}$ \\
\hline $\mathrm{IL}-1 \beta(\mathrm{pg} / \mathrm{ml})$ & $0.06(0.06-8.00)$ & $0.14(0.06-1.30)$ & $0.06(0.06-0.62)$ & $0.14(0.06-1.92)$ & 0.87 & 0.73 \\
$\mathrm{IL}-6(\mathrm{pg} / \mathrm{ml})$ & $1.16(0.23-9.57)$ & $1.09(0.25-17.39)$ & $1.27(0.30-10.13)$ & $1.08(0.37-18.57)$ & 0.64 & 0.79 \\
$\mathrm{IL}-10(\mathrm{pg} / \mathrm{ml})$ & $0.78(0.39-6.87)$ & $0.78(0.39-5.46)$ & $0.78(0.39-7.53)$ & $0.78(0.39-14.58)$ & 0.50 & 0.10 \\
\hline
\end{tabular}

Values are medians (range); ${ }^{1}$ Comparison of active control and treatment group by Mann-Whitney $U$ test; ${ }^{2}$ Comparison of levels at baseline and at the end of the add-on phase by related-samples Wilcoxon signed rank test. 


\section{Seizure frequency reduction and cytokine changes}

Four patients were excluded from seizure frequency analysis due to incomplete seizure diaries. Twenty-two percent $(\mathrm{n}=8)$ of the patients experienced $\geq 50 \%$ seizure frequency reduction. The change in seizure frequency during the add-on phase did not correlate with changes in cytokine levels.

\section{Cognitive function and cytokine changes}

Fourteen patients could not participate in cognitive testing due to cognitive and/or physical limitations. The IQ tended to increase from a mean score of 55.1 (baseline) to 58.2 (end of the add-on phase) ( $\mathrm{p}=0.08$, paired $\mathrm{t}$-test). The effects on cognition were positively correlated with a change in IL- $1 \beta(\tau=0.42, \mathrm{p}<0.01)$ : the larger the IL- $1 \beta$ increase, the greater the improvement of IQ (Figure 4.2). Changes in IL-6 and IL-10 did not significantly correlate with changes in IQ.

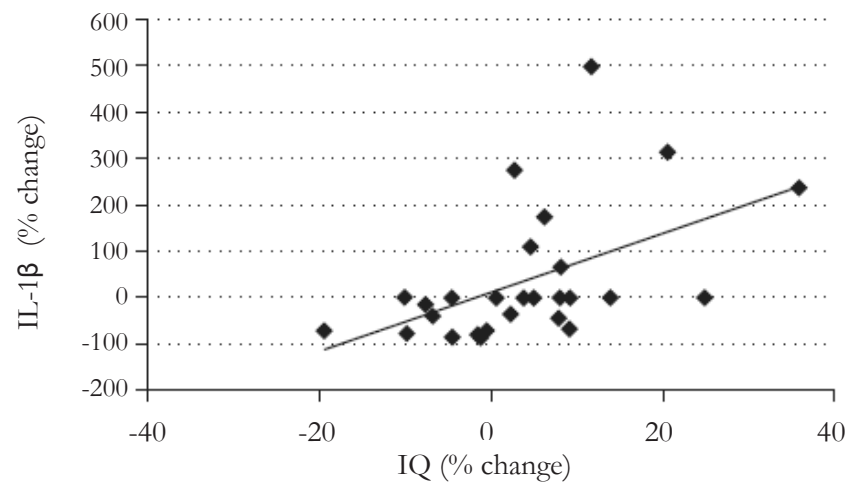

Figure 4.2 Correlation of changes in cytokine levels and IQ. Percentage change in cytokine correlation with percentage change in IQ. Percentage change in IL-1 $\beta$ correlation with percentage change in IQ (significant positive correlation, Kendall's tau, $\mathrm{p}<0.01$ ).

\section{Predictive value of baseline cytokines}

Baseline plasma levels of IL-6 predicted seizure frequency reduction during the add-on phase $\left[R^{2}=0.105(1,35), \mathrm{p}=0.050\right]$ : lower IL-6 levels were associated with more seizure frequency reduction. Pre-implantation CSF levels did not predict seizure frequency reduction. 


\section{DISCUSSION}

To our knowledge, this exploratory study is the first study that evaluates the effects of VNS on cytokine levels of children. VNS reduced seizure frequency with more than $50 \%$ in $22 \%$ of the patients. We were unable to confirm our hypothesis that VNS evokes an anti-inflammatory reaction since we did not find a statistically significant effect of VNS on interictal plasma cytokine levels. Similar to our results, two studies in adults suffering from medically refractory epilepsy did not show significant changes in blood levels of IL6, IL-10, and tumor necrosis factor alpha (TNF- $\alpha) \cdot{ }^{19,20} \mathrm{~A}$ study in adult depressed patients in contrast showed that three months of VNS increased plasma levels of IL-6, TNF- $\alpha$, and transforming growth factor beta. ${ }^{17}$

Several reasons might explain the absence of the hypothesized VNS-induced antiinflammatory reaction. Firstly, VNS did not alter interictal cytokine levels. Since epilepsy patients are known to have altered interictal cytokine levels, ${ }^{32-34}$ we specifically determined whether VNS changed cytokine levels more than twelve hours after a seizure. Nevertheless while these cytokine levels were unchanged, we cannot exclude the possibility that VNS treatment inhibits cytokine changes at a different time point. For example, the chosen interval might not have been sufficient for cytokines to return to their baseline levels. On the other hand, if VNS only inhibits cytokine expression in the immediate post-ictal phase this effect would not be detected using the present study design. Although technically challenging, future studies should compare cytokine levels immediately before and after a seizure..$^{35,36}$

Furthermore, although VNS did not alter plasma cytokine levels, it may still have affected CNS cytokine levels. CSF cytokine levels are probably the best representation of CNS cytokine levels available but for ethical reasons that limit CSF collection in children it was only obtain CSF at one time point which made longitudinal monitoring impossible.

There are several limitations, which might account for the lack of changes in cytokine levels. For example, the study included a relatively small number of patients who suffered from different epilepsy syndromes. This might have limited the possibility of detecting significant effects as there is evidence that plasma cytokine concentrations differ between various etiologies and pathologies..$^{33,35,37}$ In addition, the relatively low responder rate may have affected an association between the anticonvulsive effectiveness of VNS and any cytokine changes.

Contrary to seizure frequency reduction, changes in IQ were correlated with altered levels of IL-1 $\beta$ : a larger increase in IL- $1 \beta$ was associated with a larger improvement of IQ. IL- $1 \beta$ is a pro-inflammatory cytokine, which has pro-convulsive properties. ${ }^{38}$ It is also implicated in cognitive function and has been shown to have both beneficial and detrimental effects on learning and memory. ${ }^{39}$ However, as no causality can be inferred from the current analysis, future studies should explore whether changes in IL-1 $\beta$ actually contribute to improved cognition upon VNS. 
Our study revealed that low baseline IL-6 levels correspond to greater reduction in seizure frequency and thus predict clinical response. IL-6 is a cytokine with both proand anti-inflammatory characteristics that mediates the acute phase reaction and fever. The predictive value of IL- 6 is particularly interesting since IL- 6 is the most consistently and chronically changed circulating cytokine in epilepsy. ${ }^{32-34}$ However, other investigators failed to detect any cytokine changes that were of potential predictive value, ${ }^{18}$ possibly due to the fact that the changes were evaluated in epileptic adults using whole blood samples in vitro that were stimulated with lipopolysaccharide. In addition, studies in adults cannot be compared to studies in children without taking into account the age dependency of cytokine availability. ${ }^{40}$

\section{CONCLUSION}

VNS decreases seizure frequency with more than $50 \%$ in $22 \%$ of pediatric epilepsy patients. Larger increases in IL-1 $\beta$ were related to a greater improvement of IQ. Low baseline IL-6 levels predicted a greater reduction in seizure frequency. Thus the determination of IL-6 prior to VNS treatment may be a valuable tool to aid responder identification in future. 


\section{REFERENCES}

1 Schachter SC: Vagus nerve stimulation: Mood and cognitive effects. Epilepsy Behav. 2004;5 Suppl 1:S56-9.

2 Ben-Menachem E, Manon-Espaillat R, Ristanovic R, Wilder BJ, Stefan H, Mirza W, Tarver WB, Wernicke JF: Vagus nerve stimulation for treatment of partial seizures: 1 . A controlled study of effect on seizures. First international vagus nerve stimulation study group. Epilepsia. 1994;35:616-26.

3 Handforth A, DeGiorgio CM, Schachter SC, Uthman BM, Naritoku DK, Tecoma ES, Henry TR, Collins SD, Vaughn BV, Gilmartin RC, Labar DR, Morris GL, 3rd, Salinsky MC, Osorio I, Ristanovic RK, Labiner DM, Jones JC, Murphy JV, Ney GC, Wheless JW: Vagus nerve stimulation therapy for partial-onset seizures: A randomized active-control trial. Neurology. 1998;51:48-55.

4 The Vagus Nerve Stimulation Study Group: A randomized controlled trial of chronic vagus nerve stimulation for treatment of medically intractable seizures. . Neurology 1995;45:224-30.

5 Pavlov VA, Tracey KJ: The cholinergic anti-inflammatory pathway. Brain Behav Immun. 2005; 19:493-9.

6 Vezzani A, French J, Bartfai T, Baram TZ: The role of inflammation in epilepsy. Nat Rev Neurol. 2011;7: 3140 .

7 Bernik TR, Friedman SG, Ochani M, DiRaimo R, Susarla S, Czura CJ, Tracey KJ: Cholinergic antiinflammatory pathway inhibition of tumor necrosis factor during ischemia reperfusion. J Vasc Surg. 2002;36:1231-6.

8 Borovikova LV, Ivanova S, Zhang M, Yang H, Botchkina GI, Watkins LR, Wang H, Abumrad N, Eaton JW, Tracey KJ: Vagus nerve stimulation attenuates the systemic inflammatory response to endotoxin. Nature. 2000;405:458-62.

9 Guarini S, Altavilla D, Cainazzo MM, Giuliani D, Bigiani A, Marini H, Squadrito G, Minutoli L, Bertolini A, Marini R, Adamo EB, Venuti FS, Squadrito F: Efferent vagal fibre stimulation blunts nuclear factor-kappab activation and protects against hypovolemic hemorrhagic shock. Circulation. 2003;107: 1189-94.

10 Guarini S, Cainazzo MM, Giuliani D, Mioni C, Altavilla D, Marini H, Bigiani A, Ghiaroni V, Passaniti M, Leone S, Bazzani C, Caputi AP, Squadrito F, Bertolini A: Adrenocorticotropin reverses hemorrhagic shock in anesthetized rats through the rapid activation of a vagal anti-inflammatory pathway. Cardiovasc Res. 2004;63:357-65.

11 Hosoi T, Okuma Y, Nomura Y: Electrical stimulation of afferent vagus nerve induces il-1beta expression in the brain and activates hpa axis. Am J Physiol Regul Integr Comp Physiol 2000;279: R141-7.

12 Huston JM, Gallowitsch-Puerta M, Ochani M, Ochani K, Yuan R, Rosas-Ballina M, Ashok M, Goldstein RS, Chavan S, Pavlov VA, Metz CN, Yang H, Czura CJ, Wang H, Tracey KJ: Transcutaneous vagus nerve stimulation reduces serum high mobility group box 1 levels and improves survival in murine sepsis. Crit Care Med. 2007;35:2762-8.

13 Luyer MD, Greve JW, Hadfoune M, Jacobs JA, Dejong CH, Buurman WA: Nutritional stimulation of cholecystokinin receptors inhibits inflammation via the vagus nerve. J Exp Med. 2005;202:1023-9.

14 Wang H, Yu M, Ochani M, Amella CA, Tanovic M, Susarla S, Li JH, Yang H, Ulloa L, Al-Abed Y, Czura CJ, Tracey KJ: Nicotinic acetylcholine receptor alpha7 subunit is an essential regulator of inflammation. Nature. 2003;421:384-8.

15 Wang H, Liao H, Ochani M, Justiniani M, Lin X, Yang L, Al-Abed Y, Metz C, Miller EJ, Tracey KJ, Ulloa L: Cholinergic agonists inhibit hmgbl release and improve survival in experimental sepsis. Nat Med. 2004;10:1216-21.

16 Wu R, Dong W, Cui X, Zhou M, Simms HH, Ravikumar TS, Wang P: Ghrelin down-regulates proinflammatory cytokines in sepsis through activation of the vagus nerve. Ann Surg. 2007;245:480-6.

17 Corcoran C, Connor TJ, O'Keane V, Garland MR: The effects of vagus nerve stimulation on pro- and antiinflammatory cytokines in humans: A preliminary report. Neuroimmunomodulation. 2005;12:307-9.

18 De Herdt V, Bogaert S, Bracke KR, Raedt R, De Vos M, Vonck K, Boon P: Effects of vagus nerve stimulation on pro- and anti-inflammatory cytokine induction in patients with refractory epilepsy. J Neuroimmunol. 2009;214:104-8.

19 Barone L, Colicchio G, Policicchio D, Di Clemente F, Di Monaco A, Meglio M, Lanza GA, Crea F: Effect of vagal nerve stimulation on systemic inflammation and cardiac autonomic function in patients with refractory epilepsy. Neuroimmunomodulation. 2007;14:331-6.

20 Majoie HJ, Rijkers K, Berfelo MW, Hulsman JA, Myint A, Schwarz M, Vles JS: Vagus nerve stimulation in refractory epilepsy: Effects on pro- and anti-inflammatory cytokines in peripheral blood. Neuroimmunomodulation. 2011;18:52-6. 
21 Boer K, Jansen F, Nellist M, Redeker S, van den Ouweland AM, Spliet WG, van Nieuwenhuizen O, Troost $\mathrm{D}$, Crino PB, Aronica E: Inflammatory processes in cortical tubers and subependymal giant cell tumors of tuberous sclerosis complex. Epilepsy Res. 2008;78:7-21.

22 Choi J, Nordli DR, Jr., Alden TD, DiPatri A, Jr., Laux L, Kelley K, Rosenow J, Schuele SU, Rajaram V, Koh S: Cellular injury and neuroinflammation in children with chronic intractable epilepsy. J Neuroinflammation. 2009;6:38.

23 Ravizza T, Gagliardi B, Noe F, Boer K, Aronica E, Vezzani A: Innate and adaptive immunity during epileptogenesis and spontaneous seizures: Evidence from experimental models and human temporal lobe epilepsy. Neurobiol Dis. 2008;29:142-60.

24 Shu HF, Zhang CQ, Yin Q, An N, Liu SY, Yang H: Expression of the interleukin 6 system in cortical lesions from patients with tuberous sclerosis complex and focal cortical dysplasia type iib. J Neuropathol Exp Neurol. 2010;69:838-49.

25 Varella PP, Santiago JF, Carrete H, Jr., Higa EM, Yacubian EM, Centeno RS, Caboclo LO, Castro Neto EF, Canzian M, Amado D, Cavalheiro EA, Naffah-Mazzacoratti Mda G: Relationship between fluid-attenuated inversion-recovery (flair) signal intensity and inflammatory mediator's levels in the hippocampus of patients with temporal lobe epilepsy and mesial temporal sclerosis. Arq Neuropsiquiatr. 2011;69:91-99.

26 Yu N, Di Q, Hu Y, Zhang YF, Su LY, Liu XH, Li LC: A meta-analysis of pro-inflammatory cytokines in the plasma of epileptic patients with recent seizure. Neurosci Lett. 2012;514:110-115.

27 Sabat R, Grutz G, Warszawska K, Kirsch S, Witte E, Wolk K, Geginat J: Biology of interleukin-10. Cytokine Growth Factor Rev. 2010;21:331-344.

28 Kwan P, Arzimanoglou A, Berg AT, Brodie MJ, Allen Hauser W, Mathern G, Moshe SL, Perucca E, Wiebe S, French J: Definition of drug resistant epilepsy: Consensus proposal by the ad hoc task force of the ilae commission on therapeutic strategies. Epilepsia. 2010;51:1069-77.

29 Dunn L, Dunn L: Peabody picture vocabulary test--iii--nl, nederlandse versie door liesbeth schlichting. Amsterdam, Harcourt Assessment B.V., 2005.

30 Beery K, Beery N: The beery---buktenica developmental test of visual-motor integration. Beerytm vmi. Administration, scoring and teaching manual., ed 5th. Minneapolis, NCS Pearson, 2006.

31 Ricker LJ, Kijlstra A, Kessels AG, de Jager W, Liem AT, Hendrikse F, La Heij EC: Interleukin and growth factor levels in subretinal fluid in rhegmatogenous retinal detachment: A case-control study. PLoS One. 2011;6:e19141.

32 Hulkkonen J, Koskikallio E, Rainesalo S, Keranen T, Hurme M, Peltola J: The balance of inhibitory and excitatory cytokines is differently regulated in vivo and in vitro among therapy resistant epilepsy patients. Epilepsy Res. 2004;59:199-205.

33 Liimatainen S, Fallah M, Kharazmi E, Peltola M, Peltola J: Interleukin-6 levels are increased in temporal lobe epilepsy but not in extra-temporal lobe epilepsy. J Neurol. 2009;256:796-802.

34 Nowak M, Bauer S, Haag A, Cepok S, Todorova-Rudolph A, Tackenberg B, Norwood B, Oertel WH, Rosenow F, Hemmer B, Hamer HM: Interictal alterations of cytokines and leukocytes in patients with active epilepsy. Brain Behav Immun. 2011;25:423-8.

35 Alapirtti T, Rinta S, Hulkkonen J, Makinen R, Keranen T, Peltola J: Interleukin-6, interleukin-1 receptor antagonist and interleukin-1beta production in patients with focal epilepsy: A video-eeg study. J Neurol Sci. 2009;280:94-7.

36 Lehtimaki KA, Keranen T, Palmio J, Makinen R, Hurme M, Honkaniemi J, Peltola J: Increased plasma levels of cytokines after seizures in localization-related epilepsy. Acta Neurol Scand. 2007;116:226-30.

37 Bauer S, Cepok S, Todorova-Rudolph A, Nowak M, Koller M, Lorenz R, Oertel WH, Rosenow F, Hemmer B, Hamer HM: Etiology and site of temporal lobe epilepsy influence postictal cytokine release. Epilepsy Res. 2009;86:82-8.

38 Vezzani A, Conti M, De Luigi A, Ravizza T, Moneta D, Marchesi F, De Simoni MG: Interleukin-1beta immunoreactivity and microglia are enhanced in the rat hippocampus by focal kainate application: Functional evidence for enhancement of electrographic seizures. J Neurosci. 1999;19:5054-65.

39 Huang ZB, Sheng GQ: Interleukin-1beta with learning and memory. Neurosci Bull. 2010;26:455-68.

40 Straub RH, Cutolo M, Zietz B, Scholmerich J: The process of aging changes the interplay of the immune, endocrine and nervous systems. Mech Ageing Dev. 2001;122:1591-611.

41 Commission on Classification and Terminology of the International League Against Epilepsy. Proposal for revised classification of epilepsies and epileptic syndromes. Epilepsia. 1989;30:389-99. 



\section{CHAPTER 5}

\section{The effects of vagus nerve stimulation on tryptophan metabolites in children with intractable epilepsy}

S. Klinkenberg, C.J.H. van den Borne, M.W. Aalbers, P. Verschuure, A.G. Kessels, L. Leenen, K. Rijkers, A.P. Aldenkamp, J.S.H. Vles, H.J.M. Majoie 


\begin{abstract}

\section{Background}

The mechanism of action of vagus nerve stimulation (VNS) in intractable epilepsy is not entirely clarified. It is believed that VNS causes a alterations in cytokines, which can lead to rebalancing the release of neurotoxic and neuroprotective tryptophan metabolites.
\end{abstract}

\title{
Objectives
}

We aimed to evaluate VNS effects on tryptophan metabolites and on epileptic seizures. We investigated whether the antiepileptic effectiveness correlated to changes in tryptophan metabolism.

\section{Methods}

41 children with intractable epilepsy were included in a randomized, active-controlled, double-blind study. After a baseline period of 12 weeks, all children underwent implantation of a vagus nerve stimulator and entered a blinded active controlled phase of 20 weeks. Half of the children received high output (therapeutic) stimulation $(\mathrm{n}=21)$, while the other half received low output (active control) stimulation $(\mathrm{n}=20)$. Subsequently all children received high output stimulation for another 19 weeks (add-on phase). Tryptophan metabolites were assessed in plasma and cerebrospinal fluid (CSF) by use of liquid chromatography-tandem mass spectrometry (LC-MS/MS) and compared between high and low output groups and between the end of both study phases and baseline. Seizure frequency was recorded using seizure diaries. Mood was assessed using Profile of Mood States questionnaires (POMS).

\section{Results}

Regarding tryptophan metabolites, anthranilic acid (AA) levels were significantly higher at the end of the add-on phase compared to baseline $(\mathrm{p}=0.002)$, and correlated significantly with improvement of $\operatorname{mood}(\tau=-0.39, \mathrm{p}=0.037)$ and seizure frequency reduction $(\tau=-0.33, \mathrm{p}<0.01)$. No significant changes were found between high and low output groups regarding seizure frequency.

\section{Conclusion}

VNS induces a consistent increase in AA, a neuroprotective and anticonvulsive tryptophan metabolite. Moreover, increased AA levels are associated with improvement in mood and reduction of seizure frequency. 


\section{INTRODUCTION}

Vagus nerve stimulation (VNS) is an adjunctive treatment for therapy resistant epilepsy. The mode of action of VNS is still largely unknown. The possible underlying mechanism of action of VNS may be related to its influence on neuronal networks affecting deep brain structures such as locus coeruleus, hypothalamus and thalamus. ${ }^{1,2}$ More specifically, VNS might have immune modulating effects as the vagus nerve has anti-inflammatory properties, affecting the hypothalamic pituitary adrenal axis and the release of corticosteroids. ${ }^{3}$ The therapeutic field of VNS in inflammatory diseases is still expanding and both pro- and anti-inflammatory effects of VNS have been reported. ${ }^{4-6}$ Changes in cytokine levels upon VNS might affect metabolism of the serotonin (5-HT) precursor tryptophan. This metabolism is influenced by pro-inflammatory cytokines: the enzyme indoleamine 2,3-dioxygenase (IDO) is activated under the influence of proinflammatory cytokines, which results in tryptophan entering the 'tryptophan metabolic pathway' instead of the formation of 5-HT (for a simplified overview see Figure 5.1). ${ }^{6}$ Kynurenine (KYN) formation increases due to this shift in tryptophan metabolism. Proinflammatory cytokines appear to be present in the epileptic brain, ${ }^{7.8}$ and the tryptophan metabolic pathway may be active in epilepsy. ${ }^{9}$ Indeed, some of the tryptophan metabolites influence seizure development, and therefore, anticonvulsive effects of VNS may be partially explained by its effect on this pathway. ${ }^{10,11} \mathrm{KYN}$ and 3-hydroxykynurenine $(3 \mathrm{HK})$ are proconvulsive while kynurenic acid (KYNA) and anthranilic acid (AA) are anticonvulsive. ${ }^{12-16} \mathrm{KYN}$, KYNA, AA are presumed to be neuroprotective, while $3 \mathrm{HK}$ is presumed to be neurotoxic. Wheter the remaining metabolites 3-hydroxyantranillic acid (3HAA) and xanthurenic acid (XA) are proconvulsive, anticonvulsive, neurotoxic or neuroprotective remains to be esthablished. ${ }^{14-18}$

The only randomized controlled trial conducted in children concluded that the effect of VNS on seizure frequency in children with intractable epilepsy is limited. ${ }^{19}$ Nonrandomized studies on children treated with VNS, report a variable reduction in seizure frequency, ranging from 0 to $90 \% .^{20-28} \mathrm{~A}$ study evaluating the VNS-induced changes in tryptophan metabolism in children has not been published so far.

We hypothesize that VNS in children with refractory epilepsy affects tryptophan metabolism, resulting in reduced neurotoxic and proconvulsive metabolites and in increased neuroprotective and anticonvulsive metabolites.

In the present study we aimed at: (1) evaluating the effect of VNS on the tryptophan metabolic pathway in children, (2) evaluating if the therapeutic effect of VNS is associated with changes on the tryptophan pathway in children, and (3) evaluating whether a baseline profile of tryptophan metabolites can predict the clinical response to VNS in children. 
Figure 5.1 Metabolites of tryptophan pathway

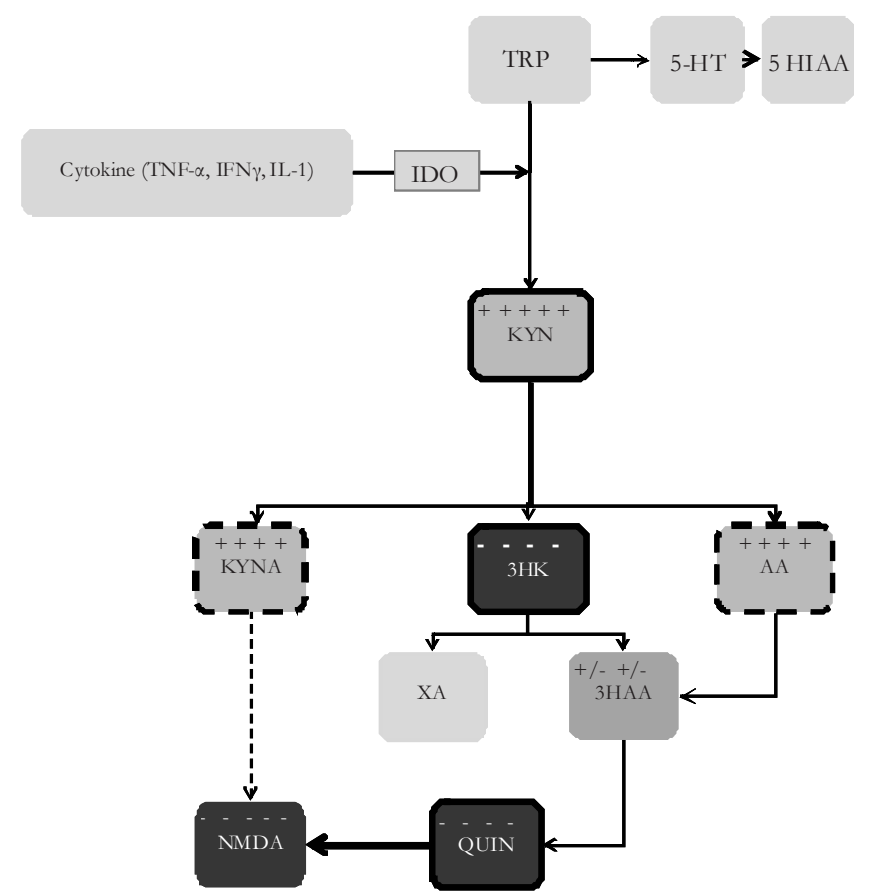

This figure depicts the tryptophan breakdown metabolic pathway. IDO activity in extra hepatic tissues, such as blood and brain, is enhanced by pro-inflammatory cytokines. This condition increases KYN formation. +: neuroprotective metabolites. - : neurotoxic metabolites. +/-: probably neurotoxic. Dashed thick outline: anticonvulsive effects, Thick outline: proconvulsive effects. Dashed arrow: antagonist, thick arrow agonist.

\section{METHODS}

\section{Study design}

This randomized active controlled double blind add-on study was divided in a baseline period (12 weeks), a blinded treatment phase ( 20 weeks), and an add-on phase (19 weeks). Following a baseline period of 12 weeks, all children were implanted with a vagus nerve stimulator. During the blinded treatment phase, children received either high (therapeutic) or low (active control) stimulation. This active control group was incorporated to protect the blinding, because participants can notice the stimulation, and to control for the surgery and the presence of an electrode. After the blinded phase, all children received 19 weeks of therapeutic stimulation during the add-on phase. Blood samples were collected before implantation of the stimulator, at the end of the blinded phase after 20 weeks of stimulation, and finally at the end of the add-on phase after 39 weeks of stimulation. Cerebral spinal fluid (CSF) samples were collected only once, 
when the children were under general anesthesia right before VNS implantation surgery. Seizure frequency was recorded throughout the study making use of a seizure diary. Mood was assessed using Profile of Mood States questionnaires (POMS) at baseline, the end of the blinded, and the add-on phase. ${ }^{29}$ See figure 5.2 for the study design.

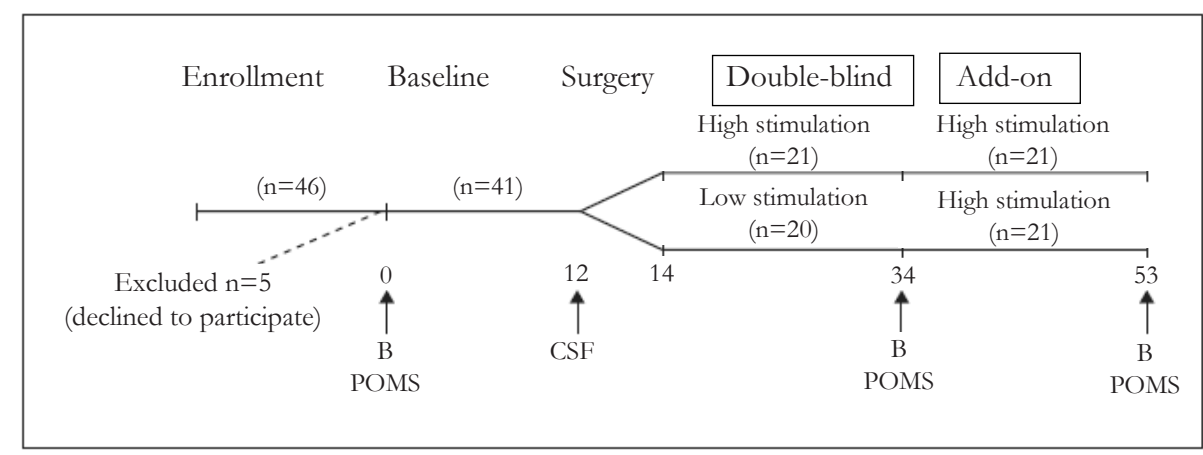

Figure 5.2 Study design.

Arrows indicate data and sample collection: $\mathrm{B}=\mathrm{Blood}$; $\mathrm{CSF}=$ cerebrospinal fluid; POMS=Profile of Mood States questionnaire. Numbers above arrows indicate weeks of study duration.

Standard protocol approvals, registrations, and patient consents

This study was approved by the ethics committee of Maastricht University Medical Center and written informed consent was obtained from all parents, guardians, and participants if aged over twelve. The authors confirm that all ongoing and related trials for this intervention are registered at ClinicalTrials.gov. (identifier: NCT01378611) Full trial protocol can be assessed online (supporting information file).

\section{Participants and setting}

Children were eligible for inclusion if they had medically refractory epilepsy despite adequate and stable anti-epileptic drug (AED) concentrations, were aged between 4 and 18 years at implantation, and were not eligible for epilepsy surgery. Medication regimens remained unchanged throughout the study. Children with a progressive cerebral lesion, malignancy, degenerative or immunological disorder, or a psychiatric history were excluded. Children were recruited from Epilepsy Center Kempenhaeghe in Heeze, The Netherlands, recruitment took place over a two year period. Follow-up of the study ended in January 2010. During the study neither type of AED nor dosage were altered.

\section{Device, implantation, and device settings}

All implantations were performed at Maastricht University Medical Center by the same team of neurosurgeons. A programmable pulse generator (Neuro Cybernetic Prosthesis 
(NCP), Cyberonics Inc., Webster, TX, USA) was implanted in a subcutaneous pocket below the left clavicle and connected to a bipolar electrode that was placed around the left vagus nerve to deliver electrical pulses to this nerve. Initial device settings for both study groups are depicted in Table 5.1. Output currents were adjusted by a trial nurse (LL) according to a fixed protocol every two weeks on the basis of the clinical evaluation of the treating neurologist (MM). In the treatment group the current was increased stepwise at 2-week intervals to the maximally tolerated output current (maximum 1.75 $\mathrm{mA}$ ). In the active control group, the output current was increased temporarily during each visit and switched back to the initial output current at the end of the visit. At the end of the blinded phase, the output parameters of the active control group were adjusted according to the schedule and parameters of the treatment group. The maximally applied current at the end of this phase was set at $2.25 \mathrm{~mA}$ for both groups.

Table $5.1 \quad$ Initial device settings.

\begin{tabular}{lcc}
\hline & Treatment group & Active control group \\
\hline Output current, $\mathrm{mA}$ & 0.25 & 0.25 \\
Pulse width, $\mathrm{ms}$ & 0.5 & 0.1 \\
Frequency, $\mathrm{Hz}$ & 30 & 1 \\
Duty cycle: on $(\mathrm{s}) /$ off $(\mathrm{min})$ & $30 / 5$ & $14 / 60$ \\
\hline
\end{tabular}

$\mathrm{mA}=$ milliampere; $\mathrm{ms}=$ milliseconds; $\mathrm{Hz}=\mathrm{Herz}$; $=$ seconds; $\mathrm{min}=$ minutes

\section{Randomization and blinding}

The treating neurologist (MM), participants, parents, and guardians were blinded to treatment conditions. Children were assigned to a treatment condition by one trial nurse (LL) using a computer program.

\section{Outcomes}

Heparinized plasma and CSF were stored at $-80^{\circ} \mathrm{C}$ until analysis was performed. Metabolites were analyzed by use of liquid chromatography-tandem mass spectrometry (LC-MS/MS) according to a protocol adapted from Midttun and co-workers. ${ }^{30}$ In blood, tryptophan (TRP), KYN, KYNA, 3HK, AA, XA, and 3HAA were measured. In CSF, TRP, KYN, KYNA and $3 \mathrm{HK}$ were measured.

Seizure frequency was recorded by participants' parents or guardians using a diary. Mean seizure frequency was calculated for baseline, for the last 30 days of the double blind phase, and for the final 30 days of the add-on phase for each child. A responder was defined as $50 \%$ or more seizure frequency reduction compared to baseline. Mood was assessed using the POMS. ${ }^{29}$ 


\section{Sample size}

Since there are no clinical data available on VNS-induced effects on tryptophan metabolism in children with intractable epilepsy, we could not base our power analysis on published effect data. Therefore, our power analysis was based upon the assumption that the minimum clinically relevant proportion of successful reduction in the treated group is $40 \%$ and in the control group 5\%. Assuming a level of significance of 0.05 (twotailed) and a power of $80 \%$ the study size population is two times 18 .

\section{Statistical analysis}

To confirm correlations between different tryptophan metabolites in both CSF and plasma at baseline we used Kendall's tau.

To compare the levels of tryptophan metabolites between the high and low output groups at the end of the double blind phase we performed the Mann-Whitney $\mathrm{U}$ test. The Wilcoxon signed-rank test was used to compare levels of tryptophan metabolites between the add-on phase and baseline.

Because the tryptophan metabolites originate from a complex scheme with numerous interactions, we used the method of O'Brien-Läuter ${ }^{31}$ to create a sum of Z-scores for analyzing the impact of favorable and unfavorable metabolites. In this sum of Z-scores we used a positive sum of $Z$-scores for neuroprotective and anticonvulsive metabolites and a negative sum of $Z$-scores for neurotoxic and convulsive metabolites. A t-test was used to analyse differences between $Z$-scores of both study groups.

Differences in tryptophan metabolites were calculated as percentage change from baseline to the end of the add-on phase and the end of the blind phase. Calculations in differences in seizure frequency and POMS are used as described earlier. ${ }^{19,31}$ To evaluate whether changes in seizure frequency or POMS depression score correlated with alterations in tryptophan metabolites between baseline and double blind phase as well as between baseline and add-on phase, we used Kendall's tau.

Differences between high and low output groups at the end of the add-on phase concerning correlations of changes in tryptophan metabolites with seizure frequency changes on the one hand, and with POMS depression scores on the other hand, were calculated using Mann-Whitney U.

Univariate linear regression analysis, including a stepwise backward variant, was performed to determine if the baseline levels of tryptophan metabolites in plasma or CSF could predict seizure frequency reduction or changes in POMS depression.

Data were analyzed using SPSS v19. A 2-tailed $\mathrm{p}$ value $<0.05$ was considered statistically significant. 


\section{RESULTS}

\section{Demographics}

We included 41 children who were randomly assigned to the high $(n=21)$ or to the low stimulation group $(n=20)$. Epilepsy surgery had been performed in two patients and was not an option in the others. Fifteen of the 41 children had been on the ketogenic diet. Baseline child characteristics and epilepsy classification according to ILAE are shown in Table 5.2. ${ }^{33}$ Results regarding clinical effects of VNS are discussed in detail elsewhere. ${ }^{19,32}$

Table 5.2 Baseline characteristics.

\begin{tabular}{lcc}
\hline & High & Low \\
\hline Number of participants (male/female) & $21(11 / 10)$ & $20(12 / 8)$ \\
Mean age at implantation, y:mo (range) & $10: 11(3: 10-17: 8)$ & $11: 6(4: 2-17: 2)$ \\
Mean age at onset, y:mo (range) & $2: 10(0-12 \mathrm{y})$ & $1: 8(0-5 \mathrm{y})$ \\
Median age at onset, y:mo (range) & $1: 2(0-12 \mathrm{y})$ & $1: 2(0-5 \mathrm{y})$ \\
Mean interval onset-implantation y:mo (range) & $7: 8(2-16 \mathrm{y})$ & $9: 5(3-15 \mathrm{y})$ \\
Median seizure frequency at baseline (seizures/day) & $2.1(0.1-53.7)$ & $0.9(0.1-31.7)$ \\
ILAE classification & & \\
Localization related & $19(90 \%)$ & $16(80 \%)$ \\
Symptomatic & $15(71 \%)$ & $10(50 \%)$ \\
Cryptogenic & $4(19 \%)$ & $6(30 \%)$ \\
Generalized & $2(10 \%)$ & $4(20 \%)$ \\
Idiopathic & 0 & $2(10 \%)$ \\
Symptomatic & $2(10 \%)$ & $2(10 \%)$ \\
Mean total exposure of AEDs & $7.0(5-10)$ & $7.3(4-14)$ \\
\hline
\end{tabular}

\section{Baseline correlations in tryptophan metabolites}

There was a significant and constant positive correlation between the different tryptophan metabolites at baseline. No differences were observed between the high and low output groups at baseline.

Tryptophan metabolite changes, baseline vs. blind phase

There were no statistically significant differences in levels of tryptophan metabolites between the high and low group at the end of the blind phase (see Table 5.3).

Tryptophan metabolite changes, baseline vs. add-on phase

VNS increased the level of all metabolites, except 3HK. For AA the increase was statistically significant $(\mathrm{p}=0.002)$. 
Table 5.3 Plasma levels tryptophan metabolites.

\begin{tabular}{|c|c|c|c|c|c|c|}
\hline & \multirow{2}{*}{$\begin{array}{l}\text { Baseline } \\
\mathrm{N}=40\end{array}$} & \multicolumn{2}{|c|}{ Blind phase } & \multirow[t]{2}{*}{$\mathrm{p}^{\mathrm{a}}$} & \multirow{2}{*}{$\begin{array}{l}\text { Add-on phase } \\
\qquad \mathrm{N}=39\end{array}$} & \multirow[t]{2}{*}{$\mathrm{P}^{\mathrm{b}}$} \\
\hline & & $\begin{array}{c}\text { High } \\
\mathrm{N}=20\end{array}$ & $\begin{array}{c}\text { Low } \\
\mathrm{N}=20\end{array}$ & & & \\
\hline TRP & $\begin{array}{c}42662 \\
(15465-73883)\end{array}$ & $\begin{array}{c}39956 \\
(14278-69037)\end{array}$ & $\begin{array}{c}41816 \\
(17649-68662)\end{array}$ & 0.69 & $\begin{array}{c}45566 \\
(16189-71280)\end{array}$ & 0.07 \\
\hline KYN & $\begin{array}{c}1453 \\
(540-2297)\end{array}$ & $\begin{array}{c}1432 \\
(527-2682)\end{array}$ & $\begin{array}{c}1399 \\
(607-2521)\end{array}$ & 0.85 & $\begin{array}{c}1519 \\
(484-2566)\end{array}$ & 0.16 \\
\hline KYNA & $\begin{array}{c}20,15 \\
(8,39-41,07)\end{array}$ & $\begin{array}{c}17,75 \\
(9,15-35,21)\end{array}$ & $\begin{array}{c}18,50 \\
(7,38-34,06)\end{array}$ & 0.74 & $\begin{array}{c}20,69 \\
(7,72-35,95)\end{array}$ & 0.58 \\
\hline $3 \mathrm{HK}$ & $\begin{array}{c}50,99 \\
(21,68-167,63)\end{array}$ & $\begin{array}{c}46,65 \\
(19,11-78,56)\end{array}$ & $\begin{array}{c}47,74 \\
(25,04-97,09)\end{array}$ & 0.91 & $\begin{array}{c}49,35 \\
(23,29-89,10)\end{array}$ & 0.68 \\
\hline $\mathrm{XA}$ & $\begin{array}{c}4,84 \\
(1,05-16,08)\end{array}$ & $\begin{array}{c}4,00 \\
(0,33-9,37)\end{array}$ & $\begin{array}{c}4,72 \\
(1,29-12,35)\end{array}$ & 0.77 & $\begin{array}{c}4,97 \\
(0,90-12,02)\end{array}$ & 0.16 \\
\hline $\mathrm{AA}$ & $\begin{array}{c}14,63 \\
(5,73-28,20)\end{array}$ & $\begin{array}{c}15,15 \\
(8,24-28,61)\end{array}$ & $\begin{array}{c}15,74 \\
(6,74-29,36)\end{array}$ & 0.76 & $\begin{array}{c}17,67 \\
(7,46-36,68)\end{array}$ & 0.002 \\
\hline 3НAA & $\begin{array}{c}24,90 \\
(7,49-62,41)\end{array}$ & $\begin{array}{c}20,46 \\
(8,33-43,24)\end{array}$ & $\begin{array}{c}23,76 \\
(8,63-74,29)\end{array}$ & 0.50 & $\begin{array}{c}26,84 \\
(6,78-53,48)\end{array}$ & 0.24 \\
\hline
\end{tabular}

Values are means (min.-max.). All metabolites are depicted in $\mathrm{nmol} / \mathrm{l}^{\cdot}{ }^{\mathrm{a}} \mathrm{Comparison}$ high and low group at the end of the blind phase by Mann-Whitney $U$ test. ${ }^{b}$ Comparison baseline and at the end of the add-on phase by relatedsamples Wilcoxon signed rank test.

\section{Z-scores}

No differences were observed between the neuroprotective, neurotoxic, and pro- and anticonvulsive sum of $\mathrm{Z}$-scores in different phases between the high and low output groups and between responders and non-responders.

\section{Seizure frequency reduction and tryptophan metabolite changes}

Due to incomplete seizure diaries, four patients were excluded from seizure frequency analysis. Results on VNS efficacy and side effects in these children have been reported more extensively elsewhere. ${ }^{19}$ On the last 30 days of the blinded phase the median seizure frequency decrease was $3.1 \%$ in the high stimulation group and $5.1 \%$ in the low stimulation group (comparison log transformed values, $\mathrm{p}=0.47$ ). At the end of the addon phase seizure frequency decreased from median 1.61 seizures a day at baseline to median 1.12 at the end of the add-on phase. Eight children (22\%) experienced a seizure frequency reduction of $50 \%$ or more at the end of the add-on phase. The change in seizure frequency reduction during the last 30 days of VNS in the add-on phase was negatively correlated with a change in AA (see Figure 5.3A, $\tau=-0.33, \mathrm{p}<0.01$ ): the larger the percentage $\mathrm{AA}$ increase, the greater the decrease in seizure frequency. 


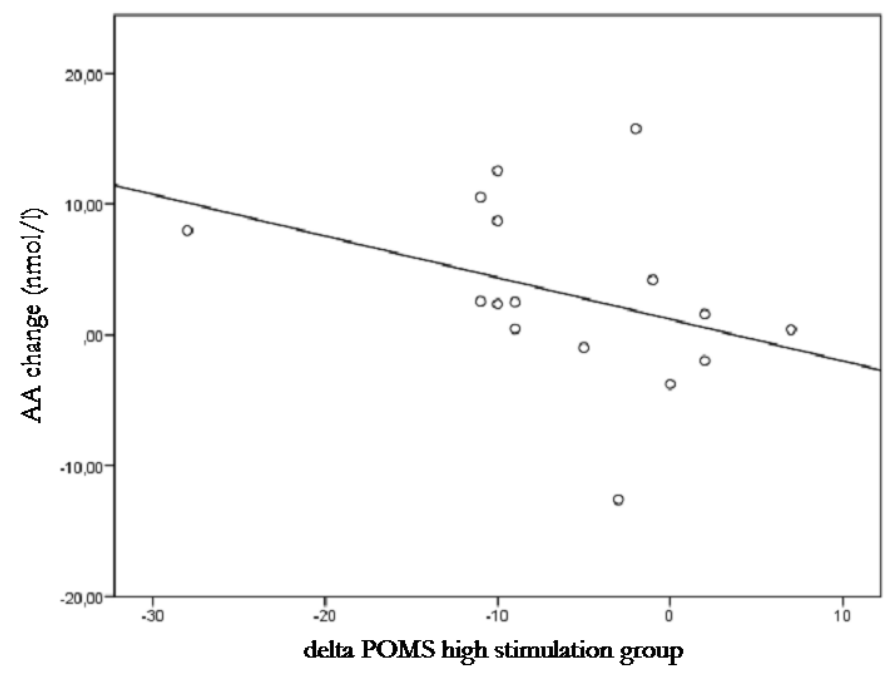

Figure 5.3A Correlation of changes in level of AA. Significant negative correlation, AA change from baseline to end of add-on phase and delta POMS depression in the high stimulation group baseline to end of add-on phase, Kendall's tau $(\tau=-0.39, \mathrm{p}=0.037)$.

POMS depression and tryptophan metabolite changes

At the end of the add-on phase, $\triangle$ POMS (POMS depression score at baseline minus POMS depression score at the end of the add-on phase) and differences in tryptophan metabolites showed no significant correlations in the group as a whole, or in the low group. However, $\triangle \mathrm{POMS}$ depression in the high group had a significant negative correlation with the difference in AA between baseline and the add-on phase (See Figure $5.3 \mathrm{~B}, \tau=-0.39, \mathrm{p}=0.037)$ : the greater the increase in $\mathrm{AA}$, the larger the reduction in depressed feelings. 


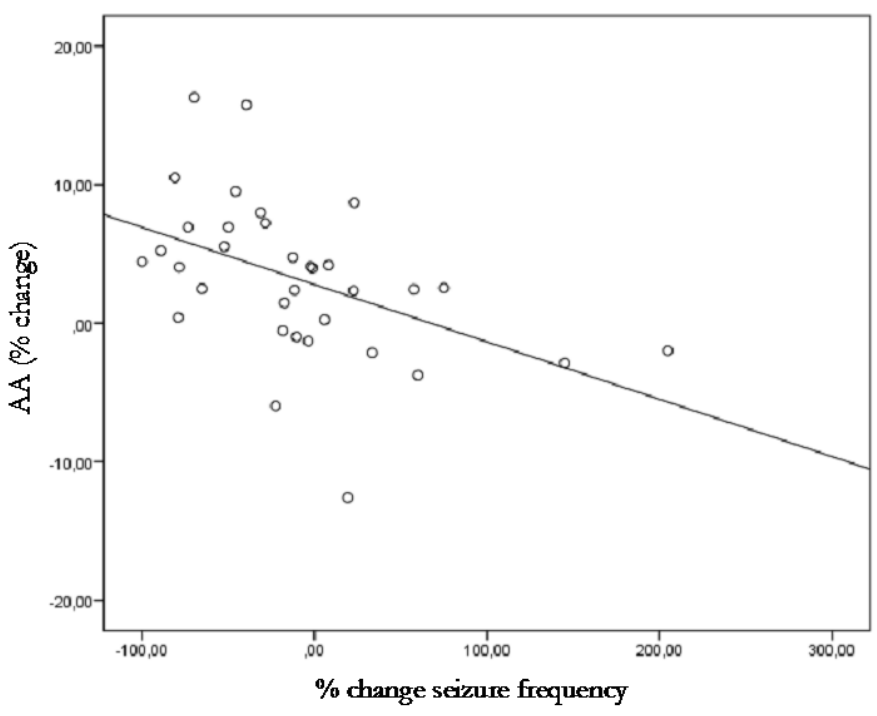

Figure 5.3B Correlation of percentage of change in level of AA and seizure frequency changes. Significant negative correlation, percentage AA change from baseline to end of add-on phase and percentage seizure frequency reduction from baseline to last 30 days of add-on phase, Kendall's tau $(\tau=-0.33, p<0.01)$.

Predictive value of baseline tryptophan metabolites

Baseline tryptophan metabolites in plasma or CSF had no predictive value for seizure frequency reduction, nor for changes in POMS depression score.

\section{DISCUSSION}

To our knowledge, this randomized controlled trial is the first study to explore the effects of VNS on tryptophan metabolite levels in children. We have demonstrated that AA levels increased significantly at the end of the add-on phase and that this increase was associated with the anticonvulsive effects of VNS.

Despite the complexity of the tryptophan pathway and several influencing factors beyond our scope we found a consistent significantly positive correlation between the different tryptophan metabolites at baseline (see Figure 5.1). In previous studies it has been estimated that close to $90-95 \%$ of tryptophan metabolism occurs via the kynurenine pathway. ${ }^{34,35}$

The unknown biological variation in peripheral blood of tryptophan metabolites and the variation or even absence of children's dietary tryptophan intake may be an influencing factor as well, since tryptophan administration is known to increase kynurenine pathway activity. ${ }^{36}$ We have no food diaries of children during this study to compare dietary 
intake. By performing several measurements of tryptophan metabolites in each child at different time points, the child is its own control.

We also can imagine that the various etiologies of epilepsy, and different ages of the children influence the levels of tryptophan metabolites as well.

There were no statistically significant differences when comparing levels of tryptophan metabolites in high- and low output groups at baseline and at the end of the blind phase. Although in initial registration trials ${ }^{37,38}$ this period was long enough to sort out the effect on seizure frequency reduction, it might have been too short to see effects on tryptophan metabolites after 20 weeks of stimulation. Possibly there is no difference with regards to the effects of some of the tryptophan metabolite levels in serum.

Our hypothesized rebalancing towards neuroprotective and anticonvulsive metabolites by VNS is partially validated. We found a statistically significant increase of AA after VNS, when comparing baseline with the end of the add-on phase. AA has shown to be a neuroprotective metabolite, with anticonvulsive properties. ${ }^{14,39}$ Furthermore there also is a moderate increase of the neuroprotective metabolites KYN and KYNA and a moderate decrease of the neurotoxic and proconvulsive metabolite $3 \mathrm{HK}$, but these changes were not significant.

It is remarkable that, in spite of the complexity of the network of interactions on the tryptophan metabolites, we did find a consistent positive effect of AA. In vivo intracerebral microdialysis showed no significant VNS effect on 5-HT concentrations although only 5-HT has been studied in this animal study. ${ }^{40} \mathrm{~A}$ study in adults with refractory epilepsy showed no significant changes in tryptophan metabolites after VNS treatment. They observed a moderate increase in KYNA and $3 \mathrm{HK}$ and a decrease in KYN, AA however was not measured. ${ }^{6}$

We also demonstrated a correlation between altered levels of AA and changes in seizure frequency reduction and POMS depression: the increase of AA was correlated with less depressed feelings and a less seizures. All correlation analysis were split in low and high output groups, because the high output group has had a longer period of VNS and represents a possible long term effect of VNS. This turned out to be a good assumption, since we found a significant correlation of POMS and AA in the high output group, which was absent in the low output group.

When performing these correlations we used the outcome of the mean seizure frequency during the last 30 days of VNS, and calculated the effect of VNS as a percentage of the seizure frequency at baseline. We deliberately did not use the mean of the whole add-on phase in this calculation, because the percentage of the last 30 days can best be compared with percentage change in tryptophan metabolites, since the metabolites are only measured at the end point during the add-on phase.

Previous studies have shown that tryptophan levels in blood are a good surrogate marker until future methods become available. ${ }^{41,42}$ We cannot exclude that VNS did affect CSF 
tryptophan metabolite levels. Because of ethical reasons and clinical applicability in children, we analyzed blood levels at different time points, while CSF was only taken once.

\section{CONCLUSION}

VNS in children consistently increases AA levels. AA is a neuroprotective and anticonvulsive metabolite, and its increase was correlated with improvement in mood and seizure frequency reduction. Future research should explore if this metabolite is of importance to identify responders. 


\section{REFERENCES}

1. Ben-Menachem E. Vagus-nerve stimulation for the treatment of epilepsy. Lancet Neurol 12002;1: 477-82.

2. Mapstone TB. Vagus nerve stimulation: current concepts. Neurosurg Focus 12008;25:E9.

3. Bonaz B, Picq C, Sinniger V, Mayol J-F, Clarençon D. Vagus nerve stimulation: from epilepsy to the cholinergic anti - inflammatory pathway. Neurogastroenterol Motil 2013;25: 208-221.

4. De Herdt V, Bogaert S, Bracke KR, Raedt R, De Vos M, Vonck K, Boon P. Effects of vagus nerve stimulation on pro- and anti-inflammatory cytokine induction in patients with refractory epilepsy. J Neuroimmunol 2009;214: 104-8.

5. Barone L, Colicchio G, Policicchio D, Di Clemente F, Di Monaco A, Meglio M, Lanza GA, Crea F. Effect of vagal nerve stimulation on systemic inflammation and cardiac autonomic function in patients with refractory epilepsy. Neuroimmunomodulation 2007;14: 331-6. 15.

6. Majoie HJ, Rijkers K, Berfelo MW, Hulsman JA, Myint A, Schwarz M, Vles JS. Vagus nerve stimulation in refractory epilepsy: effects on pro- and anti-inflammatory cytokines in peripheral blood. Neuroimmunomodulation 2011;18:52-6.

7. Sinha S, Patil SA, Jayalekshmy V, Satishchandra P. Do cytokines have any role in epilepsy? Epilepsy Res 12008;82:171-6.

8. Peltola J, Palmio J, Korhonen L, Suhonen J, Miettinen A, Hurme M, Lindholm D, Keranen T. Interleukin-6 and interleukin-1 receptor antagonist in cerebrospinal fluid from patients with recent tonic-clonic seizures. Epilepsy Res 12000;41:205-11.

9. Heyes MP, Saito K, Devinsky O, Nadi NS. Kynurenine pathway metabolites in cerebrospinal fluid and serum in complex partial seizures. Epilepsia 11994;35:251-7.

10. Hammond EJ, Uthman BM, Wilder BJ, Ben-Menachem E, Hamberger A, Hedner T, Ekman R. Neurochemical effects of vagus nerve stimulation in humans. Brain Res 11992;583:300-3.

11. Ben-Menachem E, Hamberger A, Hedner T, Hammond EJ, Uthman BM, Slater J, Treig T, Stefan H, Ramsay RE, Wernicke JF, et al. Effects of vagus nerve stimulation on amino acids and other metabolites in the CSF of patients with partial seizures. Epilepsy Res 11995;20:221-7.

12. Scharfman HE, Ofer A. Pretreatment with L-kynurenine, the precursor to the excitatory amino acid antagonist kynurenic acid, suppresses epileptiform activity in combined entorhinal/hippocampal slices. Neurosci Lett 11997;224:115-8.

13 Jhamandas K, Boegman RJ, Beninger RJ, Bialik M. Quinolinate-induced cortical cholinergic damage: modulation by tryptophan metabolites. Brain Res 11990;529:185-91.

14. Okuda S, Nishiyama N, Saito H, Katsuki H. 3-Hydroxykynurenine, an endogenous oxidative stress generator, causes neuronal cell death with apoptotic features and region selectivity. J Neurochem 11998;70:299-307.

15. Lapin IP. Antagonism of kynurenine-induced seizures by picolinic, kynurenic and xanthurenic acids. J Neural Transm 11983;56:177-85.

16. Eastman CL, Guilarte TR. Cytotoxicity of 3-hydroxykynurenine in a neuronal hybrid cell line. Brain Res 11989;495:225-31.

17. Smith AJ, Smith RA, Stone TW. 5-Hydroxyanthranilic acid, a tryptophan metabolite, generates oxidative stress and neuronal death via p38 activation in cultured cerebellar granule neurones. Neurotox Res 12009; 15:303-10.

18. Krause D, Suh HS, Tarassishin L, Cui QL, Durafourt BA, Choi N, Bauman A, Cosenza-Nashat M, Antel JP, Zhao ML, Lee SC. The tryptophan metabolite 3-hydroxyanthranilic acid plays anti-inflammatory and neuroprotective roles during inflammation: role of hemeoxygenase-1. Am J Pathol 12011;179: 1360-72.

19. Klinkenberg S, Aalbers MW, Vles JS, Cornips EM, Rijkers K, Leenen L, Kessels FG, Aldenkamp AP, Majoie M. Vagus nerve stimulation in children with intractable epilepsy: a randomized controlled trial. Dev Med Child Neurol 12012;54:855-61.

20. Majoie HJ, Berfelo MW, Aldenkamp AP, Evers SM, Kessels AG, Renier WO. Vagus nerve stimulation in children with therapy-resistant epilepsy diagnosed as Lennox-Gastaut syndrome: clinical results, neuropsychological effects, and cost-effectiveness. J Clin Neurophysiol 12001;18:419-28.

21. Majoie HJ, Berfelo MW, Aldenkamp AP, Renier WO, Kessels AG. Vagus nerve stimulation in patients with catastrophic childhood epilepsy, a 2-year follow-up study. Seizure 12005;14: 10-8.

22. Alexopoulos AV, Kotagal P, Loddenkemper T, Hammel J, Bingaman WE. Long-term results with vagus nerve stimulation in children with pharmacoresistant epilepsy. Seizure 12006;15:491-503. 
23. Saneto RP, Sotero de Menezes MA, Ojemann JG, Bournival BD, Murphy PJ, Cook WB, Avellino AM, Ellenbogen RG. Vagus nerve stimulation for intractable seizures in children. Pediatr Neurol 12006;35: 323-6.

24. Danielsson S, Viggedal G, Gillberg C, Olsson I. Lack of effects of vagus nerve stimulation on drug-resistant epilepsy in eight pediatric patients with autism spectrum disorders: a prospective 2-year follow-up study. Epilepsy Behav 12008;12:298-304.

25. Kabir SM, Rajaraman C, Rittey C, Zaki HS, Kemeny AA, McMullan J. Vagus nerve stimulation in children with intractable epilepsy: indications, complications and outcome. Childs Nerv Syst 12009;25: 1097-100.

26. Rossignol E, Lortie A, Thomas T, Bouthiller A, Scavarda D, Mercier C, Carmant L. Vagus nerve stimulation in pediatric epileptic syndromes. Seizure 12009; 18:34-7.

27. Ryzi M, Brazdil M, Novak Z, Chrastina J, Oslejskova H, Rektor I, Kuba R. Long-term vagus nerve stimulation in children with focal epilepsy. Acta Neurol Scand. 2013;127:316-22.

28. Parain D, Penniello MJ, Berquen P, Delangre T, Billard C, Murphy JV. Vagal nerve stimulation in tuberous sclerosis complex patients. Pediatr Neurol 12001;25:213-6.

29. Griffith NM, Szaflarski JP, Szaflarski M, Kent GP, Schefft BK, Howe SR, Privitera MD. Measuring depressive symptoms among treatment-resistant seizure disorder patients: POMS Depression scale as an alternative to the BDI-II. Epilepsy Behav 12005;7:266-72.

30. Midttun O, Hustad S, Ueland PM. Quantitative profiling of biomarkers related to B-vitamin status, tryptophan metabolism and inflammation in human plasma by liquid chromatography/tandem mass spectrometry. Rapid Commun Mass Spectrom 12009;23:1371-9.

31. Schouten HJA. Klinische statistiek. Een praktische inleiding in methodologie en analyse. 1st ed. Houten: Bohn Stafleu Van Loghum; 1995.

32. Klinkenberg S, van den Bosch CN, Majoie HJ, Aalbers MW, Leenen L, Hendriksen J, Cornips EM, Rijkers K, Vles JS, Aldenkamp AP. Behavioural and cognitive effects during vagus nerve stimulation in children with intractable epilepsy - A randomized controlled trial. Eur J Paediatr Neurol 2013;17:82-90.

33. Engel J, Jr. Report of the ILAE classification core group. Epilepsia 12006;47: 1558-68.

34. Oxenkrug GF. Genetic and hormonal regulation of tryptophan kynurenine metabolism: implications for vascular cognitive impairment, major depressive disorder, and aging. Ann N Y Acad Sci 12007;1122: 35-49.

35. Allegri G, Bertazzo A, Biasiolo M, Costa CV, Ragazzi E. Kynurenine pathway enzymes in different species of animals. Adv Exp Med Biol 12003;527:455-63.

36. Forrest CM, Mackay GM, Stoy N, Egerton M, Christofides J, Stone TW, Darlington LG. Tryptophan loading induces oxidative stress. Free Radic Res 12004;38:1167-71.

37. Handforth A, DeGiorgio CM, Schachter SC, Uthman BM, Naritoku DK, Tecoma ES, Henry TR, Collins SD, Vaughn BV, Gilmartin RC, Labar DR, Morris GL, 3rd, Salinsky MC, Osorio I, Ristanovic RK, Labiner DM, Jones JC, Murphy JV, Ney GC, Wheless JW. Vagus nerve stimulation therapy for partial-onset seizures: a randomized active-control trial. Neurology 11998;51:48-55.

38. The Vagus Nerve Stimulation Study Group. A randomized controlled trial of chronic vagus nerve stimulation for treatment of medically intractable seizures. Neurology 11995;45:224-30.

39. Lapin IP. Kynurenines and seizures. Epilepsia 11981;22:257-65.

40. Raedt R, Clinckers R, Mollet L, Vonck K, El Tahry R, Wyckhuys T, De Herdt V, Carrette E, Wadman W, Michotte Y, Smolders I, Boon P, Meurs A. Increased hippocampal noradrenaline is a biomarker for efficacy of vagus nerve stimulation in a limbic seizure model. J Neurochem 12011;117:461-9.

41. Heyes MP, Lackner A. Increased cerebrospinal fluid quinolinic acid, kynurenic acid, and L-kynurenine in acute septicemia. J Neurochem 11990;55:338-41.

42. Heyes MP, Brew BJ, Martin A, Price RW, Salazar AM, Sidtis JJ, Yergey JA, Mouradian MM, Sadler AE, Keilp $\mathrm{J}$, et al. Quinolinic acid in cerebrospinal fluid and serum in HIV-1 infection: relationship to clinical and neurological status. Ann Neurol 11991;29:202-9. 



\section{CHAPTER 6}

Vagus nerve stimulation has a positive effect on mood in patients with refractory epilepsy

S. Klinkenberg, H.J.M. Majoie, M.M.A.A. van der Heijden, K. Rijkers, L. Leenen, A.P. Aldenkamp 


\begin{abstract}
Background

Preliminary research on the efficacy of vagus nerve stimulation (VNS) indicated additional effects on neuropsychological variables like mood and quality of life ( $\mathrm{Q}$ L).
\end{abstract}

\title{
Objectives
}

The objectives of this prospective longitudinal observational cohort study were to assess the effects of VNS on mood, QoL and cognition in patients with refractory epilepsy and to determine whether these effects occur dependent of seizure control.

\section{Methods}

We included 41 patients with refractory epilepsy; treated with VNS as part of usual patient care. A neuropsychological battery was performed during baseline and repeated after 6 months of VNS in order to compare neuropsychological variables before and after VNS. All patients completed seizure diaries.

\section{Results}

Significant improvements were observed for both mood and QoL after 6 months of VNS; based on the results in the POMS and QOLIE-89 questionnaires $(p<0.05)$. There was no significant change in cognition. Mean percentage change in seizure frequency was $-9.0 \%$, while $20 \%$ of the patients achieved a seizure frequency reduction of $50 \%$ or more. No significant correlation was found between changes in seizure frequency and improvements in mood or QoL.

\section{Conclusions}

VNS is associated with improvements in both mood and QoL in patients with refractory epilepsy. Since these improvements appeared to be independent of seizure control, the results of this study indicate an additional antidepressant effect of VNS, which can be of extra value in view of the high co-morbidity of mood disturbances in patients with epilepsy. 


\section{INTRODUCTION}

Patients with epilepsy are prone to mood disorders. Although depression is known as the most common psychiatric comorbidity in these patients, it is often under-recognized and therefore not treated appropriately. ${ }^{1-4}$ The presence of depression tends to be the most important variable that affects quality of life of patients with epilepsy, even more than seizure frequency. ${ }^{56}$

Approximately $70 \%$ of epilepsy patients can be successfully treated with antiepileptic drugs (AED), the remaining $30 \%$ is suffering from medically refractory epilepsy. During the last decade, vagus nerve stimulation (VNS) has become an accepted treatment option for patients with refractory epilepsy who are not eligible for resective surgery. Randomized controlled trials have demonstrated considerable reduction in seizure frequency; with $\geq 50 \%$ reduction in $22-39 \%$ of the patients ${ }^{7-9}(11.7 \%$ if corrected for placebo effect and the natural course of epilepsy). Complete remission of seizures is obtained in a limited number of patients.

Preliminary studies have reported the additional effects of VNS on neuropsychological variables, such as mood, cognition and quality of life (QoL). Although different mood scales were used, several studies have demonstrated mood improvements after treatment with VNS. ${ }^{10-12}$ None of these studies have found an association between seizure reduction and mood improvement. This may indicate specific additional effects of VNS on mood, which may be independent of improved seizure control and therefore independent of epilepsy. This treatment effect became relevant for the treatment of mood disorders in general as well. Based on a randomized controlled trial and several clinical trial data the FDA approved VNS as treatment for a therapy resistant depression in 2005 (Rush 2005, FDA approval, weblink). The effects of VNS on QoL which is more difficult to assess quantitatively remain controversial. Some studies have reported increased health-related QoL, ${ }^{13,14}$ where McGlone et al have found no change in QoL. ${ }^{15}$ Concerning cognition, both Dodrill et al and Hoppe et al. report no change after treatment with VNS. ${ }^{16} 17$

The primary objective of this study is to assess the effects of VNS on mood, QoL and cognition in patients with refractory epilepsy. Furthermore our aim is to determine whether the neuropsychological effects of VNS occur dependent or independent of seizure control. 


\section{METHODS}

\section{Study design}

This prospective longitudinal observational cohort study was designed to evaluate the effects of VNS on seizure outcome, mood, cognition and QoL by comparing these variables before and after treatment with VNS. This study was approved by the ethical committee. Following a baseline period of 3 months all patients had a vagus nerve stimulator implanted which was activated after a recovery period of 2 weeks. In this study outcome was assessed at regular postoperative visits. Serum levels of antiepileptic drugs (AED) were measured three times; during baseline, 2 weeks after implantation and 6 months after activation. A neuropsychological battery was performed at baseline and repeated after 6 months of VNS. All patients completed seizure diaries during both baseline and follow-up period. During this study AED were kept as stable as possible, except for cases in which it would be necessary to maintain appropriate concentrations or in response to possible toxicity. Treatment with VNS could be stopped at the patient's request or if the responsible investigator judged continuing participation as a potential risk. Patients could leave the study at any time.

\section{Patient selection}

In this study we included 41 patients with refractory epilepsy, treated with VNS as part of usual patient care. Primary inclusion criteria were medically refractory seizures, not eligible for resective surgery, age 18 years or older and obtained informed consent. Patients were excluded in case they suffered from progressive cerebral lesions, degenerative disorders, malignancy or a history with malignancy in the past 2 years, unstable medical disease in the last 2 years and high risks for complications (obstructive respiratory disease, gastric disorders, cardiac rhythm disorders), a documented history with generalized status epilepticus in the previous 3 months, a history of substance abuse, chronic use of neuroleptics, antidepressants or MAO inhibitors in the previous 6 months, psychiatric disorder requiring electro-convulsive therapy and a history of schizophrenic disorder or any exhibited psychotic symptomatology.

\section{Vagus nerve stimulation}

VNS was carried out using the Neurocybernetic Prosthesis (NCP) system, Cyberonics Inc, Webster, Texas, USA. The NCP system and the surgical procedure have been described extensively elsewhere. ${ }^{8,18}$ The operations were performed in the Maastricht University Medical Centre between January 2007 and March 2009. In this study we used the following stimulation parameters: 'on and off cycles of 30 seconds every 5 minutes, a signal frequency of $30 \mathrm{~Hz}$ and a signal pulse width of $500 \mu \mathrm{s}$. The output current was increased stepwise to the maximum tolerated level. All patients could manually activate their device by using a handheld magnet to attempt to abort seizures. 


\section{Neuropsychological assessments}

Each of the three variables mood, cognition and QoL was assessed with a validated questionnaire twice; during baseline and after 6 months of VNS. Mood was assessed by the Profile of Mood States (POMS), a scale for state-dependent mood changes containing 65 adjectives to which subjects can react and describe how they felt during the past week. Ratings are scored for six different mood states: tension-anxiety, depressiondejection anger-hostility, vigor-activity, fatigue-inertia and confusion-bewilderment. The scores on these states are the raw scores; all subscales but the vigor scale are scored such that higher scores reflect greater mood disturbance. ${ }^{19}$ For all patients change in mood was reported by absolute difference scores for each subscale separately. Furthermore, a composite index for all six subscales was calculated. While calculating the composite index we corrected the vigor scale so that all scales scored consistently higher for more mood problems.

Global cognition was assessed with the Raven Standard Progressive Matrices. This instrument includes multiple choice tests of abstract reasoning in which patients are asked to identify the missing element required to complete a pattern. An assessment with the Raven questionnaire yields a total and a percentile score. ${ }^{20}$ Change in cognition was reported by absolute difference scores based on both total and percentile scores. In addition, the total score of the first assessment was used for calculating baseline IQ for all patients.

The outcome variable QoL was assessed by the Quality of Life in Epilepsy Inventory (QOLIE-89), a questionnaire with 86 items distributed in 17 multi-item scales and 3 additional items to measure health-related QoL in epilepsy patients. ${ }^{21}$ Besides an overall score which is obtained using a weighted average of the multi-item scale scores an additional $\mathrm{T}$-score is calculated. $\mathrm{T}$-scores represent linear transformations of the scores that produce a mean of 50 and a standard deviation of 10 . Higher T-scores represent a more favorable QoL. In our study, change in QoL was reported by absolute difference scores based on both overall and $\mathrm{T}$-scores.

\section{Seizure measurement}

Seizure frequency was measured with seizure diaries, kept by patients (or family members) during the full study period. Seizures of all seizure types were combined to demonstrate the overall seizure frequency. For all patients, change in seizure frequency was reported by mean seizure frequency percentage change as well as by mean change in absolute seizures per month after 6 months of VNS. Reporting in terms of percentage change compensates for patients with very high seizure frequencies. ${ }^{22} \mathrm{We}$ defined seizure response by a reduction in seizure frequency of $50 \%$ or more and calculated the number of patients responding with a reduction of both $50 \%$ and $75 \%$ or more. 


\section{Statistical analysis}

For analysis of all variables in this study the paired $t$-test was used to compare changes during VNS relative to baseline. In addition, intercorrelations of mood and seizure changes were calculated with a Pearson correlation test. The tests of statistical significance were two-tailed and the significance level was defined by $\mathrm{p}<0.05$. All analyses were performed with SPSS V16.0.

\section{RESULTS}

At baseline 41 patients were included in this study. One patient became a drop out after being diagnosed with Parkinson's disease during the study period. Table 6.1 summarizes the characteristics of the study population. The average age in our study population, which consisted of 22 female and 18 male patients, is 38.1 years (SD 11.5). Except one female all patients were on two AEDs or more, with an average of 2.7 (SD 0.8). Four patients had a change in AED levels. Two patients were suffering from adverse effects caused by their AED that they had experienced before, which led to a slightly decrease in their AED doses during study period. One patient insisted on decreasing AED use after having been seizure free for a few months during VNS stimulation. Another patient had a slightly increased AED dose temporarily, because her doses were not distributed appropriately over 24 hours. For none of these four patients, the changes in AED affected seizure outcome.

\section{Seizure outcome}

After 6 months of treatment with VNS the mean percentage change in overall seizure frequency as compared to baseline was $-9.0 \%$ (SD \pm 50.9$)$. Eight patients (20\%) achieved a reduction of at least $50 \%$ while 2 patients $(5 \%)$ had a decrease in seizure frequency of $75 \%$ or more. None of the patients experienced total seizure remission. Seizure frequency did not change for two patients, while four patients showed a marked increase. In Figure 6.1 the mean percentage change in seizure frequency for the patients is this study is visualized. Table 6.2 illustrates the mean values for absolute seizure frequency during baseline and after VNS. There was no significant difference in absolute seizure frequency after 6 months of VNS $(\mathrm{p}=0.19)$. The mean absolute change in seizure frequency was $1.72(\mathrm{SD} \pm 8.19)$. 
Table 6.1 Baseline characteristics of the study population.

\begin{tabular}{lc}
\hline Characteristics & \\
\hline Number of patients (male/ female) & $40(18 / 22)$ \\
Mean age at implantation \pm SD (range) & $38.1 \pm 11.5$ \\
& $(22-61)$ \\
Mean age at onset \pm SD & $11.3 \pm 10.1$ \\
Mean duration of epilepsy in years \pm SD & $26.8 \pm 11.8$ \\
Dominant seizure type & \\
Simple partial & 3 \\
Complex partial & 25 \\
Partial secondarily generalized & 12 \\
Mean overall seizure frequency per month \pm SD & $14.88 \pm 15.03$ \\
Median overall seizure frequency per month & 8.80 \\
Mean baseline IQ \pm SD & $77.9 \pm 25.8$ \\
Median baseline IQ & 76 \\
\hline
\end{tabular}

* Drug load was calculated by using the prescribed daily dose / defined daily dose (PDD/DDD) ratio.

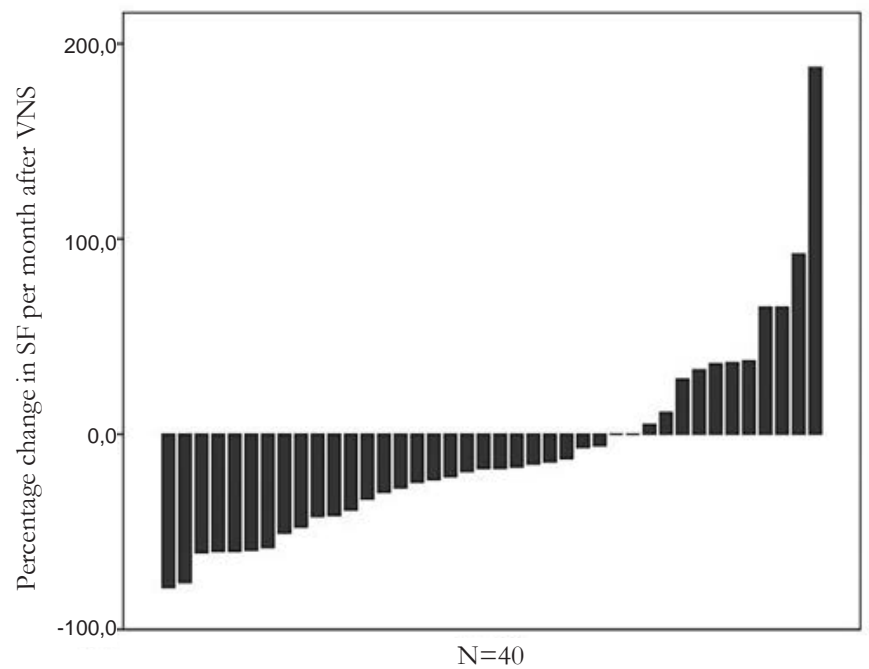

Figure 6.1 Each bar in this figure represents one patient and demonstrates the percentage change in seizure frequency after 6 months of treatment with VNS.

Table 6.2 Mean values for absolute seizure frequency during VNS.

\begin{tabular}{lccccc}
\hline Seizure frequency & $\mathrm{n}$ & $\begin{array}{c}\text { Mean } \pm \text { SD } \\
\text { baseline }\end{array}$ & $\begin{array}{c}\text { Mean } \pm \text { SD } \\
\text { after VNS }\end{array}$ & \multicolumn{2}{c}{ Paired Samples t test } \\
\cline { 4 - 6 } Seizures per month & 40 & $14.88 \pm 15.03$ & $13.14 \pm 16.01$ & $\mathrm{t}$ & Sig. \\
\hline
\end{tabular}




\section{Neuropsychological outcome}

Although the 40 patients in this study all accomplished the whole follow-up period of 6 months, not all patients appeared to be able to fulfill the entire neuropsychological screening session. Some patients were mentally retarded or too disabled to answer the questionnaires, others fulfilled just one entire screening session so a comparison between baseline and after treatment could not be performed.

For both the Raven and QOLIE-89 questionnaire an increase in scores means improvement. Otherwise, all subscales of the POMS except vigor are directed the other way around; meaning that a lower score represents improvement. Since vigor is a positive property, progress is indicated by a higher score. Table 6.3 summarizes the mean scores of each of the three rating scales performed during baseline and after VNS. For the POMS a pairwise comparison between baseline and after 6 months of VNS revealed a significantly decrease in scores on the subscales tension, depression, anxiety and confusion $(\mathrm{p}<0.05)$. There was no significant difference in scores on the subscales vigor and fatigue.

For the 30 patients who fulfilled the QOLIE-89 both the end score and T-score increased significantly after treatment with VNS $(\mathrm{p}<0.01)$. On the contrary, assessments with the Raven questionnaire did not show a statistically significance change in cognition during this study. Although the percentile scores slightly improved, it did not reach a statistically significant level $(\mathrm{p}=0.29)$.

Table 6.3 Mean scores for neuropsychological assessments during VNS.

\begin{tabular}{|c|c|c|c|c|c|}
\hline \multirow[t]{2}{*}{ Rating scale } & \multirow[t]{2}{*}{$\mathrm{n}$} & \multirow[t]{2}{*}{ Mean \pm SD baseline } & \multirow[t]{2}{*}{ Mean \pm SD after VNS } & \multicolumn{2}{|c|}{ Paired Samples t test } \\
\hline & & & & $\mathrm{t}$ & Sig. \\
\hline \multicolumn{6}{|l|}{ POMS } \\
\hline Tension & 33 & $13.97 \pm 6.03$ & $10.45 \pm 5.690$ & 3.881 & $\leq 0.001^{*}$ \\
\hline Depression & 33 & $16.67 \pm 12.07$ & $10.76 \pm 10.24$ & 3.065 & $0.004^{*}$ \\
\hline Anxiety & 33 & $12.70 \pm 9.05$ & $8.33 \pm 6.86$ & 4.146 & $\leq 0.001^{*}$ \\
\hline Vigor & 33 & $16.76 \pm 4.73$ & $17.52 \pm 4.49$ & -0.801 & 0.429 \\
\hline Fatigue & 33 & $9.73 \pm 5.86$ & $7.55 \pm 6.45$ & 1.894 & 0.067 \\
\hline Confusion & 33 & $11.30 \pm 4.19$ & $9.18 \pm 5.02$ & 2.438 & $0.021^{*}$ \\
\hline \multicolumn{6}{|l|}{ QOLIE-89 } \\
\hline End score & 30 & $61.67 \pm 13.68$ & $68.23 \pm 14.35$ & -2.923 & $0.007^{*}$ \\
\hline $\mathrm{T}$-score & 30 & $45.77 \pm 8.78$ & $49.93 \pm 9.08$ & -2.955 & $0.006^{*}$ \\
\hline \multicolumn{6}{|l|}{ Raven } \\
\hline Total score & 36 & $39.19 \pm 10.67$ & $39.11 \pm 11.66$ & 0.089 & 0.929 \\
\hline Percentile score & 36 & $33.72 \pm 27.27$ & $37.14 \pm 29.67$ & -1.075 & 0.290 \\
\hline
\end{tabular}

${ }^{*}$ P-values at a statistically significant level.

\section{Outcome intercorrelations}

The absolute change in seizure frequency was not significantly correlated with the composite index of the POMS $(r=-0.32, \mathrm{p}=0.06)$, neither with the end score $(r=-0.35$, $\mathrm{p}=0.06)$ or total score $(r=-0.34, \mathrm{p}=0.07)$ of the QOLIE-89. The composite index of the POMS was correlated with both the end score $(r=0.38, \mathrm{p}=0.04)$ and total score $(r=0.38$, 
$p=0.04)$ of the QOLIE-89. Furthermore, no significant correlation was found between change in seizure frequency and total drug load of $\operatorname{AED}(r=0.13, p=0.41)$.

\section{DISCUSSION}

The results of this prospective study demonstrate that VNS is associated with improvements in both mood and QoL in patients with refractory epilepsy, based on significant improvements in the QOLIE-89 and in four subscales of the POMS. Since no significant correlation was found between neither of these improvements and changes in seizure frequency, the neuropsychological effects of VNS appear to be independent of seizure control. Our study revealed no significant change in cognition after VNS.

The evidential value of our findings is established by the combination of a few circumstances. First of all, the four subscales of the POMS which showed significant improvements (tension, depression, anxiety and confusion), are exactly the scales that represent the most specific mood components. For vigor and fatigue which are the more 'physical components' in the scale no significant change was found. Although a placebo effect due to the achievement of being functionally involved in their treatment and having a device implanted in their chest, could be expected in patients treated with VNS, it is at least partially contradicted in this study by the specific results on the POMS. Furthermore, the mood improvement of the patients in this study was correlated with a significant increase in QoL. This confirms the opinion of mood disturbance being the most important variable that affects the QoL of patients with epilepsy. ${ }^{5,6}$ Finally, a test-retest effect for all of the neuropsychological scales is eliminated by the fact that we did not obtain a significant change on the Raven after treatment with VNS. This also contributes to the specificity of the obtained effects, which are limited to the domain of mood and related QoL areas and are not global since these are not found for physical aspects or cognition. Furthermore it illustrates that this is not a placebo effect.

The results of this prospective study confirm suggestions from earlier research on VNS and mood in epilepsy patients. ${ }^{10,11}$ There are of course limitations to a prospective study and randomized controlled data would have been preferable. However, these previous studies contained smaller sample sizes and have not considered subsequent changes in QoL. Since it is difficult to assess this variable quantitatively most of the articles that do report about QoL did not use validated, standardized rating scales and therefore have methodological limitations. Some of these studies have assessed QoL with visual analogue scales ${ }^{7,24,25}$, others have based their findings on nonstandardized clinical interviews. ${ }^{26}$ Articles based on assessments with the QOLIE-10 and QOLIE-31 which are modificated, shorter versions of the QOLIE-89 have reported contradicting findings. ${ }^{14,16,27}$ The two studies that did use the QOLIE-89 also have demonstrated conflicting results. ${ }^{13,15}$ Although McLachlan et al have earlier reported a significant 
increase in QoL that was independent of seizure control as well, our study is the first to combine these findings with an improvement in mood.

In this study, the mean percentage change in overall seizure frequency after 6 months of VNS was $-9.0 \%$ while $20 \%$ of the patients achieved a reduction of at least $50 \%$. Compared to previous randomized controlled and open clinical trials, the results in our study are rather modest. ${ }^{7-9,28,29}$ This might be partially explained by the fact that our study population contained a relatively high number of mentally retarded patients. Earlier studies have determined mental retardation to be a negative prognostic factor for the efficacy of $\mathrm{VNS}^{30,31}$. Therefore the high amount of mentally retarded patients in this study could have negatively influenced seizure outcome. In addition, the follow-up period of 6 months might not be representative for achievable seizure control. Several long-term efficacy studies have suggested a cumulative beneficial effect of VNS over time. ${ }^{28,29,32}$ Accordingly, seizure control in the patients in this study might improve to some extent in the following months. A third reason might be the presence of a few patients with a marked increase in seizure frequency. Although it can be the result of a more accurate way of keeping seizure diaries after having a device implanted, these marked increases need to be taken in account. As been shown in Figure 6.1 the marked changes in these patients lead to extreme values compared to the rest of the study population. Because extreme values particularly affect the mean percentage change, this might be an explanation for the fact that the percentage of patients with a reduction of at least $50 \%$ was less moderate in comparison to the mean percentage change. However, the efficacy of VNS after 6 months remains rather modest.

In the current study the significant improvement in mood was independent of seizure control, indicating specific VNS-induced mood changes. Additional but yet unknown mechanisms of VNS are likely to contribute to this effect. Preliminary research has provided several proposed mechanisms by which VNS can affect mood. One of the hypotheses includes the influence of VNS on neurotransmitters involved in mood regulation; in particular norepinephrine and serotonin. ${ }^{11,33,34}$ Furthermore, there is some evidence that VNS can change the metabolic activity of structures in the limbic system which contribute mood. ${ }^{11,34}$ Yet there are probably many more potential mechanisms to be elucidated.

In addition to previous studies on VNS and mood in epilepsy, the antidepressant efficacy of VNS has also been evaluated in patients with treatment resistant major depression. It is important to realize that these data cannot be extrapolated to treatment resistant epilepsy patients, of which we know there is a high co-morbidity of mood disturbances. Although it supports an additional effect on mood of VNS besides seizure frequency reduction. Rush et al have reported promising results in an open trial regarding VNS in non-epileptic patients with treatment-resistant major depression. ${ }^{35}$ The results of a longterm follow-up study of $\mathrm{Nahas}$ et al have suggested that patients with major depression may show long-term benefit after treatment with VNS. ${ }^{36}$ Although a 10 -week, double- 
blind, acute randomized controlled trial did not demonstrate short-term efficacy of VNS on primary outcome (Hamilton rating scale for depression-24) but there was a significant reduction on secondary outcome measure (Inventory of depressive symptomatology-30) in favour of $\mathrm{VNS}^{37}$, the 1-year follow up study has suggested a pattern of later but sustained response in treatment-resistant depression. ${ }^{38}$

\section{CONCLUSION}

In conclusion, the results of this prospective study suggest an improvement in mood in patients with refractory epilepsy after 6 months of treatment with VNS. In addition to its well-established anticonvulsive effects in epilepsy patients our data confirm that VNS has a positive effect on mood in epilepsy patients as well. The combination of improvement of mood and QoL and a possible reduction of AED in future and lack of negative effects on cognition make VNS a valuable treatment in medically resistant epilepsy in view of the high co-morbidity of mood disturbances. 


\section{REFERENCES}

1. Wiegartz P, Seidenberg M, Woodard A, Gidal B, Hermann B. Co-morbid psychiatric disorder in chronic epilepsy: recognition and etiology of depression. Neurology. 1999;53(5 Suppl 2):S3-8.

2. Harden CL. The co-morbidity of depression and epilepsy: epidemiology, etiology, and treatment. Neurology. 2002;59(6 Suppl 4):S48-55.

3. Kanner AM, Balabanov A. Depression and epilepsy: how closely related are they? Neurology. 2002;58 (8 Suppl 5):S27-39.

4. Barry JJ. The recognition and management of mood disorders as a comorbidity of epilepsy. Epilepsia. 2003;44(Suppl 4):30-40.

5. Viikinsalo M, Sawrie S, Kuzniecky R, Faught ER, Martin RC, F G. Depression and medication toxicity, but not seizure frequency of severity, predict health outcomes in refractory epilepsy. Epilepsia. 2000;41(Suppl 7): 175 .

6. Elger CE, Schmidt D. Modern management of epilepsy: a practical approach. Epilepsy Behav. 2008;12: 50139.

7. Handforth A, DeGiorgio CM, Schachter SC, Uthman BM, Naritoku DK, Tecoma ES, et al. Vagus nerve stimulation therapy for partial-onset seizures: a randomized active-control trial. Neurology. 1998;51: 48-55.

8. Landy HJ, Ramsay RE, Slater J, Casiano RR, Morgan R. Vagus nerve stimulation for complex partial seizures: surgical technique, safety, and efficacy. J Neurosurg. 1993;78:26-31.

9. The Vagus Nerve Stimulation Study Group. A randomized controlled trial of chronic vagus nerve stimulation for treatment of medically intractable seizures. The Vagus Nerve Stimulation Study Group. Neurology. 1995;45:224-30.

10. Elger G, Hoppe C, Falkai P, Rush AJ, Elger CE. Vagus nerve stimulation is associated with mood improvements in epilepsy patients. Epilepsy Res. 2000;42:203-10.

11. Harden CL, Pulver MC, Ravdin LD, Nikolov B, Halper JP, Labar DR. A Pilot Study of Mood in Epilepsy Patients Treated with Vagus Nerve Stimulation. Epilepsy Behav. 2000;1:93-99.

12. Aldenkamp AP, Van de Veerdonk SH, Majoie HJ, Berfelo MW, Evers SM, Kessels AG, et al. Effects of 6 Months of Treatment with Vagus Nerve Stimulation on Behavior in Children with Lennox-Gastaut Syndrome in an Open Clinical and Nonrandomized Study. Epilepsy Behav. 2001;2:343-50.

13. McLachlan RS, Sadler M, Pillay N, Guberman A, Jones M, Wiebe S, et al. Quality of life after vagus nerve stimulation for intractable epilepsy: is seizure control the only contributing factor? Eur Neurol. 2003;50: 16-9.

14. Ergene E, Behr PK, Shih JJ. Quality-of-Life Assessment in Patients Treated with Vagus Nerve Stimulation. Epilepsy Behav. 2001;2:284-7.

15. McGlone J, Valdivia I, Penner M, Williams J, Sadler RM, Clarke DB. Quality of life and memory after vagus nerve stimulator implantation for epilepsy. Can J Neurol Sci. 2008;35:287-96.

16. Dodrill CB, Morris GL. Effects of Vagal Nerve Stimulation on Cognition and Quality of Life in Epilepsy. Epilepsy Behav. 2001;2:46-53.

17. Hoppe C, Helmstaedter C, Scherrmann J, Elger CE. No Evidence for Cognitive Side Effects after 6 Months of Vagus Nerve Stimulation in Epilepsy Patients. Epilepsy Behav. 2001;2:351-6.

18. Milby AH, Halpern $\mathrm{CH}$, Baltuch GH. Vagus nerve stimulation in the treatment of refractory epilepsy. Neurotherapeutics. 2009;6:228-37.

19. McNair DM, Lorr M, Droppleman LF. POMS Manual: Profile of Mood States (Revised). San Diego, California: Educational and Industrial Testing Service, 1992.

20. Lezak MD, Howieson DB, Loring D. Neuropsychological Assessment. New York: Oxford University Press, 1995.

21. Devinsky O, Vickrey BG, Cramer J, Perrine K, Hermann B, Meador K, et al. Development of the quality of life in epilepsy inventory. Epilepsia. 1995;36:1089-104.

22. Ben-Menachem E, Manon-Espaillat R, Ristanovic R, Wilder BJ, Stefan H, Mirza W, et al. Vagus nerve stimulation for treatment of partial seizures: 1. A controlled study of effect on seizures. First International Vagus Nerve Stimulation Study Group. Epilepsia. 1994;35:616-26.

23. Deckers CL, Hekster YA, Keyser A, Meinardi H, Renier WO. Reappraisal of polytherapy in epilepsy: a critical review of drug load and adverse effects. Epilepsia. 1997;38:570-5. 
24. Hallböök T, Lundgren J, Stjernqvist K, Blennow G, Stromblad LG, Rosen I. Vagus nerve stimulation in 15 children with therapy resistant epilepsy; its impact on cognition, quality of life, behaviour and mood. Seizure. 2005;14:504-13.

25. Ramsay RE, Uthman BM, Augustinsson LE, Upton AR, Naritoku D, Willis J, et al. Vagus nerve stimulation for treatment of partial seizures: 2. Safety, side effects, and tolerability. First International Vagus Nerve Stimulation Study Group. Epilepsia. 1994;35:627-36.

26. Scherrmann J, Hoppe C, Kral T, Schramm J, Elger CE. Vagus nerve stimulation: clinical experience in a large patient series. J Clin Neurophysiol. 2001;18:408-14.

27. Hoppe C, Helmstaedter C, Scherrmann J, Elger CE. Self-Reported Mood Changes following 6 Months of Vagus Nerve Stimulation in Epilepsy Patients. Epilepsy Behav. 2001;2:335-42.

28. DeGiorgio CM, Schachter SC, Handforth A, Salinsky M, Thompson J, Uthman B, et al. Prospective longterm study of vagus nerve stimulation for the treatment of refractory seizures. Epilepsia. 2000;41:1195-200.

29. Salinsky MC, Uthman BM, Ristanovic RK, Wernicke JF, Tarver WB. Vagus nerve stimulation for the treatment of medically intractable seizures. Results of a 1-year open-extension trial. Vagus Nerve Stimulation Study Group. Arch Neurol. 1996;53:1176-80.

30. Majoie HJ, Berfelo MW, Aldenkamp AP, Evers SM, Kessels AG, Renier WO. Vagus nerve stimulation in children with therapy-resistant epilepsy diagnosed as Lennox-Gastaut syndrome: clinical results, neuropsychological effects, and cost-effectiveness. J Clin Neurophysiol. 2001;18:419-28.

31. Aldenkamp AP, Majoie HJ, Berfelo MW, Evers SM, Kessels AG, Renier WO, et al. Long-term effects of 24month treatment with vagus nerve stimulation on behaviour in children with Lennox-Gastaut syndrome. Epilepsy Behav. 2002;3:475-9.

32. Morris GL, 3rd, Mueller WM. Long-term treatment with vagus nerve stimulation in patients with refractory epilepsy. The Vagus Nerve Stimulation Study Group E01-E05. Neurology. 1999;53:1731-5.

33. George MS, Sackeim HA, Rush AJ, Marangell LB, Nahas Z, Husain MM, et al. Vagus nerve stimulation: a new tool for brain research and therapy. Biol Psychiatry. 2000;47:287-95.

34. Kanner AM, Schachter S. Psychiatric Controversies in Epilepsy. Boston: Elsevier Inc., 2008:283-95.

35. Rush AJ, George MS, Sackeim HA, Marangell LB, Husain MM, Giller C, et al. Vagus nerve stimulation (VNS) for treatment-resistant depressions: a multicenter study. Biol Psychiatry. 2000;47:276-86.

36. Nahas Z, Marangell LB, Husain MM, Rush AJ, Sackeim HA, Lisanby SH, et al. Two-year outcome of vagus nerve stimulation (VNS) for treatment of major depressive episodes. J Clin Psychiatry. 2005; 66:1097-104.

37. Rush AJ, Marangell LB, Sackeim HA, George MS, Brannan SK, Davis SM, et al. Vagus nerve stimulation for treatment-resistant depression: a randomized, controlled acute phase trial. Biol Psychiatry. 2005;58: 347-54.

38. Rush AJ, Sackeim HA, Marangell LB, George MS, Brannan SK, Davis SM, et al. Effects of 12 months of vagus nerve stimulation in treatment-resistant depression: a naturalistic study. Biol Psychiatry. 2005;58: 355-63. 



\section{CHAPTER 7}

Behavioral and cognitive effects during vagus nerve stimulation in children with intractable epilepsy: a randomized controlled trial

S. Klinkenberg, C.N.C.J. van den Bosch, H.J.M. Majoie, M.W. Aalbers,

L. Leenen, J. Hendriksen, E.M.J. Cornips, K. Rijkers, J.S.H. Vles, A.P. Aldenkamp 


\begin{abstract}
background

In addition to effects on seizure frequency in intractable epilepsy, multiple studies report benefits of vagus nerve stimulation (VNS) on behavioural outcomes and quality of life.
\end{abstract}

\title{
Objectives
}

The present study aims to investigate the effects of VNS on cognition, mood in general, depression, epilepsy-related restrictions and psychosocial adjustment in children with intractable epilepsy, as well as the relation between these effects and seizure reduction.

\section{Methods}

We conducted a randomized, active-controlled, double-blinded, add-on study in 41 children (age 4-18) with medically refractory epilepsy. We performed cognitive and behavioural testing at baseline (12 weeks), at the end of the blinded phase (20 weeks) in children receiving either high-output or lowoutput (active control) stimulation, and at the end of the open label phase (19 weeks) with all children receiving high-output stimulation. Seizure frequency was recorded using seizure diaries.

\section{Results}

VNS did not have a negative effect on cognition nor on psychosocial adjustment. At the end of the follow-up phase we noted an improvement of mood in general and the depression subscale for the entire group, unrelated to a reduction of seizure frequency. At the end of the blinded phase a $\geq 50 \%$ reduction of seizure frequency occurred in $16 \%$ of the high-stimulation group and $21 \%$ of the lowstimulation group. At the end of the open-label follow-up phase, $26 \%$ of the children experienced a seizure frequency reduction of $50 \%$ or more (responders).

\section{Conclusions}

VNS has additional beneficial effects in children with intractable epilepsy. As opposed to anti-epileptic drugs, there are no negative effects on cognition. Moreover, we observed an improvement of mood in general and depressed feelings in particular, irrespective of a reduction in seizure frequency. These beneficial effects should be taken into account when deciding whether to initiate or continue VNS treatment in these children. 


\section{INTRODUCTION}

Vagus nerve stimulation (VNS) is a non-pharmacological treatment for patients with intractable epilepsy who are not eligible for epilepsy surgery. The efficacy of VNS regarding seizure frequency control has been demonstrated by randomized, actively controlled trials mainly in adults. A $50 \%$ or more seizure frequency reduction occurred in $23-31 \%$ of patients in the treatment group compared to $13-15 \%$ in the active control group. ${ }^{1-3}$ In children the reported efficacy of VNS regarding seizure frequency control is more variable with responder rates ( $\geq 50 \%$ seizure frequency reduction) ranging from $0-90 \%$ based on uncontrolled cohort studies. ${ }^{4-39}$ In addition to the effect of VNS on seizure frequency, several uncontrolled studies have reported beneficial effects on behavioural outcome and quality of life (QoL). ${ }^{15,25,40-44}$ Elsewhere we described results of randomized controlled trial in children with intractable epilepsy concerning the effect of VNS on seizure frequency which showed a limited effect at the end of the blinded phase. ${ }^{45}$ At the end of the follow-up period VNS reduced seizure frequency by $50 \%$ or more in $26 \%$.

Intractable epilepsy is associated with cognitive impairment. ${ }^{42,46}$ Especially in children seizures may disrupt a developmental period essential to their intellectual and social maturation. ${ }^{47,48}$ Early and better seizure control may improve cognitive outcome and QoL in children as demonstrated in several retrospective studies on the effect of epilepsy surgery ${ }^{49-51}$. In addition to these negative effects of seizures, anti-epileptic drugs (AEDs) often exert a negative impact on cognition. ${ }^{42,46}$ VNS on the other hand has not been demonstrated to negatively impact on cognition. Most studies observed stable cognitive functioning during VNS treatment, ${ }^{1,33,41,44}$ and some studies even observed a mild positive effect on verbal performance, memory and/or mental age in children independent of seizure control ${ }^{8,14,19,43}$

Possibly the most remarkable beneficial effect of VNS, besides the effect on seizure control, is the improvement in the various dimensions of mood, including depression. This has been reported by several authors, independent of the effect on seizure frequency, in both children and adults. ${ }^{11,15,52-55} \mathrm{~A}$ randomized controlled trial in adults has demonstrated the efficacy of VNS as a therapy for severe refractory depression. ${ }^{56}$ Since depression is the most common psychiatric co-morbidity in adults suffering from epilepsy ${ }^{57}$, this effect may be important in children as well.

Another important factor in children with epilepsy is QoL, and in particular the degree of epilepsy-related restrictions. These restrictions are not merely important to the child but also to the parents and guardians. ${ }^{58}$ Whether a reduction of seizure frequency caused by VNS also results in a reduction of epilepsy-related restrictions, and consequently an improvement in overall QoL, remains to be evaluated. Finally, VNS may have a beneficial effect on several aspects of behaviour, for example on the child's psychosocial 
adjustment. In other words, VNS may influence the way a child copes with the consequences of their illness. Indeed, several authors have demonstrated an improvement of behaviour in general in a majority of patients regardless of seizure frequency reduction. ${ }^{19,59,60}$ Zamponi et al. observed a significant increase in adaptive behaviour one year after initiation of VNS treatment, the major effects being improvement in communication and socialization skills. ${ }^{33}$ They observed a positive correlation between seizure reduction and socialization, as well as a significant reduction in aggressive behaviour independent of seizure reduction. Unfortunately, the above mentioned studies are difficult to compare due to a large variation in study population and different methods used to examine/assess cognition, mood, behaviour, and QoL. Moreover, none of these studies investigated the behavioural effects of VNS in children and adolescents using a blinded, prospective, randomized, controlled study design.

Therefore, we conducted a blinded, prospective, randomized, controlled study in children with intractable epilepsy. We demonstrated that a limited effect on seizure frequency reduction at the end of the blinded phase. ${ }^{45}$ In this study we aimed to:

- evaluate the effects of VNS on behaviour, on mood in general and especially on the depression subscale, on psychosocial adjustment, and on epilepsy-related restrictions.

- investigate whether or not the effect of VNS on each respective outcome parameter was correlated with seizure frequency reduction (so-called indirect and direct effects of VNS respectively).

\section{MATERIALS AND METHODS}

\section{Study design}

The study followed a randomized-controlled, double blinded, add-on design in children with medically refractory epilepsy. Neuropsychological testing was performed at three distinct time points: during a baseline period of 12 weeks before VN stimulator implantation, at the end of a blinded VNS treatment period of 20 weeks, and finally after a non-controlled follow-up period of 19 weeks. Children were assigned to either the VNS treatment group receiving high level stimulation, or to the active control group receiving low level stimulation. During the non-controlled follow-up period, all children received high level stimulation. Informed consent was obtained from all parents, guardians, and children aged twelve or above. The Medical Ethical Committee of the Maastricht University Medical Center approved all procedures.

\section{Study population}

Fourty-six children with intractable epilepsy were eligible for study enrolment, however, in 5 of them consent to participate was not obtained. Inclusion criteria were intractable 
epilepsy, age between 4 and 18 years at time of VNS implantation, and not being eligible for epilepsy surgery. Exclusion criteria were a progressive cerebral lesion, schizophrenia or any (other) psychotic symptomatology, and a history of a psychiatric disorder requiring either electro-convulsive therapy or chronic use of tranquilizers (neuroleptics, or antidepressants) during the past 6 months.

\section{Device and implantation}

A programmable pulse generator (Neuro Cybernetic Prosthesis (NCP), Cyberonics Inc., Webster, TX, USA) was implanted in a subcutaneous pocket below the left clavicle and connected to a bipolar electrode, meticulously positioned around the left vagus nerve. All children were operated at the Maastricht University Medical Center.

\section{Randomization, blinding and device settings}

The treating neurologist (MM), participants, parents, and guardians were blinded to treatment conditions. A trial nurse (LL) used a computer program to allocate the treatment condition. The same trial nurse adjusted device settings according to a fixed protocol. Two weeks after implantation the device was activated. Initial stimulation parameters for both groups are depicted in Table 7.2. In the high level stimulation group, the output current was increased in a stepwise fashion with 2-week intervals (0.25-0.5 $\mathrm{mA}$ per 2 weeks) to the highest tolerated level with a maximum of $1.75 \mathrm{~mA}$ on the basis of the clinical evaluation of the treating neurologist. The stepwise increase was stopped in case of reduction in seizure frequency of $50 \%$ or more or was delayed or set back to the highest tolerable level in case of side effects occurring. In the low level stimulation group the output current was increased temporarily during each visit and switched back to the initial settings at the end of each visit to suggest stimulation and protect the blinding. Chosen device settings in the low level stimulation group are proven ineffective according to the literature ${ }^{61}$ and lower than the settings used in the active control groups of initial NCP registration studies. ${ }^{1-3}$ At the start of the non-controlled follow-up period, the device settings of the low level stimulation group were adjusted according to the settings of the high level stimulation group. The maximal output current at the end of this phase was set at $2.25 \mathrm{~mA}$ for both groups.

\section{Seizure outcome measures}

Seizure frequency was recorded during baseline phase, blinded treatment phase, and open label follow-up phase by the child's parents or guardians using a seizure diary. Responders were defined as those with $50 \%$ or more seizure frequency reduction. For every child, seizure frequency reduction at the end of both study phases was calculated as the percentage change compared to baseline seizure frequency. 


\section{Cognitive and behavioural outcome measures}

Four areas of functioning were assessed: cognitive function, mood, epilepsy-based restrictions, and psychosocial adjustment. Assessment of cognitive function was performance-based, whereas the other areas were assessed using by-proxy-reported questionnaires, completed by the child's parents or guardians.

- Cognitive function was assessed using the Peabody Picture Vocabulary test (PPVT-III$\mathrm{NL})^{62}$ and Beery VMI $5^{\text {th }}$ edition, a developmental test of visual motor integration. ${ }^{63,64}$ For both tests, raw scores were converted to age-equivalent scores. To calculate intelligence quotient (IQ), age-equivalents in months were divided by chronological age in months at the date of testing and then multiplied by 100. Based on the average IQ calculated from these two tests, children were divided into four categories: (1) $\mathrm{IQ} \geq 85$, (2) 85>IQ $\geq 70$, (3) 70>IQ $\geq 55$, and (4) IQ $<55$. Children able to participate in one test only, were divided into categories based on their performance in that particular test. Children unable to participate in both tests because of severe mental retardation were included in category $(4)(\mathrm{IQ}<55)$.

- Mood in general and depression in particular were assessed using the Profile of Mood States (POMS) questionnaire. ${ }^{65}$ The POMS questionnaire consists of 65 mood-related adjectives to be rated on a 5-point scale ( $0=$ 'not at all' to $4=$ ='extremely') reflecting the child's mood during the past week. There are six sub scores and an overall score: tension-anxiety (0-36), depression-dejection (0-60), anxiety-hostility (0-48), vigouractivity (0-32), fatigue (0-28), confusion (0-28), and the overall Total Mood Disturbance (TMD) score (-32-200). A higher score represents a greater degree of mood disturbance, except for the vigour-activity scale where a higher score represents more energy/vitality.

- Epilepsy-based restrictions were assessed using the Hague Restrictions in Childhood Epilepsy Scale (HARCES). ${ }^{58}$ This scale consists of 10 questions about the degree of limitation solely caused by the epilepsy. Scores range from 10-40. Based on their scores, children were divided into four categories: none or few restrictions (score 10-15), few to moderate restrictions (score 16-20), severe restrictions (score 21-30), and very severe restrictions (score 31-40).

- Psychosocial adjustment was assessed using the Personal Adjustment and Role Skills Scale III (PARS-III) questionnaire. ${ }^{66}$ This questionnaire assesses six areas associated with psychosocial maladjustment in children with a chronic physical illness, and also gives an overall adjustment score (range 28-112). Children were divided into two groups based on their overall adjustment score: those with normal adjustment (score $>73$ ) and those with poor adjustment (score $\leq 73$ ).

Statistical analysis

Statistical analysis was performed using SPSS v18. 


\section{Blinded phase}

Behavioural outcome measures during the blinded phase were compared between the high level and low level stimulation group using the non-parametric KolmogorovSmirnov Z Test. Despite randomization we observed some baseline differences between both study groups (see Table 7.4, baseline scores high versus low). To correct for these baseline differences, we calculated deltas $(\Delta)$ of scores between study-periods for the continuous score-scales using the following formula: score(s) at the end of the blinded phase minus score(s) at baseline. Subsequently, we repeated the Kolmogorov-Smirnov Z test using calculated deltas.

\section{Follow-up phase}

To analyse overall improvement in behavioural outcome measures after VNS, values at baseline were compared with values at the end of the follow-up period using the RelatedSamples Wilcoxon Signed Rank Test. To evaluate whether there was an increased effectiveness over time, the analysis was repeated for the group of children who received high level stimulation throughout the whole study (baseline versus end of follow-up period). To evaluate whether the effect was related to seizure frequency reduction, the analysis was repeated for responders and non-responders separately. Finally, delta-scores between baseline and the end of the follow-up period were compared between responders and non-responders using the Kolmogorov-Smirnov $Z$ test.

Statistical significance was defined by $\mathrm{p}<0.05$.

\section{RESULTS}

\section{Demographics}

Fourty-one children ( 23 boys and 18 girls) were included and randomly assigned to the high level stimulation $(n=21)$ or low level stimulation group $(n=20)$. Baseline child characteristics are summarized in Table 7.1 and epilepsy classification according to ILAE is depicted in Table 7.2. Epilepsy surgery had been performed in two patients and was not an option in the others. Onset of epilepsy was between birth and 12 years. Duration of epilepsy was between 1 and 16 years. Aetiology was unknown in 11 children with normal MRI-scans. All children had been on a stable anti-epileptic drug regimen for at least 12 weeks prior to VNS implantation, and this regimen was continued throughout the study. Fourteen children $(14 / 41,34 \%)$ were unable to participate in one or both cognitive tests because of severe mental retardation and/or physical limitations. 
Table 7.1 Baseline child characteristics.

\begin{tabular}{lcl}
\hline Child characteristics & & \\
\hline Sex male $:$ female & $23: 18$ \\
IQ $\geq 70:<70$ & $5: 36$ \\
Mean age at implantation in years (range) & $11.2(3.8-17.7)$ \\
Mean age at onset of seizures in years (range) & 2.3 & $(0-12)$ \\
Mean interval seizure onset-implantation in years (range) & 8.6 & $(2-16)$ \\
Median seizure frequency at baseline in seizures/day (range) & 1.3 & $(0.3-53.7)$ \\
Mean number of AEDs ever used & 7.2 & $(4-14)$ \\
\hline
\end{tabular}

$\mathrm{AED}=$ anti-epileptic drug.

Table 7.2 Epilepsy classification according to ILAE.

\begin{tabular}{lc}
\hline ILAE classification of children in the study & \\
\hline Localization related epilepsy & 31 \\
Symptomatic & 25 \\
Cryptogenic & 10 \\
Generalized epilepsy & 6 \\
Idiopathic & 2 \\
Symptomatic & 4 \\
\hline
\end{tabular}

ILAE $=$ The International Laegue Against Epilepsy.

Effects of low level versus high level stimulation on behavioural aspects - end of randomized controlled blinded period

\section{Cognition}

Majority of children had cognitive impairment, the average baseline IQ in the high level and low level stimulation group being 57 and 54, respectively (Table 7.3). The percentage of children with an IQ $<70$ in the high level and low level stimulation group was $90 \%$ and $85 \%$, respectively. Cognition improved significantly in the high level stimulation group, with an average IQ increase of 7.3 points $(\mathrm{z}=-2.411$; $\mathrm{p}=0.013)$.

Table 7.3 Initial stimulation parameters.

\begin{tabular}{lcc}
\hline & High level stimulation group & Low level stimulation group \\
\hline Output current $(\mathrm{mA})$ & 0.25 & 0.25 \\
Pulse width $(\mu \mathrm{s})$ & 500 & 130 \\
Frequency $(\mathrm{Hz})$ & 30 & 1 \\
Duty cycle: on $(\mathrm{sec}) /$ off $(\mathrm{min})$ & $30 / 5$ & $14 / 60$ \\
Mean maximal output current & 0.99 & 0.25 \\
Blinded phase $(\mathrm{mA})$ & & \\
Mean maximal output current & 1.98 & 1.29 \\
Follow-up phase $(\mathrm{mA})$ & & \\
\hline
\end{tabular}

\section{Mood}

There was no significant difference between the low level and high level stimulation group in degree of improvement in TMD when delta-scores were used to correct for 
baseline differences. POMS subscales (tension, depression, anxiety, vigour, fatigue, confusion) showed no significant effect of VNS when both stimulation groups were compared.

\section{Epilepsy-based restrictions}

These were not significantly different when the low and high stimulation groups were compared.

\section{Psychosocial adjustment}

Despite randomization, there was a baseline difference between the high level and low level stimulation group, as children in the latter group demonstrated better social adjustment. The total amount of children with normal $(>73)$ to poor adjustment $(\leq 73)$ at baseline was 16:2 for the low level and 9:7 for the high level stimulation group. Of note, mean scores and total amount of normal to poor social adjustment remained stable in both groups.

Overall effects of stimulation on behavioural aspects - end of follow-up period

\section{Cognition}

VNS was not observed to influence cognition during the open label period (Table 7.4 and 7.5).

\section{Mood}

At the end of the open label phase, VNS was observed to have a mood-improving effect on both TMD ( -10.456 points on a scale of $-32-200, \mathrm{p}=0.059)$ and POMS (-2.95 points on a scale of $0-60, p=0.034)$ depression subscales compared to baseline for the entire group (Figure 7.1). In children who received therapeutic stimulation throughout the study (39 weeks), this improvement on the depression subscale was even more remarkable (-7.08 points) (Table 7.4).

\section{Epilepsy-based restrictions}

These did not decrease when scores for the entire group at the end of the open label period were compared to baseline.

Psychosocial adjustment

This was not influenced by VNS as scores remained stable throughout the study. 


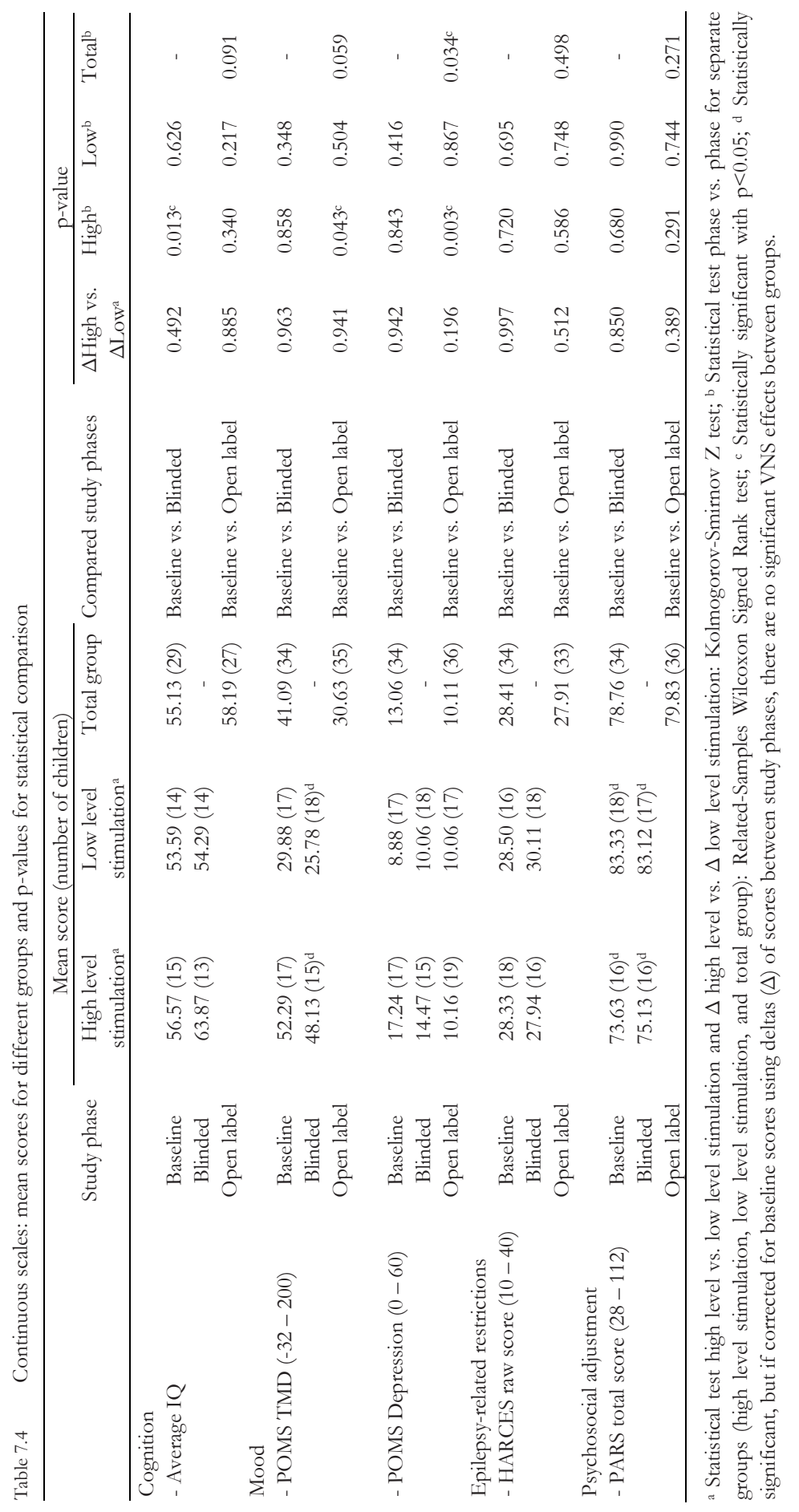




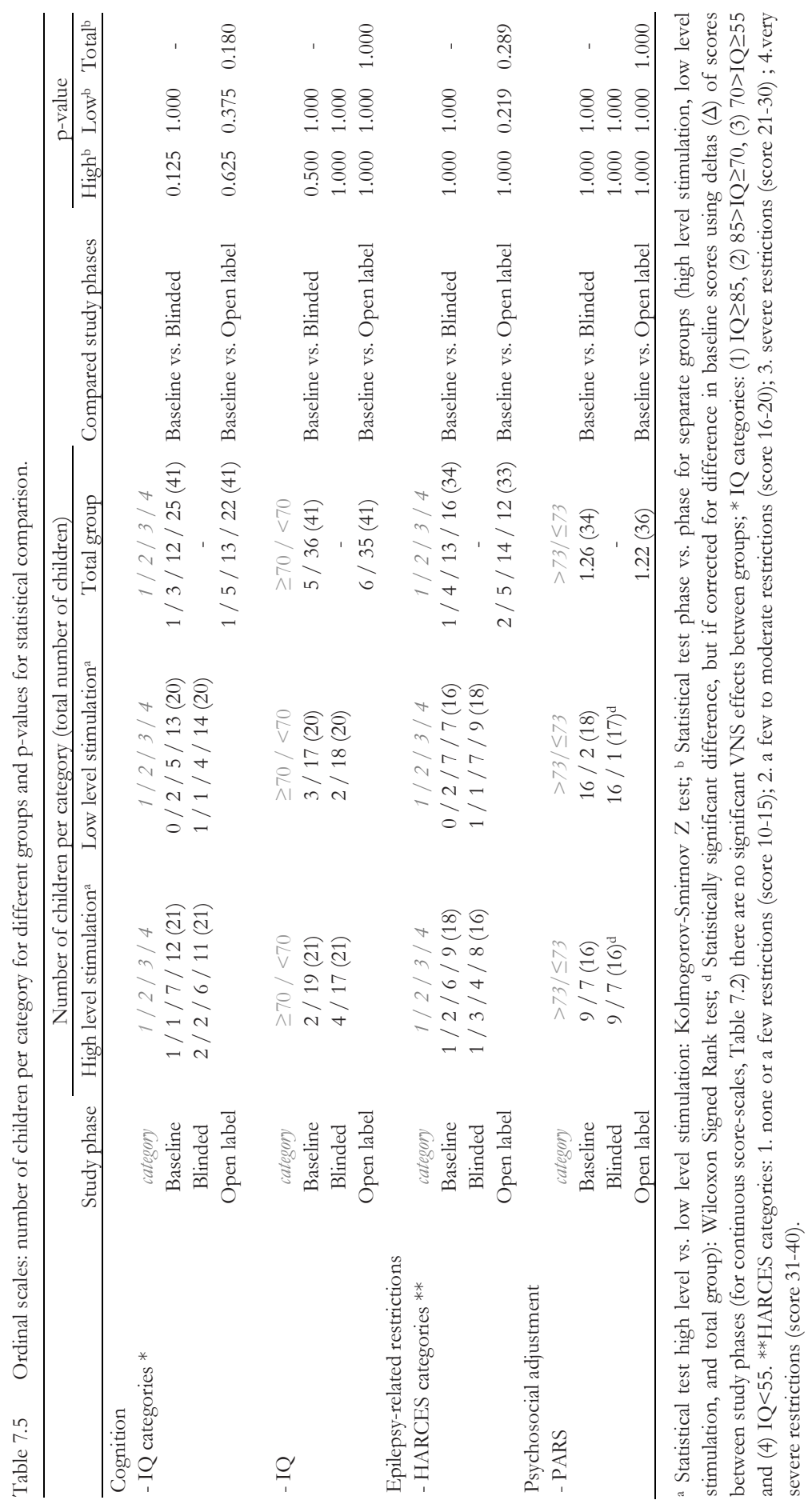




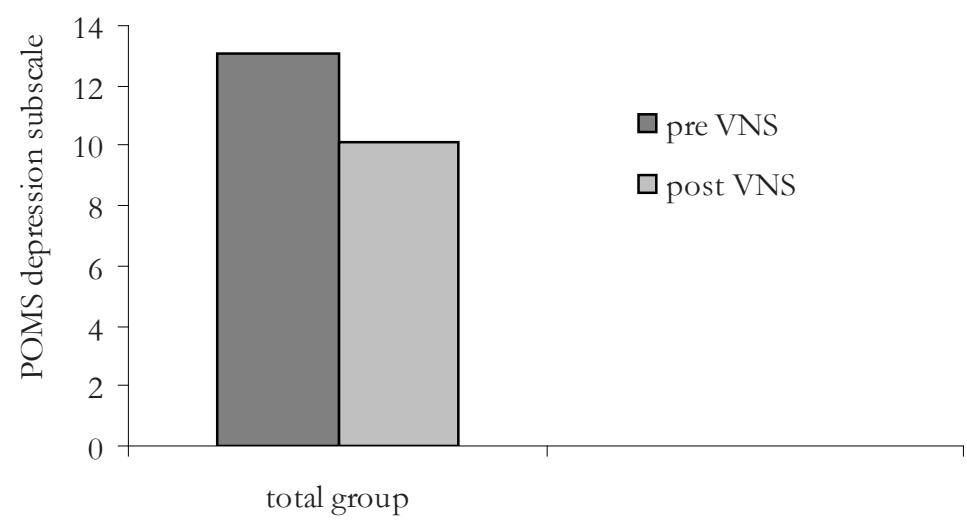

Figure 7.1 Significant effect of VNS on POMS Depression subscale. Mean scores at baseline and open label phase. A lower score represents less depressed feelings. $\mathrm{p}=0.034$.

Effects of (low level versus high level) stimulation on seizure frequency reduction

Because of incomplete seizure diaries, we were unable to calculate seizure frequency reduction for three children at the end of the blinded period and for seven children at the end of the follow-up period. At the end of the blinded period, a $50 \%$ or more seizure frequency reduction was observed in 16\% (3/19) of the high level stimulation group and $21 \%(4 / 19)$ of the low level stimulation group. At the end of the open label period, 26\% $(9 / 34)$ of the children experienced a seizure frequency reduction of $50 \%$ or more. Results on VNS efficacy with regard to seizure frequency reduction and side effects in these children have been reported more extensively elsewhere. ${ }^{45}$

Behaviour and cognition related to seizure frequency reduction - end of followup period

\section{Cognition}

There were no response-related differences in the delta scores in cognitive functioning between responders and non-responders ( $\geq 50 \%$ and $<50 \%$ seizure frequency reduction respectively) when baseline was compared to end of open label period $(\mathrm{p}=0.125)$.

\section{Mood}

TMD score did not improve significantly in responders and non-responders, when follow-up period was compared to baseline. Whereas POMS subscale scores on tension (3.5 points, $\mathrm{p}=0.012)$ and depression $(-5$ points, $\mathrm{p}=0.024)$ decreased significantly in the non-responder group, this effect was not observed in the responder group. There were no significant changes in the other subscale scores (confusion, anxiety, vigour, and fatigue). 
Epilepsy-based restrictions and psychosocial adjustment

Did not change between baseline and end of follow-up period neither for responders nor for non-responders.

\section{DISCUSSION}

We present the first randomized, actively controlled study on behavioural and cognitive effects of VNS treatment in children and adolescents with intractable epilepsy. A third of our population could not participate in one or both cognitive tests, and the majority of children who could be tested had cognitive impairment. We think that our heterogeneous study population is representative for daily practice of children with refractory epilepsy. Positive effects of VNS on cognition have been reported previously. $8,14,43,54$ Aldenkamp et al. have demonstrated an improvement in mental age in children independent of seizure control. ${ }^{41}$ A possible explanation for this improvement of functioning might be the improved quality of sleep. ${ }^{67}$ Although statistically significant, the IQ increase observed in the high level stimulation group in the present study is considered too modest to be clinically relevant and in fact could no longer be demonstrated at the end of the follow-up period. Other authors did not observe an effect of VNS on cognition in children. ${ }^{15,33,41,44}$ One may conclude that VNS at least does not have any negative effects on cognition, in contrast to some AEDs, especially in case of polytherapy. ${ }^{46,57}$

Although we did not observe a significant difference between groups during the blinded period, we did observe a favourable effect of VNS on mood in general (TMD score) and on the depression sub score in particular in the entire group at the end of the follow-up period. These findings are in line with earlier VNS studies in adults. ${ }^{52,68}$ Although improvement in the depression sub score obviously is a major factor here, it cannot be considered solely responsible for the overall effect. Hence, although improvements in other individual mood-related areas appear to be small and rather trivial, we believe combined they are an additional factor in improvement of mood, and thereby QoL, and should therefore not be neglected. The observation that improvement in the depression sub score reached clinical significance only after a prolonged period of high level (i.e. therapeutic) stimulation is in line with previous reports of continued gradual improvement in treatment-resistant depression over a period of 10 weeks up to 1 year. ${ }^{69-}$ ${ }^{71}$ Although not yet fully unravelled, VNS induces changes in various functions of the brain, including serotonin and noradrenalin pathways, both of importance in the pathophysiology of mood disorders. An increase of noradrenalin release in the amygdala in VNS treatment is known. ${ }^{72}$ Dorr et al. found an increase in basal neuronal firing by VNS in rats in brainstem nuclei for both serotonin (dorsal raphe nucleus) and noradrenalin (locus coeruleus)..$^{73}$ 
The lack of a significant difference in VNS effect on the overall mood score and depression sub score between the low level and high level stimulation group is noteworthy. The blinded period of 20 weeks may have been too short to allow significant differences between both groups to develop. The beneficial effect on the overall mood score is independent of the effect on seizure frequency, whereas the beneficial effect on the tension and depression sub scores reached significance in non-responders. Presumably the amount of responders is to low to reach a significant effect on the mentioned sub scores.

We expected to observe a decrease in epilepsy-related restrictions as well as a beneficial effect on psychosocial adjustment in VNS responders, however, this was not the case. The restrictions seem to be predominantly related to family attitudes, whereas psychosocial adjustment seems to be a stable trait. On the other hand, it may be that such factors will only change during a significantly longer treatment period.

Finally, because of their concerns regarding the adverse effects of AEDs in children, several authors have recommended to pursue non-pharmacological treatment options, including VNS, at an earlier stage in the treatment of intractable epilepsy. ${ }^{42,46}$ This recommendation is corroborated by the present study demonstrating that VNS did not exert any negative effect on cognition, mood, epilepsy-related restrictions, and psychosocial adjustment. Side effects are limited and usually tolerable and transient. ${ }^{45,74}$ Our results provide preliminary evidence that treatment with VNS in children with intractable epilepsy has additional beneficial effects on behavioural aspects, in particular on mood, independent from the effect on seizure frequency. Furthermore, there is a prospect that VNS may in time offer the possibility of reduction in AED both dosage and usage. ${ }^{75}$ These beneficial effects should be taken into account when deciding whether (or not) to initiate or continue VNS treatment in these children. 


\section{REFERENCES}

1. Ben-Menachem E, Mañon-Espaillat R, Ristanovic R, Wilder BJ, Stefan H, Mirza W, Tarver WB, Wernicke JF. Vagus nerve stimulation for treatment of partial seizures: 1. A controlled study of effect on seizures. First International Vagus Nerve Stimulation Study Group. Epilepsia. 1994;35:616-26.

2. Handforth A, DeGiorgio CM, Schachter SC, Uthman BM, Naritoku DK, Tecoma ES, Henry TR, Collins SD, Vaughn BV, Gilmartin RC, Labar DR, Morris GL 3rd, Salinsky MC, Osorio I, Ristanovic RK, Labiner DM, Jones JC, Murphy JV, Ney GC, Wheless JW. Vagus nerve stimulation therapy for partial-onset seizures: a randomized active-control trial. Neurology. 1998;51:48-55.

3. The VNS Study Group. A randomized controlled trial of chronic vagus nerve stimulation for treatment of medically intractable seizures. Neurology. 1995;45:224-30.

4. Murphy JV, Hornig G, Schallert G. Left vagal nerve stimulation in children with refractory epilepsy. Preliminary observations. Arch Neurol. 1995;52:886-9.

5. Hornig GW, Murphy JV, Schallert G, Tilton C. Left vagus nerve stimulation in children with refractory epilepsy: an update. South Med J. 1997;90:484-8.

6. Lundgren J, Amark P, Blennow G, Stromblad LG, Wallstedt L. Vagus nerve stimulation in 16 children with refractory epilepsy. Epilepsia. 1998;39:809-13.

7. Murphy JV. Left vagal nerve stimulation in children with medically refractory epilepsy. The Pediatric VNS Study Group. J Pediatr. 1999; 134:563-6.

8. Parker AP, Polkey CE, Binnie CD, Madigan C, Ferrie CD, Robinson RO. Vagal nerve stimulation in epileptic encephalopathies. Pediatrics. 1999;103:778-82.

9. Patwardhan RV, Stong B, Bebin EM, Mathisen J, Grabb PA. Efficacy of vagal nerve stimulation in children with medically refractory epilepsy. Neurosurgery. 2000;47:1353-7; discussion 7-8.

10. Murphy JV, Wheless JW, Schmoll CM. Left vagal nerve stimulation in six patients with hypothalamic hamartomas. Pediatr Neurol. 2000;23:167-8.

11. Helmers SL, Wheless JW, Frost M, Gates J, Levisohn P, Tardo C, Conry JA, Yalnizoglu D, Madsen JR. Vagus nerve stimulation therapy in pediatric patients with refractory epilepsy: retrospective study. J Child Neurol. 2001;16:843-8.

12. Wakai S, Kotagal P. Vagus nerve stimulation for children and adolescents with intractable epilepsies. Pediatr Int. 2001;43:61-5.

13. Nagarajan L, Walsh P, Gregory P, Lee M. VNS therapy in clinical practice in children with refractory epilepsy. Acta Neurol Scand. 2002;105:13-7.

14. Majoie HJ, Berfelo MW, Aldenkamp AP, Renier WO, Kessels AG. Vagus nerve stimulation in patients with catastrophic childhood epilepsy, a 2-year follow-up study. Seizure. 2005;14:10-8.

15. Hallböök T, Lundgren J, Stjernqvist K, Blennow G, Strömblad LG, Rosén I. Vagus nerve stimulation in 15 children with therapy resistant epilepsy; its impact on cognition, quality of life, behaviour and mood. Seizure. 2005;14:504-13.

16. Alexopoulos AV, Kotagal P, Loddenkemper T, Hammel J, Bingaman WE. Long-term results with vagus nerve stimulation in children with pharmacoresistant epilepsy. Seizure. 2006;15:491-503.

17. Benifla M, Rutka JT, Logan W, Donner EJ. Vagal nerve stimulation for refractory epilepsy in children: indications and experience at The Hospital for Sick Children. Childs Nerv Syst. 2006;22:1018-26.

18. Blount JP, Tubbs RS, Kankirawatana P, Kiel S, Knowlton R, Grabb PA, Bebin M. Vagus nerve stimulation in children less than 5 years old. Childs Nerv Syst. 2006;22:1167-9.

19. Kang HC, Hwang YS, Kim DS, Kim HD. Vagus nerve stimulation in pediatric intractable epilepsy: a Korean bicentric study. Acta Neurochir Suppl. 2006;99:93-6.

20. Rychlicki F, Zamponi N, Trignani R, Ricciuti RA, Iacoangeli M, Scerrati M. Vagus nerve stimulation: clinical experience in drug-resistant pediatric epileptic patients. Seizure. 2006;15:483-90.

21. Saneto RP, Sotero de Menezes MA, Ojemann JG, Bournival BD, Murphy PJ, Cook WB, Avellino AM, Ellenbogen RG. Vagus nerve stimulation for intractable seizures in children. Pediatr Neurol. 2006;35: 323-6.

22. Khurana DS, Reumann M, Hobdell EF, Neff S, Valencia I, Legido A, Kothare SV. Vagus nerve stimulation in children with refractory epilepsy: unusual complications and relationship to sleep-disordered breathing. Childs Nerv Syst. 2007;23:1309-12.

23. You SJ, Kang HC, Kim HD, Ko TS, Kim DS, Hwang YS, Kim DS, Lee JK, Park SK. Vagus nerve stimulation in intractable childhood epilepsy: a Korean multicenter experience. J Korean Med Sci. 2007; 22:442-5. 
24. Danielsson S, Viggedal G, Gillberg C, Olsson I. Lack of effects of vagus nerve stimulation on drug-resistant epilepsy in eight pediatric patients with autism spectrum disorders: a prospective 2-year follow-up study. Epilepsy Behav. 2008;12:298-304.

25. Sherman EM, Connolly MB, Slick DJ, Eyrl KL, Steinbok P, Farrell K. Quality of life and seizure outcome after vagus nerve stimulation in children with intractable epilepsy. J Child Neurol. 2008;23:991-8.

26. Zamponi N, Rychlicki F, Corpaci L, Cesaroni E, Trignani R. Vagus nerve stimulation (VNS) is effective in treating catastrophic 1 epilepsy in very young children. Neurosurg Rev. 2008;31:291-7.

27. You SJ, Kang HC, Ko TS, Kim HD, Yum MS, Hwang YS, Lee JK, Kim DS, Park SK. Comparison of corpus callosotomy and vagus nerve stimulation in children with Lennox-Gastaut syndrome. Brain Dev. 2008;30:195-9.

28. Kabir SM, Rajaraman C, Rittey C, Zaki HS, Kemeny AA, McMullan J. Vagus nerve stimulation in children with intractable epilepsy: indications, complications and outcome. Childs Nerv Syst. 2009;25:1097-100.

29. Rossignol E, Lortie A, Thomas T, Bouthiller A, Scavarda D, Mercier C, Carmant L. Vagus nerve stimulation in pediatric epileptic syndromes. Seizure. 2009;18:34-7.

30. Shahwan A, Bailey C, Maxiner W, Harvey AS. Vagus nerve stimulation for refractory epilepsy in children: More to VNS than seizure frequency reduction. Epilepsia. 2009;50:1220-8.

31. Abd-El-Barr MM, Joseph JR, Schultz R, Edmonds JL, Wilfong AA, Yoshor D. Vagus nerve stimulation for drop attacks in a pediatric population. Epilepsy Behav. 2010;19:394-9.

32. Arhan E, Serdaroglu A, Kurt G, Bilir E, Durdağ E, Erdem A, Aksakal FN, Ozcelik A, Baykaner K. The efficacy of vagal nerve stimulation in children with pharmacoresistant epilepsy: practical experience at a Turkish tertiary referral center. Eur J Paediatr Neurol. 2011;14:334-9.

33. Zamponi N, Petrelli C, Passamonti C, Moavero R, Curatolo P. Vagus nerve stimulation for refractory epilepsy in tuberous sclerosis. Pediatr Neurol. 2010;43:29-34.

34. Zamponi N, Passamonti C, Cappanera S, Petrelli C. Clinical course of young patients with Dravet syndrome after vagal nerve stimulation. Eur J Paediatr Neurol. 2011;15:8-14.

35. Zamponi N, Petrelli C, Passamonti C, Moavero R, Curatolo P. Vagus nerve stimulation for refractory epilepsy in tuberous sclerosis. Pediatr Neurol. 2010;43:29-34.

36. Cersósimo RO, Bartuluchi M, De Los Santos C, Bonvehi I, Pomata H, Caraballo RH. Vagus nerve stimulation: effectiveness and tolerability in patients with epileptic encephalopathies. Childs Nerv Syst. 2011;27:787-92.

37. Elliott RE, Rodgers SD, Bassani L, Morsi A, Geller EB, Carlson C, Devinsky O, Doyle WK. Vagus nerve stimulation for children with treatment-resistant epilepsy: a consecutive series of 141 cases. J Neurosurg Pediatr. 2011;7:491-500.

38. Pastrana EA, Estronza S, Sosa IJ. Vagus nerve stimulation for intractable seizures in children: the University of Puerto Rico experience. P R Health Sci J. 2012;30:128-31.

39. Coykendall DS, Gauderer MW, Blouin RR, Morales A. Vagus nerve stimulation for the management of seizures in children: an 8-year experience. J Pediatr Surg. 2010;45:1479-83.

40. Majoie HJ, Berfelo MW, Aldenkamp AP, Evers SM, Kessels AG, Renier WO. Vagus nerve stimulation in children with therapy-resistant epilepsy diagnosed as Lennox-Gastaut syndrome: clinical results, neuropsychological effects, and cost-effectiveness. J Clin Neurophysiol. 2001;18:419-28.

41. Aldenkamp AP, Majoie HJ, Berfelo MW, Evers SM, Kessels AG, Renier WO, Wilmink J. Long-term effects of 24-month treatment with vagus nerve stimulation on behaviour in children with Lennox-Gastaut syndrome. Epilepsy Behav. 2002;3:475-9.

42. Wheless JW, Maggio V. Vagus nerve stimulation therapy in patients younger than 18 years. Neurology. 2002;59(6 Suppl 4):S21-5.

43. McLachlan RS, Sadler M, Pillay N, Guberman A, Jones M, Wiebe S, Schneiderman J. Quality of life after vagus nerve stimulation for intractable epilepsy: is seizure control the only contributing factor? Eur Neurol. 2003;50:16-9.

44. Mikati MA, Ataya NF, El-Ferezli JC, Baghdadi TS, Turkmani AH, Comair YG, Kansagra S, Najjar MW. Quality of life after vagal nerve stimulator insertion. Epileptic Disord. 2009;11:67-74.

45. Klinkenberg S, Aalbers MW, Vles JS, Cornips EM, Rijkers K, Leenen L, Kessels FG, Aldenkamp AP, Majoie M. Vagus nerve stimulation in children with intractable epilepsy: a randomized controlled trial. Dev Med Child Neurol. 2012;54:855-61.

46. Shields WD. Management of epilepsy in mentally retarded children using the newer antiepileptic drugs, vagus nerve stimulation, and surgery. J Child Neurol. 2004;19 Suppl 1:S58-64. 
47. Dodrill CB. Neuropsychological effects of seizures. Epilepsy Behav 2004;5 Suppl 1:S21-4.

48. Thompson PJ, Duncan JS. Cognitive decline in severe intractable epilepsy. Epilepsia. 2005;46:1780-7.

49. Freitag H, Tuxhorn I. Cognitive function in preschool children after epilepsy surgery: rationale for early intervention. Epilepsia. 2005;46:561-7.

50. Loddenkemper T, Holland KD, Stanford LD, Kotagal P, Bingaman W, Wyllie E. Developmental outcome after epilepsy surgery in infancy. Pediatrics. 2007;119:930-5.

51. Zaroff CM, Morrison C, Ferraris N, Weiner HL, Miles DK, Devinsky O. Developmental outcome of epilepsy surgery in tuberous sclerosis complex. Epileptic Disord. 2005;7:321-6.

52. Elger G, Hoppe C, Falkai P, Rush AJ, Elger CE. Vagus nerve stimulation is associated with mood improvements in epilepsy patients. Epilepsy Res. 2000;42:203-10.

53. Harden CL, Pulver MC, Ravdin LD, Nikolov B, Halper JP, Labar DR. A pilot study of mood in epilepsy patients treated with vagus nerve stimulation. Epilepsy Behav. 2000;1:93-9.

54. Aldenkamp AP, Van de Veerdonk SH, Majoie HJ, Berfelo MW, Evers SM, Kessels AG, Renier WO, Wilmink J. Effects of 6 Months of Treatment with Vagus Nerve Stimulation on Behavior in Children with Lennox-Gastaut Syndrome in an Open Clinical and Nonrandomized Study. Epilepsy Behav. 2001;2:43-50.

55. Franzoni E, Gentile V, Colonnelli MC, Brunetto D, Cecconi I, Iero L, Moscano FC, Cordelli DM, Marchiani V. VNS in drug resistant epilepsy: preliminary report on a small group of patients. Ital J Pediatr. 2010;36:30.

56. Yu ZJ, Weller RA, Sandidge K, Weller EB. Vagus nerve stimulation: can it be used in adolescents or children with treatment-resistant depression? Curr Psychiatry Rep. 2008;10:116-22.

57. Hermann B, Meador KJ, Gaillard WD, Cramer JA. Cognition across the lifespan: antiepileptic drugs, epilepsy, or both? Epilepsy Behav. 2010;17:1-5.

58. Carpay HA, Vermeulen J, Stroink H, Brouwer OF, Peters AC, van Donselaar CA, Aldenkamp AP, Arts WF. Disability due to restrictions in childhood epilepsy. Dev Med Child Neurol. 1997;39:521-6.

59. Kossoff EH, Pyzik PL. Improvement in alertness and behavior in children treated with combination topiramate and vagus nerve stimulation. Epilepsy Behav. 2004;5:256-9.

60. Park YD. The effects of vagus nerve stimulation therapy on patients with intractable seizures and either Landau-Kleffner syndrome or autism. Epilepsy Behav. 2003;4:286-90.

61. Koo B, Ham SD, Sood S, Tarver B. Human vagus nerve electrophysiology: a guide to vagus nerve stimulation parameters. J Clin Neurophysiol. 2001;18:429-33.

62. Dunn LM, LM. D. Peabody Picture vocabulary Test-III-NL. In: B.V. HA, ed. Nederlandse versie door Liesbeth Stichting. Amsterdam 2005.

63. Dunn LM, Dunn LM. Peabody Picture Vocabulary Test-III-NL, Nederlandse versie door Liesbeth Schlichting. Amsterdam: Harcourt Assessment B.V. 2005.

64. Beery KE, Beery NA. The Beery-Buktenica Developmental Test of Visual-Motor Integration. BeeryTM VMI. Administration, Scoring and Teaching Manual. 5th edition ed. Minneapolis: NCS Pearson 2006.

65. Griffith NM, Szaflarski JP, Szaflarski M, Kent GP, Schefft BK, Howe SR, Privitera MD. Measuring depressive symptoms among treatment-resistant seizure disorder patients: POMS Depression scale as an alternative to the BDI-II. Epilepsy Behav. 2005;7:266-72.

66. Witt WP, Riley AW, Coiro MJ. Childhood functional status, family stressors, and psychosocial adjustment among school-aged children with disabilities in the United States. Arch Pediatr Adolesc Med. 2003;157:68795.

67. Hallböök T, Lundgren J, Köhler S, Blennow G, Strömblad LG, Rosén I. Beneficial effects on sleep of vagus nerve stimulation in children with therapy resistant epilepsy. Eur J Paediatr Neurol. 2005;9:399-407.

68. Hoppe C, Helmstaedter C, Scherrmann J, Elger CE. Self-Reported Mood Changes following 6 Months of Vagus Nerve Stimulation in Epilepsy Patients. Epilepsy Behav. 2001;2:335-42.

69. Corcoran CD, Thomas P, Phillips J, O'Keane V. Vagus nerve stimulation in chronic treatment-resistant depression: preliminary findings of an open-label study. Br J Psychiatry. 2006;189:282-3.

70. Rush AJ, Marangell LB, Sackeim HA, George MS, Brannan SK, Davis SM, Howland R, Kling MA, Rittberg BR, Burke WJ, Rapaport MH, Zajecka J, Nierenberg AA, Husain MM, Ginsberg D, Cooke RG. Vagus nerve stimulation for treatment-resistant depression: a randomized, controlled acute phase trial. Biol Psychiatry. 2005;58:347-54.

71. Sackeim HA1, Rush AJ, George MS, Marangell LB, Husain MM, Nahas Z, Johnson CR, Seidman S, Giller C, Haines S, Simpson RK Jr, Goodman RR. Vagus nerve stimulation (VNS) for treatment-resistant depression: efficacy, side effects, and predictors of outcome. Neuropsychopharmacology. 2001;25:713-28. 
72. Groves DA, Brown VJ. Vagal nerve stimulation: a review of its applications and potential mechanisms that mediate its clinical effects. Neurosci Biobehav Rev. 2005;29:493-500.

73. Dorr AE, Debonnel G. Effect of vagus nerve stimulation on serotonergic and noradrenergic transmission. J Pharmacol Exp Ther. 2006;318:890-8.

74. Fahy BG. Intraoperative and perioperative complications with a vagus nerve stimulation device. J Clin Anesth. 2010;22:213-22.

75. Tatum WO, Johnson KD, Goff S, Ferreira JA, Vale FL. Vagus nerve stimulation and drug reduction. Neurology. 2001;56:561-3. 

Epilepsy is one of the most common neurological disorders in both adults and children. In $70-80 \%$ of patients with epilepsy, seizures are controlled with anti-epileptic drugs. ${ }^{1-3}$ Developmental delay and psychiatric disorders are the most prevalent co-morbidities encountered in children with epilepsy. ${ }^{4}$ In case of refractory seizures, these comorbidities are more frequent. VNS is an additional neuromodulatory treatment option for medically refractory epilepsy if potentially curative epilepsy surgery is not a suitable option for the patient. Several randomized, active, controlled studies, which predominantly included adults, have demonstrated the efficacy and safety of VNS. ${ }^{5,6}$ In these trials, participants were randomized to receive either therapeutic (high) or active control (low) stimulation. Stimulation parameters used in the active control group were assumed not to be effective. Seizure frequency decreased by $50 \%$ or more in $28-31 \%$ of the therapeutically stimulated patients with refractory epilepsy. In the active control group, $13-15 \%$ experienced a $50 \%$ or greater reduction in seizure frequency. Complete remission of seizures is obtained in a limited number of patients. In children, there is no unequivocal evidence concerning effectiveness of VNS. In the literature, the numbers concerning efficacy ( $\geq 50 \%$ seizure frequency reduction) vary.

The objective of this thesis was to gain more insight into the effects of VNS in children.

Chapter 1 is a general introduction to set the scene.

In chapter 2 we describe our systematic search and review of the literature on VNS in children with intractable epilepsy and provide an overview. With regard to efficacy, results of different studies on $\geq 50 \%$ seizure frequency reduction showed a wide variation (ranging from 0-90\%). Study groups did, however, differ, e.g. in numbers of children included, age, epilepsy syndromes and follow-up duration. Studies were for the most part retrospective, and in the case of prospective studies, control groups were lacking. A metaanalysis in 326 children, from whom data on effectiveness were obtained prospectively, produced a responder rate ( $\geq 50 \%$ seizure frequency reduction) of $38 \%$ for VNS. The variability between the different studies included in the meta-analysis is, however, high and the evidence concerning efficacy is, therefore, limited. The device settings applied are consistent among different studies in the literature, although information is lacking about optimal settings in children. The additional value of the rapid cycling mode remains to be established. In this stimulation mode, the signal-off time is shortened $(<1.8$ minute), resulting in an increased stimulation cycle. Stimulation on demand using a magnet can abort seizures in a subpopulation of children but the evidence for this is limited. A subpopulation of patients which responds favorably to VNS cannot currently be identified. VNS is well tolerated in children with refractory epilepsy. Implantation procedures are accompanied by a small risk of infection or permanent sequelae. Stimulation-related side-effects occur frequently $(\approx 70-80 \%)$, particularly at the beginning of treatment. In the majority of the patients $(\approx 95 \%)$ they either resolve spontaneously during the course of treatment or can be treated easily by adjusting stimulation parameters. There are some indications that VNS improves sleep quality. 
Either by direct stimulation effect on the brain or by reducing seizure frequency. Before implanting a VNS device, attention should be paid to already existing sleep-related breathing disorders, especially in children with learning disabilities, obesitas, and/or large tonsils. During the course of treatment, attention should be paid to altered breathing patterns during sleep, e.g. snoring, or breathing stops as a result of specific device settings in the individual child who is already at risk of obstructive sleep apnea syndrome. In the case of excessive daytime sleepiness, stimulus-related alterations of breathing during sleep should also be considered. So far, there is no evidence that VNS causes neuroimmunological activity in children. No negative effects of VNS on behavior are reported. Moreover, VNS may contribute to improvement in behavior and mood. Two studies in children demonstrate a cost-saving effect of VNS in childhood epilepsy, although sample size and the duration of follow-up are modest. VNS in children does not seem to impact negatively on QoL. Most studies report stable outcomes or improvements in (subscales of) QoL. There is no consensus in the literature concerning the relation between seizure frequency reduction and positive effect on QoL.

\section{Approach}

In order to obtain more information about VNS, we performed the first randomized, active controlled, double-blinded add-on study in children with intractable epilepsy (Chapters 3 to 5 , and 7 ). In chapter 6 we report the results of a prospective cohort study in adults.

For the randomized controlled trial, parents and/or guardians started to collect information about seizure frequency by keeping a seizure diary during the baseline period of 12 weeks and maintained this throughout the entire study period. After the baseline period, the VNS device was implanted. During the treatment phase, children were randomized to receive either high (therapeutic) stimulation or low (active control) stimulation over a 20 -week period. Two weeks after implantation, device settings were adjusted stepwise on each visit, according to a fixed protocol, until the maximum tolerated level was reached or $50 \%$ or greater seizure frequency reduction was achieved. Subsequently, all children received therapeutic stimulation for a further 19 weeks (open label phase). Forty-one children (23 boys) with intractable epilepsy were included and underwent implantation of a VNS device. Mean age at implantation was 11 years, and ranged from nearly 4 up to 17 years. Mean age at onset of epilepsy was 2 years (range $0-12$ years). Study design and data obtained during the course of the RCT are depicted in Figure 8.1.

We also performed a prospective cohort-study in 41 adults, 22 of whom were females. Mean age was 31 years (range 22-61 years). Data on mood, QoL and cognition were obtained twice, at baseline and at the end of the study six months later. Seizure diaries were kept during the baseline period ( 3 months) and during follow-up of 6 months. 
Data analysis and description of different topics - efficacy and safety, neuro-immunemodulating effects, mood regulating effects and additional benefits - are discussed consecutively.

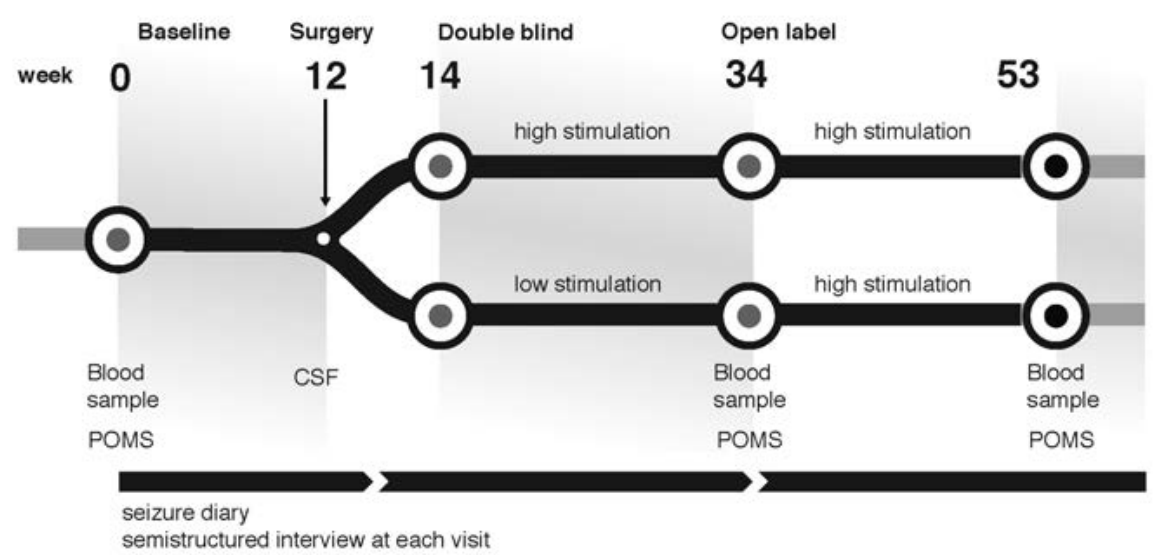

Overview of timeline, interventions, different study phases and data and sample collection. After a 12week baseline, patients were implanted with the vagus nerve stimulator. During the double blind phase ( 20 weeks) half of the patients received high output stimulation and the other half received low output stimulation. During the open label phase (19 weeks), all patients received high output stimulation.

\section{Efficacy and safety}

In chapter 3, we report on our examination of the effectiveness of VNS on seizure frequency in children. We also evaluated the possible implantation and stimulus-related side-effects. There was no difference in decrease in seizure frequency nor severity at the end of the double-blinded phase. Finally, at the end of the open-label phase, VNS reduced seizure frequency, as well as overall seizure severity. During this trial, VNS appeared to be a safe and well-tolerated adjunctive treatment in children with refractory epilepsy. In our randomized controlled trial in children, we did not find a similar beneficial effect of VNS as reported in the adult randomized trials ${ }^{5,6}$. Probably several factors are responsible. The size of our study population might have been too small to detect a favourable effect at the end of the double-blind phase. We based our power analysis on open label studies which suggested a larger effect in children than in adults. Heterogeneity within the group of children concerning age and etiology might also have been of influence.

\section{Neuro-immune-modulating effects}

The vagus nerve has important anti-inflammatory actions that might be relevant to the beneficial effects of vagus nerve stimulation (VNS). Since inflammation is one of the 
processes strongly implicated by development of seizures and epilepsy, ${ }^{7}$ we investigated the effect of VNS on cytokine levels in plasma and cerebrospinal fluid in children with refractory epilepsy (chapter 4). We could not find changes in interictal interleukin-1 $\beta$, interleukin- 6 or interleukin-10 plasma levels at any stage of the study. Although Tracey et al. assumed that VNS might result in inhibition of pro-inflammatory cytokine release due to its influence on the cholinergic anti-inflammatory pathway, ${ }^{8}$ we were not able to confirm this theory. It is feasible that changes in cytokine profile are temporary and seizure-related, and can only be demonstrated shortly after a seizure. Based on a few measurements in blood and just one sample of cerebrospinal fluid, we had the opportunity to perform this exploratory study. More extensive blood and CSF sampling was not applicable nor ethical at this stage. Furthermore, the clinical condition of each child, other than epilepsy, e.g. even a cold, might also interfere with the immunological state. As predictors of response to VNS are lacking, we also aimed to determine whether cytokine changes predicted the clinical response. A lower baseline plasma level of interleukin- 6 was associated with greater seizure frequency reduction.

\section{Mood-regulating effects}

During VNS treatment, improvement in mood is noticeable. Since psychiatric disorders are regularly encountered co-morbidities in both adults and children, we explored moodregulating effects of VNS in refractory epilepsy and our findings are presented in chapters 5 to 7 . One of the theories for an underlying mechanism of action is the elicitation of alterations in cytokines by VNS. Such a change may lead to rebalancing the release of neurotoxic and neuro-protective tryptophan metabolites. Tryptophan is a precursor of serotonin (5-HT), a neurotransmitter involved in regulation of mood, emotions and sleep, for example. Under the influence of pro-inflammatory cytokines, instead of being converted to 5-HT, tryptophan enters the 'tryptophan metabolic pathway'. Pro-inflammatory cytokines appear to be present in the epileptic brain and the tryptophan metabolic pathway may be active in epilepsy. Some of the tryptophan metabolites influence seizure development, and therefore, anticonvulsive effects of VNS may be partially explained by the way it influences this pathway. Chapter 5 describes how we evaluated VNS effects on tryptophan metabolites in children with refractory epilepsy. We used the different measurements within one child to serve as a control. Moreover, revealing a consistent positive correlation between the different tryptophan metabolites at baseline is a confirmation of the pathway. We also investigated whether the antiepileptic effectiveness of VNS correlated to changes in tryptophan metabolism. Levels of anthranilic acid, a neuroprotective metabolite with anti-convulsive properties, increased during treatment with VNS. This increase was correlated with improvement in both mood and seizure frequency reduction. Our attempt to unravel the effects of VNS on cytokines and the 'tryptophan metabolic pathway' was a challenge. Changes in anthranilic acid concentrations, with anticonvulsive and neuroprotective properties, throughout the stimulation period suggest a positive effect of VNS on this pathway. The 
network of interactions, is, however, highly complex, and there are no doubt numerous factors of influence which we are not able to detect. CSF is best feasible reflection of tryptophan-metabolites in central nervous system, only 10-20\% of 5-HT synthesis occurs in the brain. Information of tryptophan metabolites obtained in CSF during VNS treatment could have been of extra value, but for both ethical and practical reasons we obtained CSF only once, before implantation of the VNS device while children were under general anesthesia. Dietary information of the children could have been a valuable source in terms of interpretation of different levels of tryptophan metabolites. In chapter 6, we present an assessment of the effect of VNS on mood in a prospective longitudinal observational cohort of 41 adults ( 22 female), treated with VNS as part of usual care. Mood improved during the course of the study as did QoL. These improvements were unrelated to seizure control. In children, we noted an improvement in mood and feelings of depression, in particular after a prolonged period of high stimulation (chapter 7). During the double-blinded phase, there was no significant difference between high and low treatment groups as far as mood or feelings of depression were concerned. This positive mood-regulating effect in both adults and children appeared to be independent of seizure control, indicating an additional antidepressant effect of VNS. We assume that the influence of VNS on pathways involved in mood-regulation takes time. In trials with VNS to treat therapy-resistant depression, similar results are found showing improvement over time during the first year. ${ }^{?}$

\section{Additional benefits}

Cognition remained stable throughout the study, both in children (chapter 7) and in adults (chapter 6). AED regimens were not adjusted during the course of either of the studies to evaluate effectiveness of VNS. Children, as well as adults, used an average of 2 or more AEDs in the above-mentioned studies. Polytherapy increases the risk of (behavioral) side-effects. In order to minimize overtreatment, a reduction of dosage, or the amount of the AED, or a combination of the two, might have been advantageous, but we have not explored this aspect.

VNS has no negative effect on behavior. We were not able to demonstrate a positive effect of VNS on behavior of the child during the randomized controlled trial as we found no improvement concerning epilepsy-related restrictions nor in psychosocial adjustment (chapter 7). Our modest rate of responders may account for the lack of significance. Despite the limited effect on seizure frequency reduction, the overall satisfaction of parents or guardians was remarkably high.

In adults, QoL improved during VNS treatment; this was unrelated to efficacy (chapter 6). 


\section{What have we learned?}

VNS treatment in children with intractable epilepsy is safe and well tolerated. Efficacy, or more specifically, responder rate, is rather modest, especially during the doubleblinded phase. Strikingly, the completion rate of the study and overall satisfaction were very high. Moreover, there was also a reduction in seizure severity. VNS has no negative effects on cognition nor on behavioral aspects in children.

No changes in cytokine profile were found during treatment to demonstrate the influence of VNS on the cholinergic anti-inflammatory pathway. Possibly the IL6 blood level prior to implantation has a predictive value.

Effect of VNS treatment on mood was unrelated to seizure frequency reduction in children, indicating an additional antidepressant effect. Apart from the increase in levels of anthranilic acid, a neuroprotective metabolite with anti-convulsive properties, we could not confirm alterations in the tryptophan metabolic pathway during VNS treatment in children.

In the prospective adult-cohort with refractory epilepsy, VNS treatment resulted in improvement in both mood and QoL during a follow-up time of six months. Effect of VNS treatment on mood was unrelated to seizure frequency reduction in adults. Cognition remained stable.

\section{What do we still need to learn?}

There are still many unanswered questions concerning the effect of VNS treatment on seizure frequency and secondary effects in children with refractory epilepsy. Is there a reason for a difference in the size of the effect of this neuromodulatory treatment in children compared to adults? Variation is found in electrophysiology of the vagus nerve when adults are compared to children. In younger children, the vagus nerve has not fully matured. Nerve conduction in young children is reflected in lower conduction velocities and higher threshold currents. ${ }^{10}$ The chosen stimulation parameters might have been suboptimal for a number of children. One could also imagine that the developing brain responds differently from the adult brain. Our Belgian colleagues demonstrated an agerelated response detrimental to the children when compared to adults. ${ }^{11}$ On the other hand, several retrospective studies in children could not confirm an age-related difference when children under 12 years were compared with those aged twelve and over. $^{12-14}$

For the majority of children, the epilepsy was highly refractory, manifesting VNS as a last resort treatment option. Hence, even the smallest advantage without adverse events is a bonus in this patient category. Despite more than two decennia of research, we have not yet unravelled the underlying mechanism or network of VNS completely. ${ }^{15}$ However, the vagus nerve presents a unique opportunity to modulate subcortical brain areas. Positive additional effects of VNS treatment are still expanding (e.g. mood, migraine, Alzheimer's disease, eating disorders) although not all applications are as yet used on a large scale. 
In children with refractory epilepsy, a chronic illness with a high burden of uncertainties, it is not only seizure frequency reduction that matters. McHugh et al. already proposed a new classification to evaluate the effects of VNS adding information about ictal and postictal severity and reaction to the use of the magnet on demand. ${ }^{16}$ Further expansion of primary outcome measures in intractable epilepsy could be considered. Refractory epilepsy might negatively impact on development, cognition and behavior in children, but so can AED. The feeling of well-being is at risk, not only of the child, but of parents or guardians and siblings as well. Decrease of seizure severity and improvement of seizure control do have a positive spin-off for the child and have an effect on the entire family. This is why it is even more important to evaluate thoroughly the quality of life of the child and family, an aspect whose importance is probably underestimated and therefore insufficiently evaluated. Cost effectiveness is another aspect which we did not measure. The reasons for overall satisfaction of parents and caregivers during this study are difficult to explain. The decrease in seizure severity, improved mood and alertness and lack of side-effects might all have contributed, but there may be other factors.

\section{Future perspective}

There is more to efficacy of treatment in refractory epilepsy than seizure frequency reduction. Although we did not unequivocally demonstrate an effect on seizure frequency reduction, retention rate is remarkably high. The satisfaction of parents or guardians was impressive, not only because side-effects were mild and transient. Other beneficial attributing factors may have contributed - diverse network-modifying effects through a large number of processes in the brain.

We recommend evaluation of QoL of both the child and family as a standard procedure in assessing treatment effect in refractory epilepsy. We would also suggest implementing evaluation of cost effectiveness as a secondary outcome measure, especially in refractory childhood epilepsy.

More data on VNS in children are required before concluding that VNS therapy is ineffective. We must also broaden the horizon concerning standard outcome parameters, as mentioned earlier. Furthermore, points of interest for future research could be stimulation parameters applied in children and (beneficial) effects on sleep.

New devices have been developed, electrodes have been refined and extra options, such as response to tachycardia, are under evaluation (Aspire). Tailor-made stimulation programs with supplementary information on seizure-related symptoms (e.g. cardiac, respiratory, perspiratory changes or a combination) can help to detect seizures as early as possible and to respond with extra stimulation or a change in parameter settings. Selfmanagement strategies for parents or guardians also need to be explored, as one of the key factors in the burden of refractory epilepsy is lack of control. ${ }^{17}$ Then, a small degree of carer-autonomy might be restored.

One of the important thresholds of this neuro-modulating therapy which should be considered early on in the treatment trajectory is the surgical procedure itself. Fine- 
tuning in the development of external devices to identify in advance possible responders could remove one of the barriers. Since the ear is the only area where afferent neurons of the vagus nerve reach the surface of the human body, an auricular device has been developed. Limited studies have been performed with this application, stimulating two or three times daily for a period of one hour. Success rates must, therefore, be regarded with some caution. ${ }^{18,19}$ Experience with the auricular device is limited, especially in children ${ }^{20}$ and alternative methods for external stimulation need to be explored. Other ways of identifying responders to VNS therapy would be of particular interest and require further investigation, as does our finding that IL6 is a marker of a clinical responder to VNS therapy. We also have to explore if anthranilic acid, a tryptophan metabolite that increases during VNS treatment, is of importance to identify responders.

\section{CONCLUSION}

VNS is a treatment alternative worthy of consideration early in the course of refractory epilepsy in children. It is safe and can contribute to improvement of seizure control, seizure severity, mood, behavior and, QoL. 


\section{REFERENCES}

1. Kwan P, Sander J. The natural history of epilepsy: an epidemiological view. J Neurol Neurosurg Psychiatry. 2004;75:1376-81.

2. Berg AT, Vickrey BG, Testa FM, Levy SR, Shinnar S, DiMario F, Smith S. How long does it take for epilepsy to become intractable? A prospective investigation. Ann Neurol. 2006;60:73-9.

3. Geerts A, Arts WF, Stroink H, Peeters E, Brouwer O, Peters B, Laan L, Van Donselaar C. Course and outcome of childhood epilepsy: A 15 - year follow - up of the Dutch Study of Epilepsy in Childhood. Epilepsia. 2010;51:1189-97.

4. Baca CB, Vickrey BG, Caplan R, Vassar SD, Berg AT. Psychiatric and medical comorbidity and quality of life outcomes in childhood-onset epilepsy. Pediatrics. 2011;128:e1532-e43.

5. Handforth A, DeGiorgio CM, Schachter SC, Uthman BM, Naritoku DK, Tecoma ES, Henry TR, Collins SD, Vaughn BV, Gilmartin RC, Labar DR, Morris GL, 3rd, Salinsky MC, Osorio I, Ristanovic RK, Labiner DM, Jones JC, Murphy JV, Ney GC, Wheless JW. Vagus nerve stimulation therapy for partial-onset seizures: a randomized active-control trial. Neurology. 1998;51:48-55.

6. The VNS Study Group. A randomized controlled trial of chronic vagus nerve stimulation for treatment of medically intractable seizures. Neurology. 1995;45:224-30.

7. Vezzani A, French J, Bartfai T, Baram TZ. The role of inflammation in epilepsy. Nat Rev Neurol. 2011;7: 3140.

8. Tracey KJ. Physiology and immunology of the cholinergic antiinflammatory pathway. J Clin Invest. 2007;117:289-96.

9. Rush AJ, Siefert SE. Clinical issues in considering vagus nerve stimulation for treatment-resistant depression. Exp Neurol. 2009;219:36-43.

10. Koo B, Ham SD, Sood S, Tarver B. Human vagus nerve electrophysiology: a guide to vagus nerve stimulation parameters. J Clin Neurophysiol. 2001;18:429-33.

11. De Herdt V, Boon P, Ceulemans B, Hauman H, Lagae L, Legros B, Sadzot B, Van Bogaert P, van Rijckevorsel K, Verhelst H, Vonck K. Vagus nerve stimulation for refractory epilepsy: a Belgian multicenter study. Eur J Paediatr Neurol. 2007;11:261-9.

12. Helmers SL, Wheless JW, Frost M, Gates J, Levisohn P, Tardo C, Conry JA, Yalnizoglu D, Madsen JR. Vagus nerve stimulation therapy in pediatric patients with refractory epilepsy: retrospective study. J Child Neurol. 2001;16:843-8.

13. Coykendall DS, Gauderer MW, Blouin RR, Morales A. Vagus nerve stimulation for the management of seizures in children: an 8-year experience. J Pediatr Surg. 2010;45: 479-83.

14. Thompson EM, Wozniak SE, Roberts CM, Kao A, Anderson VC, Selden NR. Vagus nerve stimulation for partial and generalized epilepsy from infancy to adolescence: Clinical article. J Neurosurg Pediatr 2012;10:200-5.

15. Beekwilder JP, Beems T. Overview of the clinical applications of vagus nerve stimulation. J Clin Neurophysiol. 2010;27: 130-8.

16. McHugh JC, Singh HW, Phillips J, Murphy K, Doherty CP, Delanty N. Outcome measurement after vagal nerve stimulation therapy: proposal of a new classification. Epilepsia. 2007;48:375-8.

17. DiIorio CK, Bamps YA, Edwards AL, Escoffery C, Thompson NJ, Begley CE, Shegog R, Clark NM, Selwa L, Stoll SC. The prevention research centers' managing epilepsy well network. Epilepsy Behav. 2010; 19:218-24.

18. Stefan H, Kreiselmeyer G, Kerling F, Kurzbuch K, Rauch C, Heers M, Kasper BS, Hammen T, Rzonsa M, Pauli E. Transcutaneous vagus nerve stimulation $(t-V N S)$ in pharmacoresistant epilepsies: A proof of concept trial. Epilepsia. 2012;53:e115-e8.

19. Peijing R, Aihua L, Jianguo Z, Yuping W, Anchao Y, Liang L, Hui B, Liping L, Rupeng L, Wei H. An alternative therapy for drug-resistant epilepsy: transcutaneous auricular vagus nerve stimulation. Chin Med J. 2014;127:300-4.

20. He W, Jing X, Wang X, Rong P, Li L, Shi H, Shang H, Wang Y, Zhang J, Zhu B. Transcutaneous auricular vagus nerve stimulation as a complementary therapy for pediatric epilepsy: a pilot trial. Epilepsy Behav. 2013;28:343-6. 

Discussie en samenvatting

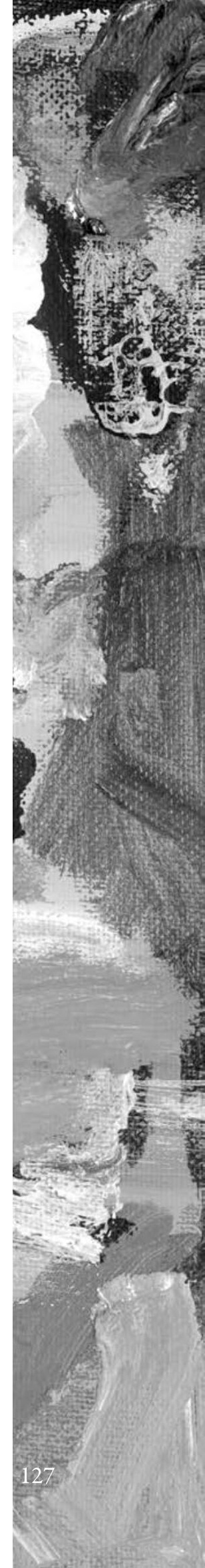



Epilepsie is één van de meest voorkomende neurologische aandoeningen, zowel bij volwassenen als bij kinderen. $\mathrm{Bij} 70$ tot $80 \%$ van de patiënten met epilepsie wordt een goede aanvalscontrole bereikt met anti-epileptica. De meest voorkomende bijkomende problemen bij kinderen met epilepsie zijn een ontwikkelingsachterstand en psychiatrische aandoeningen. Bij moeilijk behandelbare epilepsie komt dit zelfs vaker voor. Nervus Vagus Stimulatie (NVS) is een aanvullende neuro-modulerende behandelingsmogelijkheid voor epilepsie. Het is een goed behandelalternatief voor patiënten met epilepsie als epileptische aanvallen niet, of onvoldoende, reageren op medicatie en epilepsiechirurgie met als doel aanvalsvrijheid niet mogelijk is. De effectiviteit en veiligheid van NVS is aangetoond in gerandomiseerde actief gecontroleerde studies met hoofdzakelijk volwassenen. De deelnemers in deze studies werden gerandomiseerd waarbij ze óf hoog (therapeutisch) óf laag (actieve controle) gestimuleerd werden. Er wordt vanuit gegaan dat de gebruikte stimulatieparameters in de actieve controlegroep niet effectief zijn. Afname van aanvalsfrequentie van $50 \%$ of meer werd bereikt bij 28 $31 \%$ van de deelnemers met moeilijk behandelbare epilepsie in de therapeutisch gestimuleerde groep. In de actieve controlegroep werd dit bij 13-15\% bereikt. Slechts in een zeer select aantal deelnemers werd volledige aanvalsvrijheid bereikt. Bij kinderen is er nog geen onomstotelijk bewijs geleverd over de effectiviteit van NVS. In de literatuur variëren de getallen met betrekking tot effectiviteit (> 50\% aanvalsreductie) sterk.

Het doel van dit proefschrift is meer inzicht verkrijgen in het effect van NVS bij kinderen met moeilijk behandelbare epilepsie. Hoofdstuk 1 is een algemene introductie om het huidige beeld te schetsen. In hoofdstuk 2 beschrijven we een systematisch zoektocht en geven we een overzicht van de literatuur over NVS bij kinderen met moeilijk behandelbare epilepsie. Effectiviteit, dat wil zeggen een afname van aanvalsfrequentie, varieert (0-90\%) tussen de verschillende studies. De studiepopulaties verschilden ook in aantal kinderen, leeftijd, epilepsie syndromen en de duur van de follow-up. De meerderheid van de onderzoeken was retrospectief en de prospectieve studies maakten geen gebruik van controle groepen. Een meta-analyse betreffende de effectiviteit van NVS met prospectief verzamelde gegevens van 326 kinderentoonde aan dat de aanvalsfrequentie minstens halveerde bij 38\%. De gebruikte instellingen van het NVSapparaat zijn vergelijkbaar in de verschillende studies, maar voor de optimale instellingen voor kinderen ontbreekt bewijs. 'Rapid cycling'is een stimulatiemethode waarbij de parameters zodanig worden aangepast dat de periode dat er geen pulsen worden gegeven verkort wordt tot minder dan 1.8 minuut. De aanvullende waarde hiervan moet nog worden aagetoond. Stoppen van een epileptische aanval lukt soms door gebruik te maken van de bijgeleverde magneet die zorgt voor stimulatie op verzoek. Het bewijs dat dit effectief is, is eveneens vrij beperkt. Het is tot nu toe niet mogelijk om voor aanvang van de behandeling een specifieke patiënten categorie (een subpopulatie) aan te wijzen die goed zal reageren op NVS. De behandeling wordt goed verdragen door kinderen met moeilijk behandelbare epilepsie. Het risico op infectie of blijvende neurologische problemen bij de implantatieprocedure is zeer klein. Stimulatie-gerelateerde bijwerkin- 
gen treden daarentegen zeer frequent op (70-80\%), met name aan het begin van de behandeling. Bij vrijwel alle kinderen verdwijnen deze bijwerkingen spontaan na verloop van tijd, of kunnen ze eenvoudig verholpen worden door aanpassing van de stimulatie parameters. Er zijn aanwijzingen dat NVS de slaapkwaliteit verbetert. Dit zou kunnen komen door het directe stimulatie-effect op de hersenen zelf of door de afname van aanvalsfrequentie. Er moet aandacht besteed worden aan veranderde ademhalingspatronen tijdens de slaap vóórdat een stimulator geïmplanteerd wordt. Dit is met name van belang bij kinderen met een verstandelijke beperking, obesitas en/of grote tonsillen. Tijdens de behandeling moet er gevraagd worden naar een veranderd ademhalingspatroon tijdens de slaap, zoals snurken of ademstops als gevolg van specifieke stimulator instellingen bij een kind met risico factoren voor een obstructief slaap-apneu-syndroom. Ook in geval van overmatige slaperigheid overdag moeten stimulus-gerelateerde veranderingen van het ademhalingspatroon tijdens de slaap overwogen worden. Er is tot nu toe geen bewijs dat NVS (neuro)immunologische veranderingen teweeg kan brengen bij kinderen. Er zijn geen negatieve effecten van NVS op gedrag gerapporteerd. NVS kan bijdragen aan verbetering van gedrag en stemming. Twee studies bij kinderen tonen een kostenbesparend effect aan van NVS als behandeling van therapieresistente epilepsie. Het aantal kinderen in deze studies en de duur van deze studies zijn echter beperkt. Deze behandeling heeft geen negatief effect op kwaliteit van leven. De meerderheid van de studies rapporteren een stabiele kwaliteit van leven of een verbetering van onderdelen van vragenlijsten over kwaliteit van leven. In de literatuur is er geen consensus betreffende de relatie tussen afname van aanvallen en positief effect op de kwaliteit van leven.

\section{Aanpak}

Om meer informatie te verzamelen over NVS hebben we als eerste een gerandomiseerde actief gecontroleerde dubbelblinde studie gedaan bij kinderen met therapie resistente epilepsie (hoofdstukken 3 tot en met 5 en 7). In hoofdstuk 6 beschrijven we de resultaten van een prospectieve cohortstudie bij volwassenen.

Voor de gerandomiseerde gecontroleerde studie (RCT) hebben ouders en/of verzorgers aanvallen bijgehouden in een aanvalsdagboek. Zij begonnen hiermee gedurende de baseline periode van 12 weken en hebben dit dagboek gedurende de rest van de studie bijgehouden. $\mathrm{Na}$ de baseline periode werd de stimulator geïmplanteerd. De kinderen werden tijdens de behandelfase gerandomiseerd voor hoge (therapeutisch) dan wel lage (actieve controle) stimulatie gedurende een periode van 20 weken. De stimulator werd twee weken na de implantatie aangezet en stapsgewijs opgehoogd in de therapeutische groep en tijdelijk opgehoogd en weer lager gezet in de actieve controlegroep volgens een vast protocol. Aanpassing van stimulatieparameters gebeurde op vaste bezoekmomenten tot dat een afname van aanvallen van meer dan $50 \%$ werd bereikt of verdere aanpassing niet verdragen werd gedurende de dubbelblinde fase. Daarna kregen alle kinderen gedurende een periode van 19 weken nog therapeutische stimulatie (open label fase). Er werden 41 kinderen, 18 meisjes en 23 jongens, met therapie resistente epilepsie 
geïncludeerd in de studie. Zij kregen allen een nervus vagus stimulator geïmplanteerd. De gemiddelde leeftijd bij implantatie was 11 jaar en varieerde van vier tot 17 jaar. Bij het debuut van de epilepsie was de gemiddelde leeftijd twee jaar (range 0-12 jaar). De studieopzet en data die verzameld werden tijdens de studie staan vermeld in Figuur 9.1. Daarnaast hebben we ook een prospectieve cohortstudie uitgevoerd bij 41 volwassenen, 22 vrouwen en 19 mannen. De gemiddelde leeftijd bij implantatie was 31 jaar en varieerde van 22 tot 61 jaar. Gegevens betreffende stemming, kwaliteit van leven en cognitie werden twee maal verzameld, bij baseline en aan het einde van de studie, zes maanden later. Tijdens de baseline periode van drie maanden en gedurende de studie van zes maanden werden aanvalsdagboeken bijgehouden.

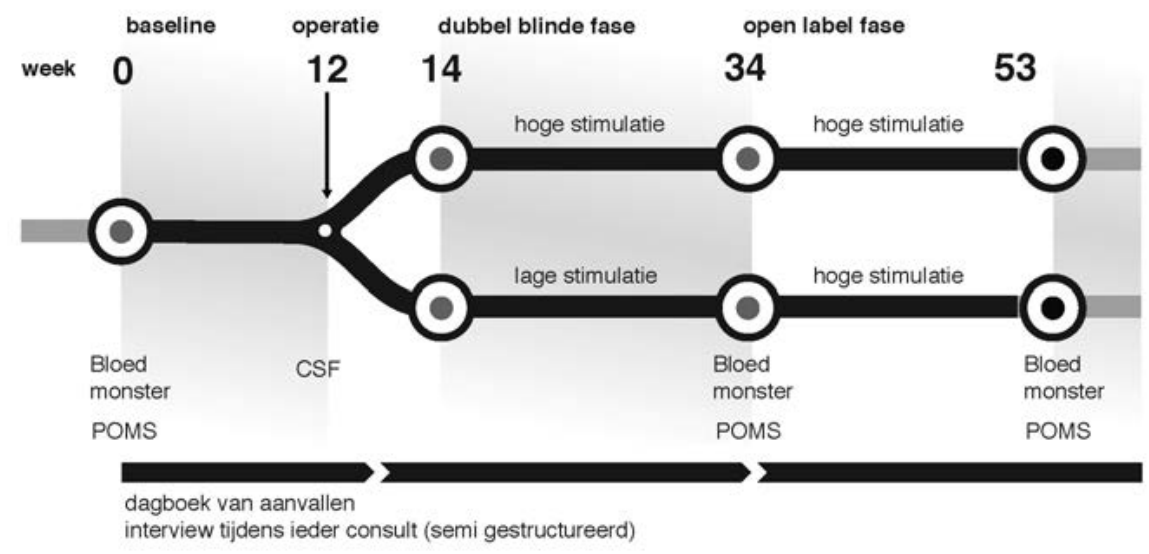

Figuur 9.1 Studie design.

Overzicht van tijdslijn, interventies, verschillende fasen in de studie en verzamel-momenten van data (o.a. aanvalsdagboeken, vragenlijsten, neuropsychologische data) en materialen (bloed en liquor). Na een baselineperiode van 12 weken werd de nervus vagus stimulator geïmplanteerd bij de kinderen. Tijdens de dubbelblinde fase (20 weken) kreeg de helft van de kinderen hoge stimulatie en de andere helft lage stimulatie. Tijdens de open label fase (19 weken) kregen alle kinderen hoge stimulatie.

\section{Effectiviteit en veiligheid}

In hoofdstuk 3 beschrijven we de effecten op aanvallen bij kinderen met therapie resistente epilepsie. We evalueren ook de mogelijke bijwerkingen gerelateerd aan de implantatie en aan de stimulatie. Er is geen verschil tussen de therapeutische geroep en de actieve controle groep met betrekking tot afname van aanvalsfrequentie noch met aanvalsernst aan het einde van de dubbelblinde fase. NVS reduceert zowel aanvalsfrequentie als aanvalsernst aan het einde van de open label fase. NVS blijkt goed te worden verdragen en veilig gegeven te kunnen worden als aanvullende behandeling bij kinderen met therapie resistente epilepsie. De gerapporteerde resultaten in de NVSstudies bij volwassenen bevestigen wij niet. Waarschijnlijk hebben meer factoren daaraan 
bijgedragen. Een van deze factoren is de grootte van de studiepopulatie. Deze is bepaald aan de hand van een power analyse gebaseerd op de resultaten van open label studies. Deze resultaten geven waarschijnlijk een te gunstige inschatting van het effect bij kinderen. Een andere factor is de heterogeniteit in etiologie en leeftijd.

\section{Neuro- immuun- modulerende effecten}

De nervus vagus heeft een belangrijke anti-inflammatoire rol die een relevante bijdragende factor zou kunnen zijn voor het gunstige effect van NVS. Inflammatie is één van de processen die betrokken zijn bij de ontwikkeling van aanvallen en epilepsie. Tracey et al. nemen aan dat NVS zou kunnen leiden tot een inhibitie van het vrijkomen van proinflammatoire cytokines door de invloed van NVS op de cholinerge anti-inflammatoire route. Wij onderzochten het effect van NVS op cytokine spiegels in plasma en liquor bij kinderen met therapieresistente epilepsie (hoofdstuk 4). Wij hebben gekeken naar veranderingen in het cytokine profiel tijdens de behandeling. Voorspellers voor een goed effect van NVS ontbreken op dit moment daarom wilden wij graag weten of bepaalde veranderingen in cytokines de klinische respons zouden kunnen voorspellen.

Wij vonden geen veranderingen in de interictaal gemeten interleukine- $1 \beta$, interleukine- 6 of interleukine-10 plasmaspiegels gedurende de gehele studie. Mogelijk is de verandering in het cytokineprofiel tijdelijk en kan deze alleen kort na een aanval aangetoond worden. Gebaseerd op een paar meetmomenten in bloed en slechts eenmaal in liquor waren wij slechts in staat een explorerende studie uit te voeren. Meer frequente bloed- en liquorbepalingen waren in dit stadium niet ethisch verantwoord. De klinische conditie van ieder kind kan, los van de epilepsie, ook interfereren met de immunologische status, bijvoorbeeld een eenvoudige verkoudheid. Een lagere baseline plasmaspiegel van interleukine- 6 werd geassocieerd met een grotere aanvalsreductie door NVS, dit lijkt derhalve mogelijk een gunstige prognostisch factor.

\section{Stemmingsregulerende effecten}

Tijdens behandeling met NVS is een verbetering van stemming merkbaar. Aangezien psychiatrische aandoeningen de meest voorkomende co-morbiditeit is bij zowel volwassenen als kinderen met epilepsie hebben we het stemmingsregulerende effect van NVS voor de behandeling van therapieresistente epilepsie onderzocht. Onze bevindingen worden uiteengezet in hoofdstuk 5 tot en met 7 .

Eén van de theorieën voor het werkingsmechanisme van NVS is het initiëren van cytokineveranderingen. Dergelijke veranderingen kunnen leiden tot een nieuw evenwicht in het vrijkomen van neurotoxische en neuroprotectieve tryptofaanmetabolieten. Tryptofaan is een precursor van serotonine $(5-\mathrm{HT})$, een neurotransmitter betrokken bij de regulatie van stemming, emoties en slaap. Onder invloed van proinflammatoire cytokines gaat tryptofaan, in plaats van omgezet te worden in 5-HT, de 'tryptophan metabolic pathway' in. 
In het epileptische brein bevinden zich pro-inflammatoire cytokines en ook de 'tryptophan metabolic pathway' zou meer actief kunnen zijn. Een aantal tryptofaan metabolieten hebben invloed op het ontstaan van epileptische aanvallen. De anti-convulsieve effecten van NVS zouden deels verklaard kunnen worden door de manier waarop deze omzettingsroute van tryptofaan door NVS wordt beïnvloedt. Hoofdstuk 5 beschrijft hoe wij het effect van NVS op de tryptofaanmetabolieten bij kinderen met therapieresistente epilepsie evalueerden. We maakten gebruik van verschillende meetmomenten per kind, zodat dit kon dienen als controle. Bovendien bevestigden wij de veronderstelde 'tryptophan metabolic pathway' doordat wij een consistente positieve correlatie vonden tussen de verschillende tryptofaanmetabolieten bij de baseline meting. Daarnaast onderzochten wij of er een correlatie bestond tussen het positieve effect van NVS op aanvallen en veranderingen in het tryptofaanmetabolisme. De serumconcentratie van antranilzuur, een neuroprotectieve metaboliet met anti-convulsieve eigenschappen, steeg gedurende de behandeling met NVS. Deze stijging was gecorreleerd met verbetering van zowel stemming als aanvalsfrequentie. Onze poging om het effect van NVS op cytokines en tryptofaan metabolisme te ontrafelen was een uitdaging. Veranderingen in antranilzuurconcentratie gedurende de gehele stimulatie periode veronderstelt een positief effect van NVS op deze route. Het netwerk van interacties is echter bijzonder complex en er zijn zonder twijfel verscheidene factoren die dit beïnvloeden die wij niet hebben kunnen aantonen.

Onderzoek van liquor geeft de best beschikbare afspiegeling van de tryptofaan- metabolieten in het centrale zenuwstelsel, slechts 10-20\% van de 5-HT-synthese gebeurt in de hersenen. Informatie van tryptofaan metabolieten verkregen uit liquor tijdens de behandeling met NVS zou extra informatief geweest zijn, maar uit zowel ethische als praktische overwegingen hebben we slechts eenmaal liquor verkregen namelijk, voor de implantatie van het NVS-apparaat. De kinderen waren op dat moment onder algehele narcose. Voedingsdagboeken van de kinderen zouden eveneens een waardevolle bron van informatie geweest kunnen zijn bij de interpretatie van de verschillende concentraties van de tryptofaanmetabolieten. In hoofdstuk 6 rapporteren wij het effect van NVS op stemming in een prospectief longitudinaal cohort van 41 volwassenen die zijn behandeld met NVS als onderdeel van een standaard behandeling. Stemming verbeterde gedurende de studieperiode net als de kwaliteit van leven. Deze verbeteringen traden op ongeacht het effect op de aanvallen. Bij kinderen zagen we met name na een langere periode van therapeutische stimulatie een verbetering van stemming (hoofdstuk 7). Tijdens de dubbelblinde fase was er geen significant verschil tussen de 'hoge' en 'lage' behandelgroep voor wat betreft stemming. Het positieve effect op stemming trad op onafhankelijk van verbetering van aanvalscontrole. Hieruit concluderen wij dat NVS ook een effect heeft op stemming. Wij nemen aan dat de stemmingsregulerende invloed van NVS tijd kost. In studies naar het effect van NVS op therapie resistente depressie worden vergelijkbare resultaten gevonden, waarbij er gedurende het eerste jaar van de behandeling verbeteringen worden gezien. 


\section{Bijkomende voordelen}

Therapieresistente epilepsie is geassocieerd met cognitieve beperkingen. Met name bij kinderen kunnen de aanvallen verstorend werken op hun intellectuele en sociale ontwikkeling. Ook anti-epileptica kunnen een negatieve impact hebben op cognitie. Cognitie bleef stabiel, zowel bij de studie met kinderen (hoofdstuk 7) als bij de studie met volwassenen (hoofdstuk 6). Anti-epileptica werden niet aangepast tijdens de studies. Zowel kinderen als volwassenen gebruikten gemiddeld twee of meer antiepileptica. Door polytherapie neemt het risico op een nadelige effect van medicatie op het gedrag toe. Wij hebben, gezien de studieopzet en vraagstelling, geen aanpassingen gedaan aan de anti-epileptica. Reductie van het aantal middelen of de dosering, of een combinatie van beide zou zeker een overweging kunnen zijn bij een langere studieduur. NVS heeft geen negatief effect op gedrag. Wij hebben echter ook geen positief effect van NVS kunnen aantonen op het gedrag van de kinderen tijdens de duur van de gerandomiseerde gecontroleerde studie. Ook vonden wij geen verbetering in epilepsie-gerelateerde beperkingen noch in psychosociale aanpassingen (hoofdstuk 7). Mogelijk dat het bescheiden aantal kinderen met een goed effect van NVS op hun aanvalsfrequentie de oorzaak is van het ontbreken van een significant effect. Ondanks het beperkte effect op aanvalsfrequentiereductie was de algehele tevredenheid opvallend hoog. Wij hebben de kwaliteit van leven bij kinderen niet specifiek gemeten. Bij volwassenen verbeterde de kwaliteit van leven tijdens de behandeling met NVS; ongeacht het effect op de aanvallen (hoofdstuk 6).

\section{Wat hebben we geleerd?}

Behandeling met NVS bij kinderen met therapieresistente epilepsie is veilig en wordt goed verdragen. De effectiviteit, dat wil zeggen het aantal kinderen bij wiede aanvalsfrequentie minimaal halveert, is bescheiden, zeker tijdens de dubbel blinde fase. Opvallend genoeg is het aantal kinderen dat de studie afrondt groot, dat zelfde geldt voor de tevredenheid van ouders en/of verzorgers. Bovendien was er ook een afname van aanvalsernst. NVS heeft geen negatieve effecten op cognitie of gedrag bij kinderen. Tijdens de behandeling met NVS werden geen veranderingen gevonden in het cytokineprofiel die het effect van NVS op de cholinerge anti-inflammatoire route aantonen. De waarde van interleukine- 6 in het bloed voor de implantatie van een stimulator, heeft mogelijk een voorspellende waarde. Het effect van NVS op aanvallen bij kinderen staat los van het effect van NVS op stemming; dit is een indicatie voor een aanvullend stemmings verbeterend effect. Behoudens de stijging van concentraties van antranilzuur, een neuroprotectieve metaboliet met anti-convulsieve eigenschappen, konden wij geen veranderingen aantonen in specifieke metabolieten van de 'tryptophan metabolic pathway' tijdens behandeling met NVS bij kinderen.

In het prospectieve volwassencohort met therapie resistente epilepsie resulteerde de behandeling met NVS in een verbetering van stemming en kwaliteit van leven bij een 
follow-up duur van zes maanden. Effect van NVS-behandeling op stemming was niet gerelateerd aan een afname van aanvalsfrequentie bij volwassenen. Cognitie bleef stabiel.

\section{Wat kunnen we nog leren?}

Er zijn nog steeds veel vragen onbeantwoord over het effect van NVS-behandeling op aanvalsfrequentie en over secundaire effecten bij kinderen met therapie- resistente epilepsie. Is er een aanwijsbare reden voor het verschil in effect van deze neuromodulerende behandeling tussen kinderen en volwassenen? Er bestaan neurofysiologische verschillen van de nervus vagus wanneer volwassenen vergeleken worden met kinderen. Bij de jongere kinderen is de maturatie nog onvolledig. Zenuwgeleiding bij jongere kinderen kenmerkt zich door lagere geleidingssnelheden en hogere drempelwaarden. De gekozen stimulatieparameters zouden suboptimaal geweest kunnen zijn voor een aantal kinderen. Ook is voor te stellen dat zich nog ontwikkelende hersenen anders reageren dan hersenen van volwassenen. De Herdt et al. toonden aan dat respons op NVS gerelateerd is aan leeftijd, ten nadele van de kinderen, wanneer zij vergeleken werden met volwassenen. Er zijn echter ook een aantal retrospectieve studies bij kinderen die deze leeftijd gerelateerde verschillen niet aantoonden, bijvoorbeeld wanneer kinderen onder de twaalf jaar werden vergeleken met kinderen van twaalf jaar en ouder.

Bij een meerderheid van de kinderen waren er geen behandelalternatieven meer voor de epilepsie en was NVS een laatste behandeloptie. Dus zelfs de kleinste verbetering zonder nadelige effecten is winst in deze patiëntencategorie. Het onderliggende werkingsmechanisme of netwerk van NVS is nog altijd niet ontrafeld ondanks meer dan twee decennia van onderzoek. Niettemin geeft de nervus vagus een unieke gelegenheid om subcorticale hersenstructuren te moduleren. Er worden nog altijd positieve additionele effecten onderzocht, op bijvoorbeeld stemming, migraine, de ziekte van Alzheimer en eetstoornissen, maar dit gebeurt niet voor alle toepassingen op grote schaal.

Bij kinderen met therapieresistente epilepsie, een chronische aandoening met een groot aantal onzekere factoren, draait het niet meer alleen om reductie van aanvalsfrequentie. McHugh et al. stelden al een nieuwe classificatie voor om het effect van NVS te evalueren, waarbij ook aanvullende informatie wordt meegenomen over ictale ernst en duur van postictale conditie en reactie op gebruik van de magneet op verzoek. Verdere uitbreiding van primaire uitkomstmaten bij therapieresistente epilepsie zou overwogen kunnen worden. Therapieresistente epilepsie kan een negatieve impact hebben op ontwikkeling, cognitie en gedrag van kinderen, net als anti-epileptica. Het gevoel van welbevinden staat op het spel, niet alleen van het kind, maar ook van ouders/verzorgers en andere kinderen binnen het gezin. Afname van aanvalsernst en verbetering van aanvalscontrole hebben een positieve effect op het kind. Deze verbeteringen kunnen ook een positieve weerslag hebben op het gehele gezin. Dit geeft het belang aan van het goed in acht nemen van de kwaliteit van leven van het kind en diens gezin. Dit aspect wordt mogelijk onderschat en om die reden onvoldoende geëvalueerd. Wij hebben niet gekeken naar kosteneffectiviteit van deze behandeling. Het is lastig om de grote tevredenheid van 
ouders en verzorgers te verklaren. Mogelijk hebben afname van aanvalsernst, verbeterde stemming, alertheid en het ontbreken van bijwerkingen hieraan een bijdrage geleverd, maar er kunnen ook andere factoren zijn.

\section{Toekomstperspectief}

Bij de behandeling van therapieresistente epilepsie spelen naast louter aanvalsreductie ook andere factoren een rol als het gaat om effectiviteit van een behandeling. Ondanks het feit dat wij geen onomstotelijk bewijs voor effect op aanvalsfrequentie leverden, is het aantal kinderen dat gedurende de gehele studie de behandeling continueerde opvallend hoog. De tevredenheid bij ouders of verzorgers was groot, waarschijnlijk niet alleen omdat de bijwerkingen relatief beperkt en van voorbijgaande aard waren. Mogelijk dat modificatie van netwerken door NVS, middels een invloed op een groot aantal processen in de hersenen, nog gezorgd heeft voor andere positieve factoren die hieraan hebben bijgedragen.

Wij bevelen aan om de kwaliteit van leven van zowel kind als het gezin als standaardprocedure mee te nemen bij evaluatie van effectiviteit van behandeling bij therapieresistente epilepsie. Ook zouden wij kosteneffectiviteit als secundaire uitkomst-maat aanraden, juist bij therapie resistente epilepsie bij kinderen. Er zijn meer gegevens nodig alvorens de conclusie getrokken kan worden dat NVS effectief is bij kinderen. We moeten de horizon verbreden als het gaat om standaard-uitkomstmaten, zoals eerder genoemd. Daarnaast zouden stimulatieparameters toegepast bij kinderen en (positieve) effect op slaap punten van aandacht kunnen zijn bij vervolgonderzoek. Inmiddels worden er al nieuwe apparaten ontwikkeld, electroden worden verbeterd en extra mogelijkheden, zoals een reactie van de stimulator op een versnelling van de hartslag, als vroeg symptoom van een insult worden nu geëvalueerd (Aspire). Een aan het individu aangepast stimulatie programma met integratie van bijvoorbeeld aanvullende informatie van aanval gerelateerde symptomen als hartslag, ademhaling, transpiratie of een combinatie van symptomen zou kunnen helpen bij het zo vroeg mogelijk detecteren van aanvallen met als resultaat een extra stimulatie of aanpassing van de stimulatieparameters. Mogelijkheden voor 'zelfmanagement' voor ouders of verzorgers en de kinderen zouden verder onderzocht kunnen worden. Het gebrek aan controle speelt een sleutelrol bij de ziektelast van therapie resistente epilepsie. Een deel van de autonomie van de kinderen en hun directe omgeving zou hiermee kunnen worden hersteld.

Deze neuromodulerende behandeling kan vroeg in het behandeltraject overwogen worden. Eén van de belangrijke drempels voor deze neuromodulerende behandeling is de operatieve ingreep zelf. Afstemming bij ontwikkeling van extern toepasbare apparaten om vroegtijdig kinderen die baat hebben bij behandeling met NVS te identificeren. Dit zou een barrière kunnen wegnemen. Er is een auriculair apparaat ontwikkeld, aangezien het oor een gebied is waar afferente neuronen van de nervus vagus de oppervlakte van het menselijk lichaam bereiken. Er zijn slechts een beperkt aantal studies uitgevoerd die deze toepassing onderzoeken, waarbij twee tot drie maal daags gedurende een uur gestimu- 
leerd wordt. Succeservaringen moeten om die reden met enige terughoudendheid bekeken worden. De ervaringen met dergelijke externe apparaatjes is beperkt. Bij kinderen zouden deze mogelijkheden voor externe stimulatie eveneens verder geëxploreerd kunnen worden. Er is veel interesse om op voorafgaand aan implantatie van NVSapparaat al patiënten te kunnen identificeren die baat hebben bij de behandeling, hier zou zeker meer onderzoek naar gedaan kunnen worden. Onze bevinding dat de waarde van interleukine- 6 bij baseline een mogelijke marker zou kunnen zijn voor de patiënten die goed zullen reageren op de behandeling met NVS is een mogelijk onderwerp voor verder onderzoek. Hetzelfde geldt voor antranilzuur.

\section{CONCLUSIE}

NVS is een behandelalternatief dat al vroeg in het beloop van therapieresistente epilepsie bij kinderen het overwegen waard is. De behandeling is veilig en kan een bijdrage leveren aan verbetering van aanvalscontrole, aanvalsernst, stemming, gedrag en kwaliteit van leven. 



\section{ADDENDUM VALORISATIE \\ Vertaling van wetenschap naar maatschappij}

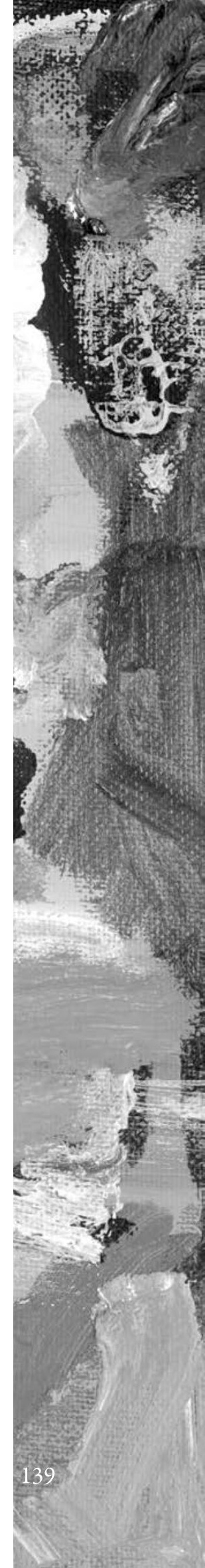




\section{SAMENVATTING}

Dit hoofdstuk beschrijft wat de onderzoeken gebundeld in dit proefschrift concreet aan resultaten hebben opgeleverd en op welke manier deze resultaten van waarde kunnen zijn voor de maatschappij. We gaan in op de mogelijke maatschappelijke relevantie van deze bevindingen. Verder beschrijven we voor welke doelgroepen, ook buiten het medische veld, deze nieuwe informatie van waarde zou kunnen zijn en op welke manier we deze kennis kunnen delen. Vervolgens geven we een korte beschouwing over de mogelijkheden om onze resultaten om te zetten in concrete producten en innovatie. Tot slot bespreken we hoe de verworven kennis uit dit onderzoek kunnen vertalen in een vervolgtraject. 


\section{Introductie}

De Vereniging van Universiteiten (VSNU) behartigt de belangen van de 14 Nederlandse universiteiten tegenover het kabinet, de politiek, overheid en maatschappelijke organisaties. Eén van de doelen van deze vereniging is het versterken van de Nederlandse kenniseconomie; valorisatie van wetenschappelijk onderzoek levert hieraan een belangrijke bijdrage.

De definitie van het begrip valorisatie volgens de VSNU is als volgt: 'Het proces van waarde creatie uit kennis, door kennis geschikt en/of beschikbaar te maken voor economische en/of maatschappelijke benutting en geschikt te maken voor vertaling in concurrerende producten, diensten, processen en nieuwe bedrijvigheid.' (VSNU Raamwerk valorisatie-indicatoren)

\section{Maatschappelijke relevantie}

Epilepsie is een veel voorkomende neurologische aandoening: in Nederland heeft ongeveer 1 op de 150 mensen epilepsie. Bij ongeveer de helft van deze mensen is de epilepsie ontstaan op de kinderleeftijd. Kinderen maken dan ook een groot deel uit van deze patiëntenpopulatie.

Bij ongeveer 70 tot $80 \%$ van deze patiënten kunnen de aanvallen onder controle blijven of zelfs geheel uitblijven dankzij behandeling met medicijnen. Daarnaast is er op kinderleeftijd een aantal epilepsiesyndromen waar kinderen overheen kunnen groeien. Verder komt een klein deel van de epilepsiepatiënten, veelal met een hardnekkige vorm van epilepsie, in aanmerking voor een operatie waarbij de insteek aanvalsvrijheid is. Maar er is helaas ook een groep patiënten, bij wie er geen goede aanvalscontrole wordt bereikt met medicatie, die niet in aanmerking komt voor een operatie. Dat is de onderzoekspopulatie van dit proefschrift. Een behandelalternatief voor deze patiënten met therapieresistente epilepsie is Nervus Vagus Stimulatie (NVS). Over deze behandeling gaat dit proefschrift.

Epilepsie kenmerkt zich door terugkerende onvoorspelbare spontane aanvallen. Een belangrijk aandeel in de ziektelast is de onzekerheid óf en zo ja, wanneer een volgende aanval zich voordoet. Goede aanvalscontrole is dus van groot belang. Kinderen met therapieresistente epilepsie, maar ook hun ouders en eventuele broertjes en zusjes, worden dagelijks met deze onzekerheid geconfronteerd. Dat zelfde geldt voor volwassenen met epilepsie en hun naasten. $\mathrm{Zij}$ moeten rekening houden met de mogelijkheid van een aanval. Dit beperkt hen bij bepaalde activiteiten en dit beïnvloedt de kwaliteit van leven op een negatieve manier.

Er moet niet alleen altijd iemand aanwezig zijn die op de hoogte is van hoe te handelen in geval van een aanval, maar er zijn ook activiteiten die deze kinderen niet zo maar kunnen doen, bijvoorbeeld deelnemen aan het verkeer, of zwemmen. Voor volwassenen geldt dat bepaalde beroepen, waarbij bijvoorbeeld gewerkt wordt met zware machines of waarbij er op zekere hoogte gewerkt wordt, minder geschikt zijn. Ook heeft moeilijk behandelbare 
epilepsie consequenties voor het autorijden. Streven naar uitbreiding van behandelmogelijkheden, maar ook optimalisatie van bestaande behandelmogelijkheden kunnen om die reden een positieve bijdrage leveren aan de samenleving.

Een betere aanvalscontrole, afname van aanvalsernst en minder frequent optreden van een status epilepticus leiden alle tot een afname van de zorgkosten. Het aantal ziekenhuisopnames en ziekenhuisbezoeken zal afnemen doordat er minder frequent complicaties optreden door aanvallen. Bovendien heeft een betere aanvalscontrole bij kinderen effect op afname van werkverzuim bij ouders. De kosteneffectiviteit van deze behandeling werd reeds aangetoond.

\section{Resultaten}

Een deel van de kinderen met therapieresistente epilepsie reageert zeer goed op NVS, bij hen wordt een afname van meer dan 50\% van de aanvallen geconstateerd. Dit is een belangrijke winst voor deze moeilijk te behandelen groep patiënten. Bij de andere kinderen die NVS ondergingen zien we dit effect niet, maar wordt de stimulatie wel goed verdragen en zijn er geen nadelige effecten van deze behandeling op gedrag en cognitie. NVS is veilig bij kinderen, en er zijn in onze onderzoekspopulatie geen blijvende nadelen opgetreden als gevolg van dit behandelalternatief. Ouders en/of verzorgers waren uiterst tevreden over NVS, zelfs als er geen overtuigend effect werd gezien op aanvalsfrequentie. Gedurende de studieduur heeft geen enkel kind een status epilepticus doorgemaakt. We konden op verschillende wijzen de positieve effecten bevestigen. Niet alleen door de aanvalsfrequentie te vervolgen, maar ook door met vragenlijsten aanvalsernst en epilepsie gerelateerde beperkingen te evalueren, zowel voor aanvang van NVS, als op meerdere momenten tijdens de studie. Stemming en kwaliteit van leven verbeterden gedurende de studie. Doordat we in bloed en liquor keken naar immunologische parameters en tryptofaanmetabolisme verkregen we meer inzichten in de veronderstelde werkingsmechanismen. Zo bleek de stijging die wij vonden van antranilzuur tijdens de behandeling met NVS te correleren met een afname van aanvallen en een verbetering van stemming. Ook hebben we gezocht naar mogelijke factoren die positief effect van NVS voorspellen. Een lage baseline waarde van interleukine- 6 was geassocieerd met een betere aanvalsreductie.

\section{Doelgroepen}

Dit proefschrift beschrijft klinisch onderzoek, de belangrijkste doelgroep betreft derhalve patiënten met epilepsie. Zoals eerder aangegeven zijn de resultaten van ons onderzoek niet alleen relevant voor kinderen met therapieresistente epilepsie, maar ook voor hun ouders en/of verzorgers en eventuele broertjes en zusjes. Ook voor volwassenen met moeilijk behandelbare epilepsie en hun naasten zijn de resultaten relevant. Werkgevers van patiënten, of van ouders van patiënten kunnen direct voordeel bemerken van verbetering van behandeling van therapieresistente epilepsie, doordat er minder 
werkverzuim optreedt bij verbetering van aanvalscontrole en afname van epilepsiegerelateerde complicaties zoals een ziekenhuisopname. Deze behandeling blijkt binnen 2,5 jaar na implantatie kosteneffectief, dus ook de overheid kan voordeel hebben van deze behandeling door dat de zorgkosten afnemen. Bevestiging van de vermoedelijke werkingsmechanismen van NVS is relevant voor ons inzicht. Het draagt bij aan kennis voor neurologen en kinderneurologen, en anderen die betrokken bij de verfijning en ontwikkeling van behandelingen. De gepubliceerde artikelen zijn beschikbaar voor productontwikkelaars van neuromodulerende apparatuur en voor bedrijven die andere behandelmogelijkheden van epilepsie bieden. Gezien het positieve effect op stemming suggereren deze resultaten mogelijke toepassing van NVS voor de behandeling van stemmingsproblemen. Bevindingen kunnen derhalve ook relevant zijn voor patiënten met een depressie en hun behandelaars.

\section{Kennisoverdracht}

Aangezien ons onderzoek klinisch werk betrof, zijn deze bevindingen van directe waarde voor alle behandelaars van epilepsie en daarmee dus ook voor de patiënten met therapieresistente epilepsie en hun families.

Dit onderzoek had nooit kunnen plaatsvinden zonder intensieve samenwerking tussen neurologen en kinderneurologen, verpleegkundig specialisten, neurochirurgen, neuropsychologen, een klinisch chemicus, laboranten, geneeskundestudenten en een statisticus. Bundeling van kennis vanuit deze verschillende disciplines, maar ook het kijken vanuit verschillende invalshoeken draagt bij aan nieuwe inzichten en helpt bij interpretatie van bevindingen.

Onze onderzoeksresultaten hebben geleid tot diverse wetenschappelijke publicaties en wetenschappelijke voordrachten. De resultaten zijn daardoor ook beschikbaar voor bedrijven die zich bezig houden met behandelmogelijkheden voor epilepsie, zowel neuromodulerende behandelingen alsook farmaceutische behandelingen. Wij toonden niet alleen effect aan op de behandeling van epilepsie, maar onze behandeling had ook effect op stemming en dit was ongeacht het effect op aanvallen. Daarmee suggereren onze resultaten ook een toegevoegde waarde van deze behandeling voor andere doelgroepen dan epilepsiepatiënten.

Door bestudering van het effect van de behandeling niet alleen op klinische uitkomstmaten (afname van epileptische aanvallen), maar ook op immunologisch gebied en op het niveau van neurotransmitters hebben we veronderstelde werkingsmechanismen getoetst. Deze bevindingen hebben niet alleen inzicht gegeven, maar roepen ook nieuwe vragen op. De complexiteit van het werkingsmechanisme wordt bevestigd. Dit onderstreept de uitdagingen die nog voor ons liggen ('life long learning').

Ook werden resultaten van onderzoek besproken op bijeenkomsten van de Epilepsie Vereniging Nederland, de patiëntenbelangenvereniging en er werd aandacht besteed aan onze onderzoeksbevindingen in het informatieblad van het Epilepsiefonds Nederland. 


\section{Innovatie}

Wij hebben voor het onderzoek in dit proefschrift gebruik gemaakt van de bestaande en geregistreerde nervus vagus stimulator. We hebben het effect van de behandeling met NVS placebo gecontroleerd getest bij kinderen, dit werd nog niet eerder gedaan. Er werden geen nieuwe uitvindingen gedaan of aanleidingen gevonden voor bijvoorbeeld een aanpassing van octrooi.

\section{Toekomst}

Op basis van de onderzoeksresultaten in dit proefschrift lijkt slechts een deel van de populatie kinderen met therapieresistente epilepsie goed effect te hebben van de behandeling met NVS. Vooralsnog hebben wij niet kunnen identificeren welke specifieke kenmerken deze kinderen hebben. Idealiter zou je voorafgaand aan de implantatie van de stimulator willen bepalen of de patiënt goed gaat reageren op de behandeling, om te voorkomen dat er patiënten een operatie ondergaan en er kosten worden gemaakt zonder dat het uiteindelijke doel bereikt wordt.

Een alternatieve mogelijkheid om responders reeds voor een operatie te identificeren is dat je met behulp van een extern apparaat deze behandeling op proef start. Op die manier kun je zien of de patiënt goed reageert en dus een responder zal zijn, alvorens het NVS apparaat geïmplanteerd wordt. Op dit terrein zijn nu wel ontwikkelingen gaande en er is een tNVS (transcutane NVS) op de markt die de n. vagus stimuleert via het oor. Met deze apparatuur werden tot nu toe enkele kleine studies gedaan bij patiënten met moeilijk behandelbare epilepsie. Stimulatie met tNVS wordt niet continue gedaan, zoals bij de reguliere NVS behandeling (dag en nacht), maar slechts enkele uren per dag. Het blijft voorlopig nog de vraag of het effect van tNVS voorspellend is voor NVS. Ook is nog onvoldoende bekend of tNVS alle responders van een behandeling met NVS daadwerkelijk kan identificeren.

Verder zijn er nieuwe mogelijkheden met een 'closed-loop' systeem. Hartfrequentie stijging, als vroeg symptoom van een insult, wordt opgepikt door een sensor in de stimulator die vervolgens zorgt voor extra stimulus van de stimulator. Dit werkt vergelijkbaar met de magneet, die bij debuut van de aanval door iemand boven de stimulator gehouden moet worden. Een dergelijk slim systeem biedt mogelijkheden om maatwerk te leveren per patiënt. Bovendien kunnen in de toekomst mogelijk ook andere vroege symptomen van een insult aanleiding zijn voor activering van een dergelijk 'closed-loop' systeem om de behandeling met NVS te optimaliseren.

Bovendien zou ook een deel van aanpassing van instellingen van de stimulator eventueel in handen van patiënt zelf of diens ouders/verzorgers kunnen komen, zodat zij zelf een deel van de controle in handen krijgen. Mogelijkheden om de stimulator ook als registrator te gebruiken zouden verder geëxploreerd kunnen worden. De NVS zou gebruikt kunnen worden als aanvalsdagboek.

De kwaliteit van de batterij van de NVS is eveneens van belang, hoe langer de levensduur, hoe minder frequent revisies noodzakelijk zijn. Verdere verbetering van batterijkwaliteit 
lijkt een belangrijke voorwaarde voor een eventuele uitbreiding van mogelijkheden zoals bijvoorbeeld als registrator van aanvallen. Voor dergelijke uitbreiding van functies zal het apparaat regelmatig worden uitgelezen. 

Dankwoord

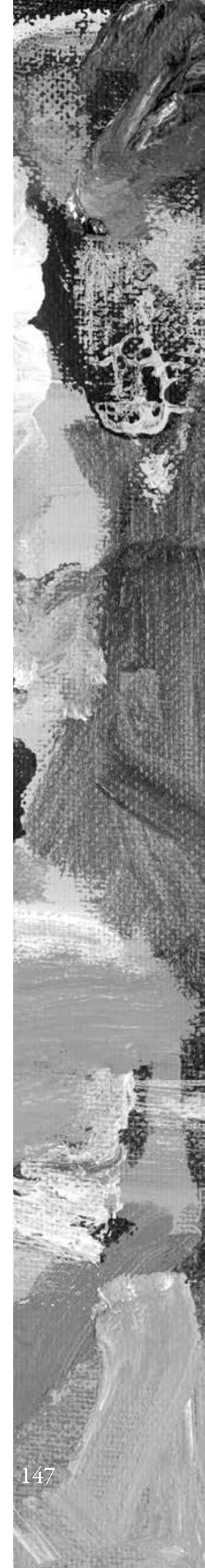



En dan is het af! Het boekje kan eindelijk op mijn plank. Nu het klaar is sluit ik een fase af. Daarmee neem ik afscheid van een intensieve periode waarin ik op zeer uiteenlopende terreinen bijzonder veel geleerd heb. Dit promotie-traject was nooit gelukt zonder hulp van en fijne samenwerking met een heleboel mensen. Ik heb erg uit gekeken naar het schrijven van dit dankwoord, maar nu het eenmaal zo ver is, is het toch lastiger dan gedacht. Ik wil niemand vergeten.

Ik wil iedereen, die op welke manier dan ook, heeft bijgedragen aan de totstandkoming van dit proefschrift, heel hartelijk danken. Er is echter een groot aantal mensen die ik speciaal wil noemen.

Allereerst mijn promotieteam, ik heb mij zeer vaak gelukkig geprijsd met dit super-team: experts in hun vak, razendsnel in hun feedback en geduldig.

Prof. J.S.H. Vles, lieve Hans, vanaf onze eerste ontmoeting in 2008 heb ik zeer veel bewondering en respect voor je oprechtheid en integriteit. Het is een groot voorrecht om onder jouw begeleiding te mogen promoveren. Het is verbluffend hoe jij steeds feilloos je vinger op 'de zere plek' weet te leggen. En jouw ogenschijnlijk simpele vragen wierpen regelmatig een nieuw licht op een onderwerp. Ik heb bijzonder veel van je geleerd. Zowel vakinhoudelijk, als op wetenschappelijk terrein, en niet te vergeten de zaken buiten het vak. Je bent een inspirerend mens. Ik waardeer het vertrouwen dat je geeft enorm. Als hoofd van de afdeling Kinderneurologie gaf je mij deze kans en daarbij creëerde je tegelijkertijd ook ruimte. Je was een goede stok achter de deur en dat was niet overbodig. Je adviezen en inzichten zijn voor mij van grote waarde.

Prof A.P. Aldenkamp, beste Bert, de manier waarop jij bijdraagt aan het beoefenen van wetenschap is bewonderenswaardig. Het lijkt allemaal zo eenvoudig en voor de hand liggend als jij de dingen brengt, maar het tegendeel is waar. Het gemak waarmee jij steeds de rode draad uit een grote berg data vist, maar ook je haarscherpe oog voor nieuwe mogelijkheden waren een grote stimulans.

Dr. H.J.M. Majoie, beste Marian, jij bent de drijvende kracht achter het NVS onderzoek. Ik ben je zeer dankbaar voor de kans die je mij gaf, het voelt nog steeds als een zeer groot cadeau. Ik heb jouw altijd aanwezige enthousiasme, jouw opbouwende feedback, maar ook je supersnelle reacties op nieuwe versies van een manuscript tot in de late uurtjes en je trouwe aanwezigheid bij alle besprekingen enorm gewaardeerd. Ik heb altijd op je kunnen rekenen.

Graag wil ik de leden van de leescommissie, prof. dr. van Oostenbrugge, dr. Nicolai, prof dr. Y. Temel, prof. dr. L. Lagae en prof. dr. R.P.C. van Kessel hartelijk danken voor de tijd en genomen moeite om mijn manuscript te beoordelen.

De kinderen met therapieresistente epilepsie en hun ouders/verzorgers en ook de volwassenen met epilepsie wil ik oprecht danken voor hun bereidwilligheid deel te nemen aan ons onderzoek. 
Loes Leenen, dank voor je inspanningen en bijdragen aan de studie. Het verzamelen van alle aanvalsdagboeken is bijvoorbeeld één van jouw verdiensten geweest. Wat een klus, achter iedereen aan zitten om deze te verzamelen. De compleetheid van de data zeggen iets over jouw toewijding, maar geven ook aan dat de ouders dat graag voor je deden. Je bent een erg fijne collega en een kundige epilepsieverpleegkundige. Het doet mij veel deugd om te zien hoe jij Jeske Nelissen, onze verpleegkundig specialist i.o., op sleeptouw neemt en haar betrekt in je eigen onderzoek. Dat wordt vast een meesterwerk.

Dr. K. Rijkers, beste Kim, dank voor je toegewijde bijdrage aan de studie, in het bijzonder alle liquores die je hebt verzameld. Veel dank.

Dr. E.J.M. Cornips, beste Erwin, jij was verantwoordelijk voor de implantaties van de stimulatoren samen met je collega's, zonder jullie was het niet gelukt.

Dr. P. Verschuure, beste Pauline, dank voor je hulp bij alle bepalingen in het klinisch chemisch laboratorium van Kempenhaeghe. Het reusachtige apparaat liet lang op zich wachten, maar mede door de volhardende inzet van jou en de medewerkers op het lab en de gastvrijheid waarmee Carlie werd ontvangen is het gelukkig allemaal goed gekomen.

Fons, ik ben je veel dank verschuldigd voor je tijd, geduld en hulp bij de statistiek, ook na je pensioen. Al was er soms een stuk walnotentaart nodig om je te strikken voor je advies, steeds leverde het mij weer -een beetje meer-inzicht en orde in mijn hoofd op.

Linda Linssen-Ghielen ik wil ook jou hartelijk danken, niet alleen voor je logistieke ondersteuning bij de studie, maar ook voor je grote behulpzaamheid en voor de kunst van het regelen van de afspraken met Marian.

Ik kreeg alle ruimte van mijn collega's, de kinderneurologen van het MUMC: Hans, Joost, Suzanne, Jeroen en Biene. Lieve Biene en Joost, ook mede door jullie is dit boekje een feit. Samen met Hans zorgden jullie voor een warm nest, voor mij als puppy, om in te landen in Maastricht. Ook kreeg ik alle tijd en ruimte, waarvoor ongelofelijk veel dank. Inmiddels zijn we, ondanks het vertrek van Biene, weer op volledige oorlogssterkte met de komst van Suzanne en Jeroen. Ik bof met jullie vieren als collega's.

Lieve Desiree en Kim, mijn helpende handen, jullie zijn toppers! Ook het stroomlijnen van mijn agenda is jullie toevertrouwd. Nooit waren mijn verzoekjes teveel! (of jullie lieten dat in ieder geval niet blijken...). Ook Miranda, Rachel, Vivianne, Wilma, Maddy en Lise wil ik noemen. Jullie zijn altijd bereid even een klusje te doen in afwezigheid van Desiree en Kim, dank daarvoor. En Kitty en Christa ook jullie bedankt!

Prof Dr. Van Oostenbrugge, beste Robert, je bent niet alleen de voorzitter van de leescommissie en een fijne collega, maar ook het afdelingshoofd van de afdeling 
Neurologie. De afgelopen jaren is jouw rol cruciaal geweest om een hecht team te creëren binnen de afdeling Neurologie. Beste Robert, Marielle, Mayke, Karin, Manuela, Mark, Julie, Lisette, Rob, Ger, Wim en Monique. Ik wil jullie danken voor jullie bijdrage aan de fijne werksfeer en jullie interesse in mijn vorderingen en jullie bemoedigende woorden. Ook alle AIOS Neurologie wil ik danken voor hun gezellige en leerzame samenwerking. Eveline en Loreen, Charlotte, Trea, Desiree, Margot, Linda en Jolanda dank ik voor de ondersteuning op de polikliniek: niet alleen regelen jullie alle logistiek rondom de poli's, handelen jullie mijn verzoekjes op onleesbare briefjes af en zijn jullie onderdeel van de bewakingseenheid van mijn agenda, maar hebben jullie steeds warme belangstelling op de werkvloer en zijn jullie betrokken bij de patiënten. Dat waardeer ik enorm.

Riny wil ik danken voor de gezellige momenten met een goeie koffie, dat was nooit zonder iets lekkers dankzij jou. Jij zorgde regelmatig voor een welkome pauze op de onderzoeksdagen.

Irene Gijselhart, het Epilepsie Centrum Kempenhaeghe boft enorm met een bibliothecaresse zoals jij! Ik wil je heel hartelijk danken voor je hulp bij het maken van de 'search' voor de review. Maar ook op andere momenten kon ik steeds rekenen op je hulp, bijvoorbeeld voor de lastig te verkrijgen artikelen, of je advies bij een Endnote kwestie. Ook blijf ik dankzij jou eenvoudig op de hoogte met je mails met alle nieuw verschenen literatuur over onder andere NVS.

Dr. J.H. Hendriksen, beste Jos, dank voor je gastvrijheid, ik heb met veel werkplezier gebruik gemaakt van jouw mooie werksuite op Kempenhaeghe de eerste jaren.

(Destijds) studenten, maar inmiddels professionals op diverse terreinen:

Dr. M.W. Aalbers, lieve Marlien, ik vond het een erg plezierige en leerrijke samenwerking. Je zorgde voor een vliegende start: jij bezit namelijk het vermogen om binnen de kortste keren een boemelende diesel te transformeren tot een T.G.V. Ik heb groot respect voor al je (computer)vaardigheden. Drs. van den Bosch, beste Charlotte, dank voor je hulp bij de analyse van alle psychologische data. De zorgvuldigheid waarmee jij te werk ging, heb ik erg gewaardeerd. Drs. C.J.H. van de Borne, beste Carlie, dank voor het aangaan van de uitdaging en je grote hulp bij het gevecht met de metabolieten. Ook Monique van der Heijden ben ik dank verschuldigd.

Dr. G. Hageman, beste Gerard, jij bent, naast mijn opleider in Enschede, mijn inspirator en grote voorbeeld geweest om te kiezen voor de opleiding tot kinderneuroloog. Samen met Laetitia Wagener was jij daarnaast verantwoordelijk voor mijn eerste kennismaking met NVS.

Drs. Wagener-Schimmel, lieve Lae, vanaf mijn komst in Enschede ben jij voor mij een maatje geweest. Niet alleen kreeg ik direct je telefoonnummer zodat ik je kon bellen voor 
eventuele morele steun bij mijn eerste diensten als AIOS neurologie. Samen met de andere AIOS in Enschede heb jij een belangrijk aandeel gehad in de fijne opleidingstijd, maar ook in mijn 'neurologische opvoeding'. Ik noem enkele voorbeelden: Ik leerde hoe je op legendarische wijze een LP kan doen (Joffrey). Ik leerde hoe ik resoluut kon omgaan met ongewenste intimiteiten (Janneke). Ik leerde hoe je het nuttige met het aangename kon combineren en er dus nooit gebrek aan tijd was om een goeie grap uit te halen (Anneke). Ik leerde wat het moment is om koffiemelk te gaan halen in een verhitte assistentenvergadering (Laetitia). Ik leerde het $\mathrm{ABC}$ van de neuroloog bij een traumateam: Aankomst, Babinski, CT-scan (Jørgen). Ook weet ik inmiddels alle ins en outs van steenmarters op parkeerplaatsen en erken ik de tijdloosheid van toekans op stropdassen (Rico). Ook Nienke, Jacqueline, Maarten, Theo, Birgit en alle andere AIOS neurologie en neurologen uit Enschede wil ik danken voor de fijne en leerzame opleidingstijd. En Laetitia, ook in de weg die volgde na Enschede ben je mijn werkvriendinnetje gebleven, je was soms mijn klankbord voor het vak, dan weer als werkende moeder, en ook bij de minder fijne gebeurtenissen van de afgelopen jaren waren we maatjes. Dikke, dikke merci! En met betrekking tot wetenschap en NVS: wie had dat gedacht, hè?

Verder wil ik de kinderneurologen in Groningen bedanken voor de genoten opleiding, evenals de Zwolse kinderartsen en neonatologen.

Tiny Wouters, dank voor je hulp bij de layout (en je geduld bij de zoveelste versie met aanpassingen), door jou werd het een prachtig boekje.

Brenda Vollers, hartelijk dank voor het corrigeren en verfraaien van het Engels.

Paul Mohr en Olga Teunis dank voor jullie spiegels, de verkregen inzichten en de nieuwe oplader voor mijn batterij.

Mijn familie en vrienden zijn onmisbaar geweest in dit traject. Alle kletsjes, peptalks, morele steun en interesse, maar vooral alle gezellige momenten hebben zeker bijgedragen aan de totstandkoming van dit boekje.

Dikke merci in het bijzonder aan Marcia voor alle fijne gesprekken en oprechte adviezen. Ook dank voor de tijd die jij en Fabio hebben genomen om e.e.a. te lezen. Ook Fleur wil ik hartelijk danken. Jullie warme belangstelling, opbeurende woorden op de lastige momenten, maar vooral jullie jarenlange vriendschap is mij dierbaar.

Dikke, dikke merci aan mijn paranimfen.

Lieve Daisy en lieve Saskia, wat vind ik het ongelofelijk fijn dat jullie op deze dag naast mij staan. We hebben elkaar leren kennen tijdens de eerste maand van de geneeskundestudie in Maastricht. Sindsdien is er een zeer hechte vriendschap gegroeid, ondanks de geografische afstand die er geruime tijd bestond. Zonder jullie onvoorwaardelijke steun in goede en slechte tijden, zelfs bij nacht en ontij, was deze klus mij nooit gelukt. Jullie 
hebben mij geholpen het moederschap te combineren met mijn werk (en alle diensten!) en onderzoek. Jullie waren mijn externe relativerende factoren, waarvoor dank. Ik koester de luxe dat ik altijd op jullie kan rekenen en geniet altijd van alle fijne momenten. De etentjes, de feestjes, de wandelingen, de freubel momenten, de weekenden erop uit met elkaar. Ik wil ook jullie mannen (Leo en Patrick) en jullie kinderen (Seb, Lina, Emi, Emme, Daan en Isa) danken, gewoon omdat ze er zijn. In het bijzonder nog een extra dank aan Leo voor zijn kritische (grammaticale) oog en de tijd om de Nederlandse stukken te lezen

Lieve papa, maar ook lieve mama*, dank voor de fijne basis. Jullie hebben mij veel geleerd en steeds gesteund in mijn keuzes ('alles kan als je het maar wil' hè, mam?) en gestimuleerd om door te zetten. Vanaf het moment dat ik plannen kon maken, gaven jullie mij daarvoor alle ruimte en vrijheid. Altijd kon ik op jullie rekenen, en dat is zo gebleven pap, waarvoor dank. Cindy en Jeroen, Robin en Sven, ook jullie wil ik danken voor de fijne momenten, veelal als welkome afleiding. Ook jullie luisterend oor en handige handen doen een mens goed.

Lieve, lieve Sofie, mijn kostbaarste geschenk. Mama’s boekje is klaar! Je hebt mij goed geholpen. Alleen al door er te zijn. Maar ook het feit dat jij graag gaat slapen met mij rammelend achter de computer is regelmatig voor mij een stok achter de deur geweest. Het is een genot jou te zien ontwikkelen, dat maakt mij alle dagen duidelijk waar het eigenlijk om draait. 


Sylvia Klinkenberg werd op 9 april 1975 geboren in Dordrecht. Zij behaalde haar gymnasiumdiploma in 1993 aan het Johan de Witt Gymnasium te Dordrecht. In datzelfde jaar ging zij geneeskunde studeren aan de Universiteit van Maastricht. Tijdens haar studie deed zij een wetenschapsstage in Vina del Mar in Chili. Zij haalde in 1999 haar artsendiploma $\mathrm{Na}$ haar studie heeft zij een jaar gewerkt bij de GGD Twente als jeugdarts en als gemeentelijk lijkschouwer. Vervolgens heeft zij een kortdurende periode gewerkt in het SMT Hengelo, nu ZGT (Almelo/Hengelo) als ANIOS beschouwende specialis-

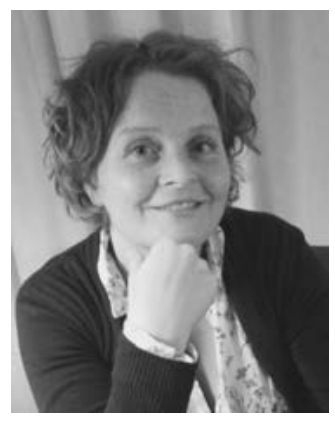
men. Zij kreeg de kans om op de afdeling neurologie in het Medisch Spectrum Twente Enschede te werken en kon na korte tijd starten met de opleiding tot neuroloog (opleider dr. J.A.G. Geelen en vervolgens dr. G. Hageman). Zij verhuisde naar Groningen voor een fellowship kinderneurologie in het UMC Groningen (opleider prof. dr. O.F. Brouwer). Aldaar rondde zij ook het laatste deel van haar neurologie opleiding af waarbij extra aandacht werd besteed aan klinische neurofysiologie bij kinderen (opleider dr. J.H. Van der Hoeven). Het jaar kindergeneeskunde en neonatologie in het kader van het fellowship kinderneurologie deed zij in de Isala klinieken te Zwolle (opleider prof. dr. P.L.P. Brand). Sinds de zomer van 2008 is zij werkzaam als kinderneuroloog binnen de afdeling neurologie van het Maastricht Universitair Medisch Centrum. Zij startte in 2010 promotieonderzoek naar het effect van NVS bij kinderen onder begeleiding van dr. H.J.M. Majoie (Epilepsiecentrum Kempenhaeghe), prof. dr. J.S.H. Vles (Maastricht Universitair Medisch Centrum) en prof. dr. A.P. Aldenkamp (Kempenhaeghe en Maastricht Universitair Medisch Centrum). De afgelopen jaren heeft zij haar taken binnen de patiëntenzorg gecombineerd met promotieonderzoek. De resultaten van dit onderzoek zijn beschreven in dit proefschrift. $\mathrm{Zij}$ is trotse mama van Sofie (4 jaar). Zij woont samen met haar dochter in Lanaken in België. 


\section{List of publications}

Klinkenberg S, Nicolai J. Classificatie en behandeling van epilepsie op de kinderleeftijd. Praktische Pediatrie maart 2009.

Panis B, Vlaar AM, van Well GT, Granzen B, Weber JW, Postma AA, Klinkenberg S. Posterior reversible encephalopathy syndrome in paediatric leukaemia Eur J Paediatr Neurol. 2010;14:539-545.

Overvliet GM, Besseling RM, Vles JS, Hofman PA, Backes WH, van Hall MH, Klinkenberg S, Hendriksen J, Aldenkamp AP. Nocturnal epileptiform EEG discharges, nocturnal epileptic seizures, and language impairments in children: review of the literature. Epilepsy Behav. 2010;19:550-558.

Overvliet GM, Aldenkamp AP, Klinkenberg S, Vles JS, Hendriksen J. Impaired language performance as a precursor or a consequence of Rolandic epilepsy. J Neurol Sci. 2011;304:71-74.

Aalbers M, Vles J, Klinkenberg S, Hoogland G, Majoie M, Rijkers K. Animal models for Vagus nerve stimulation in animals. Exp Neurol. 2011;230:167-175.

Creten C, van der Zwaan S, Blankespoor RJ, Maatkamp A, Klinkenberg S, van KranenMastenbroek VHJM, Nicolai J, Dhossche DM, van Os J, Schieveld JNM. Anti-NMDAreceptor encefalitis: een nieuwe as III stoornis in de differentiaal diagnose van desintegratiestoornis van de Kinderleeftijd, Vroeg Optredende Schizofrenie en Laat Optredend Autisme Tijdschrift voor psychiatrie. 2012;54:475-479.

Vlooswijk MCG, Klinkenberg S, Hageman G, Dellemijn PLI, Roeleveld ABC, Vles JSH. Epiduraal hematoom bij kinderen na val van kleine hoogte. Tijdschrift voor neurologie en neurochirurgie. 2012;113:74-81.

Klinkenberg S, Majoie HJM, Van der Heijden MMAA, Rijkers K, Leenen L, Aldenkamp AP. Vagus nerve stimulation has a positive effect on mood in patients with refractory epilepsy. Clin Neurol Neurosurg. 2012;114:336-340.

Klinkenberg S, Aalbers MW, Vles JSH, Cornips EMJ, Rijkers K, Leenen L, Kessels FGH, Aldenkamp AP, Majoie M. Vagus nerve stimulation in children with intractable epilepsy: a randomized controlled trial. Dev Med Child Neurol. 2012;54:855-861. 
Klinkenberg S, Van den Bosch, CNCJ Majoie HJM , Aalbers MW, Leenen L, Hendriksen J, Cornips EMJ, Rijkers K, Vles JSH, Aldenkamp AP. Behavioural and cognitive effects during vagus nerve stimulation in children with intractable epilepsy a randomized controlled trial. Eur J Paediatr Neurol. 2013;17:82-90.

Aalbers MW, Klinkenberg S, Rijkers K, Verschuure P, Kessels A, Aldenkamp AP, Vles JSH, Majoie M. The Effects of Vagus Nerve Stimulation on Pro- and Anti-Inflammatory Cytokines in Children with refractory epilepsy: An Exploratory Study. Neuroimmunomodulation. 2012;19:352-358.

De Kleermaeker FG, Bouwmans AE, Nicolai J, Klinkenberg S. Anterior opercular syndrome as a first presentation of herpes simplex encephalitis. J Child Neurol. 2014; 29:560-563.

Brandt-Wouters E, Klinkenberg S, Roelfsema V, Ginjaar IB, Faber CG, Nicolai J. Teaching video neuroimages: sodium channel myotonia can present with stridor. Neurology. 2013; 80:e108.

Klinkenberg S, Aalbers MW, Vles JS, Cornips EM, Rijkers K, Leenen L, Kessels FG, Aldenkamp AP, Majoie M. Klinkenberg et al. Reply. Dev Med Child Neurol. 2013;55: 195-196.

Klinkenberg S, Ubbink S, Vles JSH, de Louw A, Scheijen D, Brokx J. Non-invasive treatment alternative for intractable startle epilepsy. Epilepsy\& Behavior Case Reports (2) $201449-53$.

Klinkenberg S, van den Borne CJ, Aalbers MW, Verschuure P, Kessels AG, Leenen L, Rijkers K, Aldenkamp AP, Vles JS, Majoie HJ. The effects of vagus nerve stimulation on tryptophan metabolites in children with intractable epilepsy. Epilepsy Behav. 2014;37: 133-138.

Halma E, de Louw AJ, Klinkenberg S, Aldenkamp AP, Ijff DM, Majoie M. Behavioral side-effects of levetiracetam in children with epilepsy: A systematic review. Seizure. 2014;23:685-691. 
The printing of this thesis was financially supported by Cyberonics Europe BVBA, Eisai B.V., UCB Pharma B.V., Eurocept B.V., afdeling O\&O van het Epilepsiecentrum Kempenhaeghe en het Nationaal Epilepsie Fonds. 


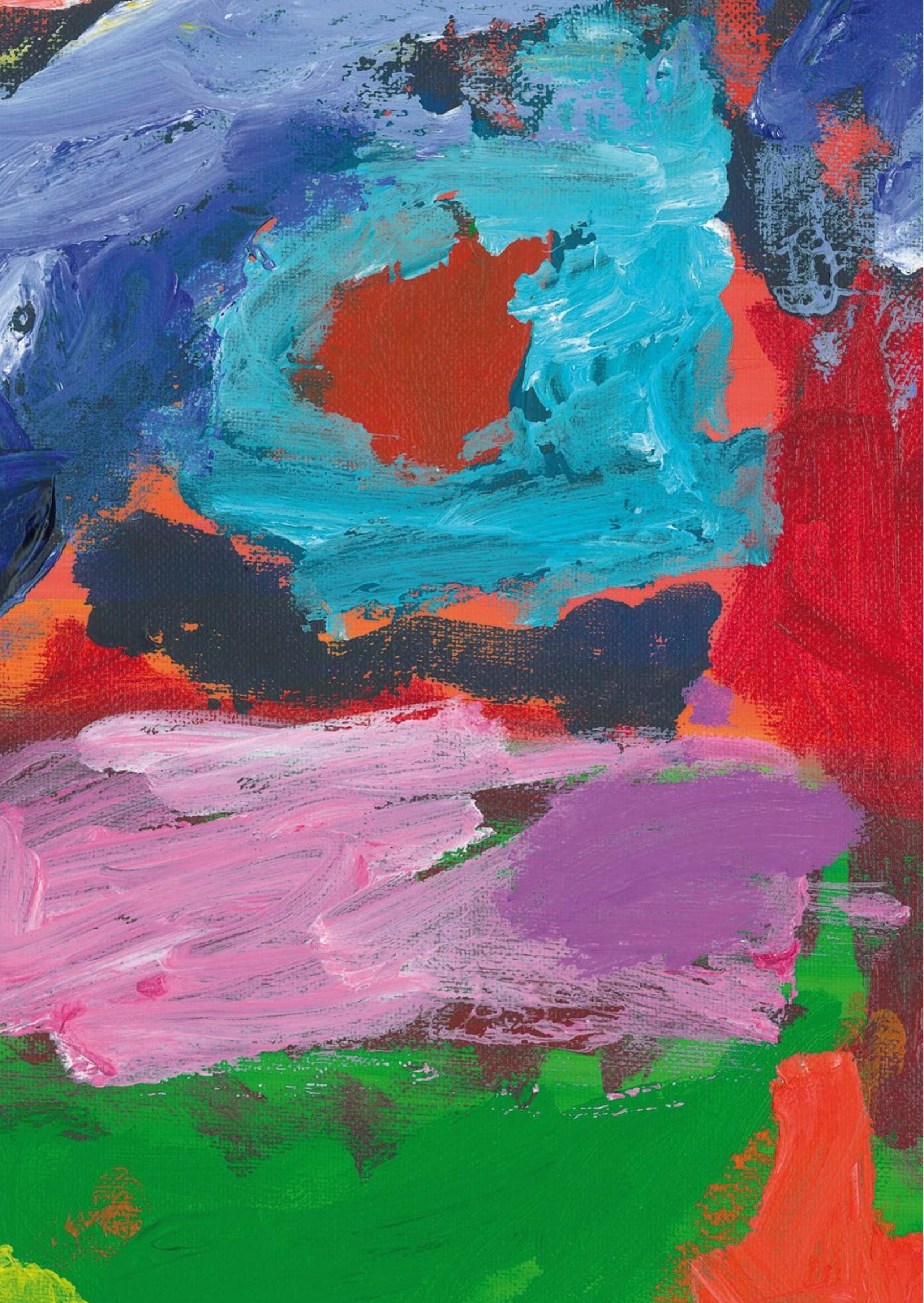

